\title{
Article
}

\section{Maximizing fracture productivity in unconventional fields; analysis of post hydraulic fracturing flowback cleanup}

\author{
Nasriani, Hamid Reza and Jamiolahmady, Mahmoud \\ Available at http://clok.uclan.ac.uk/21646/ \\ Nasriani, Hamid Reza ORCID: 0000-0001-9556-7218 and Jamiolahmady, \\ Mahmoud (2018) Maximizing fracture productivity in unconventional fields; \\ analysis of post hydraulic fracturing flowback cleanup. Journal of Natural Gas \\ Science and Engineering . ISSN 1875-5100
}

It is advisable to refer to the publisher's version if you intend to cite from the work. http://dx.doi.org/10.1016/j.jngse.2018.01.045

For more information about UCLan's research in this area go to http://www.uclan.ac.uk/researchgroups/ and search for <name of research Group>.

For information about Research generally at UCLan please go to http://www.uclan.ac.uk/research/

All outputs in CLoK are protected by Intellectual Property Rights law, including Copyright law. Copyright, IPR and Moral Rights for the works on this site are retained by the individual authors and/or other copyright owners. Terms and conditions for use of this material are defined in the policies page.

\section{CLoK}

Central Lancashire online Knowledge www.clok.uclan.ac.uk

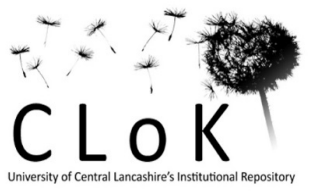


Natural Gas Science \& Engineering

Elsevier Editorial System(tm) for Journal of

Manuscript Draft

Manuscript Number: JNGSE-D-17-01687R1

Title: Maximizing Fracture Productivity in Unconventional Fields; Analysis of Post Hydraulic Fracturing Flowback Cleanup

Article Type: Full Length Article

Keywords: Post Fracturing Cleanup; tight and ultra-tight reservoirs; Hydraulic Fracturing; Flowback; productivity; fracturing fluid

Corresponding Author: Dr. Hamid Reza Nasriani, PhD

Corresponding Author's Institution: University of Central Lancashire

First Author: Hamid Reza Nasriani, PhD

Order of Authors: Hamid Reza Nasriani, PhD; Mahmoud Jamiolahmady, Professor

Abstract: Hydraulic fracturing, is a promising stimulation technique which is also known as hydrofracturing, hydrofracking and fracking. During the hydraulic fracturing ( $\mathrm{HF})$, the rock is cracked, i.e., fractured, by a high pressure injection of a fluid which is known as fracturing fluid $(\mathrm{FF})$. The FF is mainly water, carrying suspended sand or another type of proppants into the well to initiate fractures in the reservoir rock, and consequently, hydrocarbon and FF will move towards the well more easily through fractures.

Hydro-fracturing is extensively used to increase the well productivity index, particularly in unconventional, tight and ultra-tight reservoirs. This expensive procedure, though, sometimes fails to meet expectations regarding the production enhancement. The leading explanations for this reduced performance is fracture clean-up inefficiency of the fracturing fluid ( $\mathrm{FF})$ that was primarily injected.

In this study, a parametric investigation of FF clean-up effectiveness of fractures was performed with 143360 simulations (in 35 different sets) including injection, shut-in and production stages. Because of the vast number of simulation runs which was required to be implemented by a reservoir simulator, a computer code was developed and utilised to routinely read input data, implement the simulation runs and produce output data. In each set (which consists of 4096 runs), instantaneous impacts of twelve different parameters (fracture and matrix permeability (i.e., Kf and $\mathrm{Km}$ ) and capillary pressure (PC), end points and exponents of gas and $\mathrm{FF}$ in the Brooks-Corey relative permeability correlation in both fracture and matrix) were investigated. To sample the domain of variables and to study the results, full factorial experimental design (two-level FFS) and linear surface methodology explaining the dependency of the loss in gas production, compared to the case there is no loss (i.e., 100\% clean-up) to the related parameters at different production stages were investigated through he tornado charts of the response surface models, frequency of simulation runs with obtained Gas Production Loss, GPL, and saturation distribution maps of FF.

Results pointed out that in general, factors that control the mobility of FF inside the fracture had the most significant impact on cleanup 
efficiency. Conversely, in tight and ultratight sets, particularly when the applied pressure drawdown for the duration of production stage was small, the impact of fluid mobility within the matrix on gas production loss was more noticeable, i.e., it is crucial how fluids flow inside the matrix rather than how fast fracture is cleaned. In lower permeability matrix, in general, more gas production loss was detected and clean-up was slower. The impact of PC on GPL minimisation was stronger when pressure drawdown was small and/or shut-in time was prolonged. As the formation becomes tighter, this observation was more pronounced, in other words, for such formations, the impact of a change in pressure drawdown and/or shut-in time on PC and GPL was more noticeable.

Additionally, the results showed that as the length of the fracture reduced the impact of fracture pertinent parameters (i.e., fracture permeability and fluid (gas and FF) mobility pertinent parameters of Corey correlation in the fracture) on GPL reduced and the impact of those pertinent parameters in the matrix on GPL increased. The impact of PC on minimising GPL is less noticeable in shorter fractures and vice versa. As the length of fracture reduced, quicker fracture clean-up was detected compared to those for longer fracture.

These discoveries help us to better understand the hydraulic fracturing process and can be used to settle issues regarding the performance of hydraulic fracturing and to improve the design of hydro-fracturing operations, which is an expensive but popular stimulation method for tight and ultra-tight reservoirs. 


\section{Highlights}

- Hydro-fracturing is extensively used to increase the well productivity index, particularly in unconventional, tight and ultra-tight reservoirs.

- This expensive procedure, though, sometimes fails to meet expectations regarding the production enhancement. The leading explanations for this reduced performance is fracture clean-up inefficiency of the fracturing fluid (FF) that was primarily injected.

- In this study, a parametric investigation of FF clean-up effectiveness of fractures was performed with 143360 simulations (in 35 different sets) including injection, shut-in and production stages.

- Results pointed out that in general, factors that control the mobility of FF inside the fracture had the most significant impact on cleanup efficiency.

- Conversely, in tight and ultratight sets, particularly when the applied pressure drawdown for the duration of production stage was small, the impact of fluid mobility within the matrix on gas production loss was more noticeable, i.e., it is crucial how fluids flow inside the matrix rather than how fast fracture is cleaned.

- The larger the Pc the lower the production loss.

- The impact of Pc on GPL minimisation was stronger when pressure drawdown was small and/or shut-in time was prolonged.

- As the formation becomes tighter, this observation was more pronounced, in other words, for such formations, the impact of a change in pressure drawdown and/or shut-in time on Pc and GPL was more noticeable.

- The impact of Pc on minimising GPL is less noticeable in shorter fractures and vice versa. As the length of fracture reduced, quicker fracture clean-up was detected compared to those for longer fracture.

- These discoveries help us to better understand the hydraulic fracturing process and can be used to settle issues regarding the performance of hydraulic fracturing and to improve the design of hydro-fracturing operations, which is an expensive but popular stimulation method for tight and ultra-tight reservoirs. 


\title{
Maximizing Fracture Productivity in \\ Unconventional Fields; Analysis of Post Hydraulic Fracturing Flowback Cleanup
}

\author{
H.R. Nasriani ${ }^{1}$, M. Jamiolahmady ${ }^{1}$ \\ ${ }^{1}$ Heriot-Watt University, Institute of Petroleum Engineering, Edinburgh, United Kingdom
}

\begin{abstract}
Hydraulic fracturing, is a promising stimulation technique which is also known as hydrofracturing, hydrofracking and fracking. During the hydraulic fracturing (HF), the rock is cracked, i.e., fractured, by a high pressure injection of a fluid which is known as fracturing fluid (FF). The FF is mainly water, carrying suspended sand or another type of proppants into the well to initiate fractures in the reservoir rock, and consequently, hydrocarbon and FF will move towards the well more easily through fractures.

Hydro-fracturing is extensively used to increase the well productivity index, particularly in unconventional, tight and ultra-tight reservoirs. This expensive procedure, though, sometimes fails to meet expectations regarding the production enhancement. The leading explanations for this reduced performance is fracture clean-up inefficiency of the fracturing fluid (FF) that was primarily injected.

In this study, a parametric investigation of FF clean-up effectiveness of fractures was performed with 143360 simulations (in 35 different sets) including injection, shut-in and production stages. Because of the vast number of simulation runs which was required to be implemented by a reservoir simulator, a computer code was developed and utilised to routinely read input data, implement the simulation runs and produce output data. In each set (which consists of 4096 runs), instantaneous impacts of twelve different parameters (fracture and matrix permeability (i.e., $\mathrm{Kf}$ and $\mathrm{Km}$ ) and capillary pressure $(\mathrm{Pc})$, end points and exponents of gas and FF in the Brooks-Corey relative permeability correlation in both fracture and matrix) were investigated. To sample the domain of variables and to study the results, full factorial experimental design (two-level FFS) and linear surface methodology explaining the dependency of the loss in gas production, compared to the case there is no loss (i.e., 100\% clean-up) to the related parameters at different production stages were investigated through he
\end{abstract}


tornado charts of the response surface models, frequency of simulation runs with obtained Gas Production Loss, GPL, and saturation distribution maps of FF.

Results pointed out that in general, factors that control the mobility of FF inside the fracture had the most significant impact on cleanup efficiency. Conversely, in tight and ultratight sets, particularly when the applied pressure drawdown for the duration of production stage was small, the impact of fluid mobility within the matrix on gas production loss was more noticeable, i.e., it is crucial how fluids flow inside the matrix rather than how fast fracture is cleaned. In lower permeability matrix, in general, more gas production loss was detected and clean-up was slower. The impact of Pc on GPL minimisation was stronger when pressure drawdown was small and/or shut-in time was prolonged. As the formation becomes tighter, this observation was more pronounced, in other words, for such formations, the impact of a change in pressure drawdown and/or shut-in time on Pc and GPL was more noticeable.

Additionally, the results showed that as the length of the fracture reduced the impact of fracture pertinent parameters (i.e., fracture permeability and fluid (gas and FF) mobility pertinent parameters of Corey correlation in the fracture) on GPL reduced and the impact of those pertinent parameters in the matrix on GPL increased. The impact of Pc on minimising GPL is less noticeable in shorter fractures and vice versa. As the length of fracture reduced, quicker fracture clean-up was detected compared to those for longer fracture.

These discoveries help us to better understand the hydraulic fracturing process and can be used to settle issues regarding the performance of hydraulic fracturing and to improve the design of hydro-fracturing operations, which is an expensive but popular stimulation method for tight and ultra-tight reservoirs.

\section{Introduction}

There is a substantial amount of hydrocarbon that is trapped in unconventional formations, i.e., Tight and ultra-tight formations, Shale, coal bed methane, etc... Similar to conventional wells, first, a hole is drilled in unconventional formations. when the well extends through the last freshwater zone, the drill-string is retrieved from the borehole and a casing, surface casing, is run into the hole. The cement is then injected down through the surface casing and once the cement reaches the bottomhole it is forced to go into the annulus space between the borehole wall and the casing. Several casings may be installed in a well depending on the depth of the well and the characteristics of different formations.

The need to fracture the unconventional formation to attain an economically viable well makes drilling for hydrocarbon in unconventional resources different from conventional fields. After 
reaching the total depth, the drill string is retrieved from the well and the last steel casing is set, the rig is removed from the well site. At the well completion stage, a connection between the wellbore and the reservoir rock is made by the creation of the perforations. In order to create connection, a perforation gun that is loaded with explosive charges is run into the well and then fired to create the perforations. The well is now prepared for hydraulic fracturing operation. the hydraulic fracturing process consists of pumping a combination of water, proppant (generally sand) and some chemical additives with high pressure in a controlled manner into the formation. The additives are generally used for lubrication and to help the fracturing fluid (FF) to transmit the sand into the fractures. The FF consists of typically $99.5 \%$ by volume water and sand (proppant) and $0.1 \%$ to $0.5 \%$ by volume chemical additives. The FF is injected into the wellbore and out through the perforations with high pressure that leads to the rupture of the rock and initiation and propagation of the fractures in the reservoir rock. The sands and the FF remain in the fractures and keep them open when the injection pressure is released.

Once the stimulation operation is complete, the production stage begins. Primarily FF flowback (mainly water) and then natural gas flow to the surface. During the initial stages of the production of a well that is also known as post-fracturing cleanup, roughly $15 \%-70 \%$ of the injected FF flows back to the surface. In other words, the cleanup period is next stage after the fracturing operation, in which some of the FF returns from the reservoir formation to the surface. The cleanup procedure has to be accompanied thoughtfully to avoid any long-term damage to the productivity of the well. Therefore, FF flowback has a significant impact on the post-fracturing operation and subsequent gas production.

Hydraulic fracturing, as a popular and expensive stimulation approach in the oil and gas industry, is widely utilised to boost the productivity of wells in unconventional fields. Despite the fact that $\mathrm{HF}$ is an economically viable solution to the development of unconventional tight and ultratight fields, this promising approach sometimes is unsuccessful to meet expectations regarding the production enhancement. The most common explanations for this deficiency is clean-up inefficiency of the injected fracturing fluid.

Numerous mathematical and laboratory investigation has been implemented to understand this failure and related parameters impacting the efficiency of FF cleanup.

Tannich (1975) demonstrated that production rate loss as a consequence of FF is much more prominent at initial stages of the production. He also highlighted that as the length of fracture increases or the fracture conductivity reduces, the cleanup process becomes slower. 
Cooke Jr. \& C.E., (1973) and Cooke Jr. \& Cooke, (1975) conducted experimental work on cleanup efficiency and they showed that the conductivity of fracture could be considerably impaired by the FF presence in the fracture.

Quite a lot of mathematical and numerical research works have been implemented on the FF cleanup and its underperformance to further understand the HF procedure. (Ahmed et al., 1979; Montgomery et al., 1990; Bennion et al., 1996; Mahadevan and Sharma, 2005; Gdanski et al., 2006; Ghahri et al., 2009; Bazin et al., 2010; Gdanski and Walters, 2010)

Considering the single parameter investigation that Ghahri et al.(2009) conducted on the fracture cleanup of tight formations, they extended the line of their study to further understand the impact of sixteen different but relevant parameters concurrently for 2 simulation sets (with different volume of injected FF) using experimental design linked with the response surface model theory (Panteha Ghahri et al., 2011).

they highlighted that the FF and gas mobility have a substantial impact on the production of gas and increasing the volume of the injected FF impairs the cleanup and it takes a longer time for flowback to be removed to a certain degree from the matrix and the fracture.

These two works (i.e., Ghahri et al., 2009, 2011) required a very long central processing unit time (CPU time) restricting the authors to conducting two sets of simulations. With the aim of conducting more sets of simulations and consequently investigating more cases of cleanup in unconventional formations, Jamiolahmady et al. (2014) reduced the number of relevant parameters from sixteen to twelve parameters by excluding four least important variables on cleanup efficiency. The twelve parameters were matrix and fracture permeability, pore size distribution index, surface tension and fluid (gas and FF) mobility pertinent parameters in the fracture and matrix. Consequently, they were able to conduct more simulation sets with shorter CPU time.

They conducted ten different sets of simulations with various arrangement of applied post fracturing shut-in time, pressure drawdown during the subsequent production stage, total volume of injected FF and different matrix permeability range. They reported that reduction in matrix permeability variation range increased the gas production loss and impairs the cleanup. They highlighted that the higher the capillary pressure in the matrix, the better the cleanup performance. They also reported that the impact of Pc is more pronounced in low drawdown pressure and/or prolonged soaking time sets.

This current work extends the line of studies that were previously implemented by (Ghahri et al., 2009; P Ghahri et al., 2011; Jamiolahmady et al., 2014) to investigate the FF cleanup 
performance in tight and ultra-tight formations with substantially low matrix permeability. Some numerical issues were reported for some sets when $\mathrm{Km}$ and applied DP were small. i.e., synthetic over-pressure. it is demonstrated that although the effect of considering permeability enhancement in high permeability high/moderate DP SFVW-Sets was minimal, it significantly alleviated the overpressure effect in low permeability moderate/low DP SFVW-Sets.

In total, 35 new sets were performed considering different pressure drawdown during the production stage, shut-in time periods, matrix permeability range and different fracture lengths. Significant efforts were devoted to fitting the response surface models to the output data that could be more demonstrative of the trends noted in the implemented numerical simulations, i.e., to attain more precise equations for response surface models, the dependent variable, i.e., gas production loss, was transferred to another domain. The dependency of the dependent variable, i.e., gas production loss, in the new domain, to the 12 pertinent parameters were investigated at different production stages (ten, thirty and 365 days), by the tornado charts of fitted response surface coefficients, frequency of simulation runs with obtained GPL and saturation distribution maps of FF in the matrix in the vicinity of fracture and within the fracture.

\section{Single Fractured Vertical Well (SFVW) Model}

In order to investigate the single fractured vertical well, SFVW, a pre-fractured single well model was built using ECLIPSE 100 (Schlumberger, 2015). The initial reservoir pressure and matrix porosity were $7500 \mathrm{psi}$ and $15 \%$ respectively. Table 1 displays the fracture and the reference model dimensions used in this study. The fracture half-length (Xf) was either 400m (long SFVW) or 100m (short SFVW). The gas properties of the reference model are tabulated in Table 2. The fracturing fluid, FF, was considered as water. The viscosity of $0.5 \mathrm{cp}$ and compressibility of $5 \mathrm{e}-6(1 / \mathrm{psi})$ were considered for FF. For the base set defined as a reference, FF volume of twice the volume of the fracture was considered for the injection stage. Since a section of the system (a quarter of the system) was modelled (Figure 1), FF with a total injection volume of either $64 \mathrm{~m}^{3}$ (long SFVW) or $16 \mathrm{~m}^{3}$ (short SFVW) was considered. That is, the FF volume per fracture length, defined as (=Vinj / Lf, $\mathrm{m}^{3} / \mathrm{m}$ ) was equal to $0.16 \mathrm{~m}^{3} / \mathrm{m}$ equivalent to 2 FVR (The injected FF volume to fracture volume ratio) defined as FVR=Vinj / Vf, $\mathrm{m}^{3} / \mathrm{m}^{3}$. In the second stages of the modelling, gas and FF phases are allowed to produce under 
controlled bottom-hole flowing pressure. After FF injection and before production, the well is shut-in for two days.

\subsection{Validation of the developed Model of Single Fractured Vertical Well}

To validate the model developed for SFVW cleanup operation, the predicted bottom hole pressures from the reservoir simulation outputs were compared with analytical models. It should be noted that cleanup period is during early time flow period i.e., transient period (MoradiDowlatAbad M, 2016).

In this section, the governing equations for early time flow period are discussed. It should be noted that the fracture linear flow period has been ignored in this study due to its short life span in comparison to the linear flow time towards the fracture.

The linear flow regime is considered as parallel flow lines that move toward a plane orthogonally. The linear flow regime could be identified by a half-slope in the derivative on a $\log$-log diagnostic plot or by a straight line on a square root of time (linear flow specialized) plot.

Equation (1) has been generally used for describing the linear flow regimes:

$$
P_{w f}=P_{i}-\left(\frac{8.128 q B}{A} \sqrt{\frac{\mu t}{K_{m} \varnothing C_{t}}}\right)
$$

where

- $\mathrm{A}$ is the area perpendicular to the linear flow $\left(\mathrm{ft}^{2}\right)$

- $\mathrm{h}$ is the formation thickness, $\mathrm{t}$ is the time(ft)

- $\mathrm{Pi}$ is the initial reservoir pressure (psi)

- $\mathrm{q}$ is the flow rate produced from one fracture (MScf/D)

- $\mu$ is the viscosity (cp)

- $\mathrm{t}$ is time (hrs)

- $\mathrm{K}_{\mathrm{m}}$ is the matrix permeability (md)

- $\varphi$ is the porosity

- $\mathrm{C}_{\mathrm{t}}$ is the total compressibility $\left(\mathrm{psi}^{-1}\right)$

- $\mathrm{B}$ is the formation volume factor, reservoir volume/surface volume 
At the early time flow period, the early linear flow is the main flow regime in most of SFVWs and MFHWs in tight reservoirs. For this flow regime, as the area perpendicular to the flow is the cross section of a fracture ( $2 \mathrm{Xfh})$, the corresponding equation is as follows:

$$
P_{w f}=P_{i}-\left\{\sqrt{\frac{16.52 q^{2} B^{2} \mu}{h^{2} \emptyset C_{t}}} \frac{\sqrt{t}}{\sqrt{K_{m} X_{f}^{2}}}+\frac{141.2 q \mu B}{K_{m} h}\left(S_{D}+S_{c}\right)\right\}
$$

Where in Equation ((2)):

- $\mathrm{S}_{\mathrm{D}}$ is the damage skin,

- $\mathrm{S}_{\mathrm{c}}$ is the convergence skin in a fractured horizontal well

- $\mathrm{h}$ is the formation thickness (ft)

- $\mathrm{Xf}$ is the fracture half-length (ft)

- The rest of the parameters and their units are explained in the Equation (1)

For a multiple fractured horizontal well in a tight and ultratight reservoir, the total production rate, qt, in the early-time flow period can be calculated from Equation(3).

$$
q_{t}=\sum_{i=1}^{N} q_{i}
$$

Considering a constant fracture spacing and homogeneous formation within the fractures as well as equal fractures properties, the total production rate of the well could be estimated by multiplying the production rate from a single fracture by the number of fractures during the early-time flow period, i.e., q in Equation (2) is (qt/Nf).

As soon as pressure perturbations of neighbouring fractures reach each other (i.e. fracture interference starts), The early linear flow regime ends. The corresponding time can be estimated by Equation (4).

$$
t_{e l}=237 \frac{\emptyset \mu C_{t} S_{f}^{2}}{K_{m}}
$$

where $\emptyset, \mu, \mathrm{Ct}, \mathrm{S}_{\mathrm{f}}$ and tel are the porosity, viscosity, total compressibility, fracture spacing (in ft) and the time of interference (in hrs) respectively. It should be highlighted that the fracture interference time depends on the reservoir and fracture properties.

If the bilinear flow happens rather than early linear flow in MFHWs, Equation (2) should be substituted by Equation (5). 


$$
P_{w f}=P_{i}-\left\{\frac{44.13 q B \mu \sqrt[4]{t}}{h \sqrt{K_{f} W_{f}} * \sqrt[4]{K_{m} \emptyset \mu C_{t}}}+\frac{141.2 q \mu B}{K_{m} h}\left(S_{D}+S_{c}\right)\right\}
$$

Where in Equation (5):

- $\mathrm{K}_{\mathrm{f}}$ is the fracture permeability (md)

- $\mathrm{W}_{\mathrm{f}}$ is the fracture aperture (ft)

- $\mathrm{S}_{\mathrm{D}}$ is the damage skin,

- $\mathrm{S}_{\mathrm{c}}$ is the convergence skin in a fractured horizontal well

- $\mathrm{h}$ is the formation thickness ( $\mathrm{ft}$ )

- The rest of the parameters and their units are explained in the Equations (1) \& (2)

In this section, to validate the model developed for SFVW cleanup operation and in order to give confidence that the model is consistent, the predicted bottom hole pressures from the reservoir simulation outputs were compared with the analytical model.

Figure 2 shows the predicted bottom hole pressure by simulation model and also the predicted bottom hole pressure by the analytical model (Equation (2)) versus production time, it should be noted that both graphs are overlapping and almost on top of one another which confirms the accuracy of the developed model. Figure 3 shows the predicted bottom hole pressure by the analytical model (Equation (2)) versus those of the simulation model where satisfactory $\mathrm{R}^{2}$ of 0.9993 is noted.

\section{Sets Analysed}

In this study, the results of a total of 35 different sets for long fracture SFVW, 400m, (19 sets), short fracture SFVW, 100m, (13 sets) and 3 long fracture SFVWs (3 sets) with permeability enhancement are analysed. The results have been compared with those of a base reference set and other similar sets. These sets have identical reservoir dimensions as those of the SFVW base reference set but differ in the shut-in time period (ST), matrix permeability variation range (Kmr), pressure drawdown (DP) and length of the hydraulic fracture.

For SFVW simulation sets, there is a Base Reference set with parameters in the ranges indicated in Table 3 as defaulted values. The other sets are cited based on the differences of the parameters variation range from the Base Reference set, i.e., in each SFVW-Set any parameter 
that has a tick mark has the defaulted values otherwise the parameter's value is stated in the table. The SFVW sets that have been considered in this work are listed here for the reference and convenience. The analysed SFVW sets in this study are listed in Table 4a to Table 4c.

It should be noted that the results of each SFVW-Set are compared either with base reference set or with similar SFVW-Sets reported highlighting the impact of pertinent parameters studied in this work. This means that set numbering might not be monotonic for sets reported in different sections.

\section{Considered Variables}

Table 3 displays the ranges of variation of relevant parameters (12 parameters) that were considered in the numerical simulations during this study. These variables were considered based on the understanding of the process gained by the work of the GCR team, i.e., Ghahri (2010) and Alajmi(2012), literature data and support of Total as one of the sponsors of the project, which is gratefully appreciated. As shown in Table 3, the other remaining 6 parameters, i.e., porosity and critical gas and water saturations in the matrix and fracture and pressure drawdown (DP), were considered constant in each simulation set. Porosity was fixed at a value of 0.15 and both residual gas saturation in the matrix (Sgrm) and fracture (Sgrf) were fixed at a value of 0.1 . Additionally, critical water saturation in the matrix $(\mathrm{Swcm})$ and fracture (Swcf) were fixed at a value of 0.15 .

Equations (6,7,8 \&9) describe the capillary pressure (Thomas, Katz and Tek, 1968) and relative permeability curves (Brooks and Corey, 1966) for data of Table 3.

$$
\frac{P d}{I F T}=0.0075 \times K^{-0.5}
$$

- Entry pressure Pd, bar, (Thomas, Katz and Tek, 1968)

- Interfacial tension IFT (dyne/cm)

- Matrix permeability $(\mathrm{K}(\mathrm{mD}))$

$$
\begin{aligned}
& \left(\frac{P d}{P c}\right)^{\lambda}=\frac{S w-S w r}{1-S w r} \\
& k_{r w}=K_{\max w} \times\left(\frac{S w-S w r}{1-S w r-S g r}\right)^{n w} \\
& k_{r g}=K_{\max g} \times\left(\frac{S g-S g r}{1-S w r-S g r}\right)^{n g}
\end{aligned}
$$


Equation (7) is used to calculate Pc. This equation is linked to Equation (6).

The impact of pressure drop (DP), which was considered constant, was treated separately, i.e. different sets of simulations were considered for each pressure drop (please note Table 4.a to 4.c). This brings the total number of variables from 16 in Ghahri's work (Ghahri (2010)) to 12 in Alajmi's work (Alajmi (2012)) and this work. Based on this number of parameters, each fracture well model (mentioned earlier) requires 4096 simulation runs (for a two-level full factorial sampling (FSS) design), this brings the total number of simulation runs for all the analysed 35 sets of 12-parameter models to 143,360 simulation runs. As it was mentioned previously Ghahri (2010) had conducted 4 sets and Alajmi (2012) had 7 sets and those runs did not investigate the cases that are addressed in this work. Furthermore, the results of each SFVW-Set are compared either with base reference set or with similar SFVW-Sets reported in this work or Alajmi (2012) highlighting the impact of pertinent parameters studied in this work.

Given that in this study and to analyse the results more efficiently using the response surface method, described below, the parameters are scaled between 0 and 1 with zero corresponding to the lower bound of variation of a parameter and 1 corresponding to the maximum point. It also should be highlighted that in FFS approach, as one parameter changes and kept the other constant and due to the nature of the sensitivity analysis, no correlation is considered between the parameters that might be dependent on one another (e.g., Permeability and porosity, or Swi and porosity)

\section{Methodology}

Analysing an enormous number of numerical simulation runs is a real challenge and therefore, should be conducted in a very organised method or it will lose its advantage. This section introduces the analysis method which was assumed in this study and defines terminologies that are used to make it more convenient for the reader to follow the presented results and conclusions.

\subsection{Main Response}

The key output, i.e., main response, in this work is Gas Production Loss (GPL, \%). GPL is described as a measure of unclean fracture cumulative production deviation from the cumulative production of the case with completely clean fracture. 


$$
G P L=100 \times\left[\frac{F G P T_{\text {clean }}-F G P T_{\text {un-clean }}}{F G P T_{\text {clean }}}\right]
$$

FGPT: total gas cumulative production

In real field applications, it is hard, if not technically impractical, to get a completely clean fracture job. However, if one understands the relevant parameters and their impact on the cleanup procedure then it will be possible to define real field strategies to approach a $100 \%$ clean fracture job. One of the main benefits of using GPL is that GPL is a normalised quantity, it allows the user to compare different cases more easily and draw conclusions more appropriately. In this work, the impact of 12 parameters on GPL is addressed. In this exercise, a parameter is assumed to have a positive impact if it decreases the GPL, i.e., more gas production, while parameter's value is increased, whereas a negative impact parameter is the one, which increases GPL as parameter's value is increased.

\subsection{Response Surface Method (RSM)}

Response Surface Method, i.e., RSM, is a valuable means of analysing and expressing the sensitivity of a set of variables relevant to a specific output. It is a combination of mathematical and statistical approaches to find a suitable relationship between the main response y and independent variables $\mathrm{x} 1, \mathrm{x} 2, \mathrm{x} 3 \ldots \mathrm{xn}$. The fitted polynomial function (f(xi)) is called the response surface model. This model can be a linear or quadratic (with or without interaction term) and described by Equation (11).

$$
y=a_{0}+\sum_{k=1}^{n} a_{k} x_{k}+\sum_{i=1}^{n} \sum_{j=i+1}^{n} a_{i} a_{j} x_{i} x_{j}+\sum_{l=1}^{n} a_{l} x_{l}^{2}
$$

In Equation (11) four different models could be considered:

- Linear Surface model, if constant (a) and linear terms $\left(\mathrm{a}_{\mathrm{k}} \mathrm{X}_{\mathrm{k}}\right)$ are considered.

- Interactive Linear Surface model, if the interaction terms $\left(\mathrm{a}_{\mathrm{i}} \mathrm{a}_{\mathrm{j}} \mathrm{X}_{\mathrm{i}} \mathrm{X}_{\mathrm{j}}\right)$ are also considered.

- Pure Quadratic Surface model, if constant \& linear and quadratic terms $\left(\mathrm{al}^{2} \mathrm{Xl}^{2}\right)$ are considered.

- Full Quadratic Surface model, if constant\& linear, interaction and quadratic terms are considered.

The interactive and non-interactive linear response models were employed to define the dependency of gas production loss (GPL) on pertinent parameters affecting the cleanup performance of an HFW. A MATLAB code (The MathWorks, 2013) was developed for 
SFVW-Sets to link different stages of the simulation and to model the two-level full factorial sampling approach.

\subsection{Pertinent Parameters}

As it was mentioned earlier, 12 pertinent parameters have been considered in this work.

The exponents of Brooks-Corey (gas or FF) relative permeability curve ( $\mathrm{n}_{\mathrm{gi}}$ and $\mathrm{n}_{\mathrm{wi}}$, where i refer to inside fracture or inside matrix), i.e., ngf, nwf, ngm \& nwm respectively.

The end points of Brooks-Corey (gas or FF) relative permeability curve ( $K_{\operatorname{maxgi}}$ and $\mathrm{K}_{\operatorname{maxwi}}$, where $\mathrm{i}$ refer to inside fracture or inside matrix), i.e., $K_{\operatorname{maxgf}}, K_{\operatorname{maxwf}}, K_{\operatorname{maxgm}} \& K_{\operatorname{maxwm}}$ respectively.

There are three parameters, that control capillary pressure as described by Equations (6) and (7). These parameters are permeability of the matrix ( $\mathrm{Km})$, Interfacial Tension (IFT) and pore size distribution index $(\lambda)$.

\subsection{Figures Used for the Analysis of the Results}

There are two main figure types that are used for the analysis of the results. the Histogram chart is one of the two figures, it is used to display the cumulative frequency of a specific range of the GPL for any set. Here the GPL of 20\% (named henceforth GPL20) is considered as the reference line for comparison between different models. I.e., knowing the frequency of runs, which have GPL20, allows the user to compare how severe GPL is between different cases. For example, referring to Figure 4, that demonstrates the GPL cumulative frequency for two different cases (case A and B), it is noted that case A has a GPL 20 of $25 \%$ whereas case B has GPL $_{20}$ of $60 \%$. It shows that $75 \%$ of the runs in case A has a GPL of more than $20 \%$, whereas the corresponding value in case B is $40 \%$, i.e., faster cleanup is observed for case B compared to case A due to the larger cumulative frequency of runs with GPL less than $20 \%$. This also recommends that the GPL is more severe in case A compared to that in case B.

Another type of figure is the tornado chart; this is used to express the impact of the pertinent parameter on the GPL (i.e., the main response). It displays parameter's trend of impact (negative or positive) and the magnitude, which each parameter has on the performance of the GPL. Figure 5 displays a tornado chart of the impact of two parameters (A and B) on GPL. Given that in Figure 5, the parameters' values range from 0 to 1, this is due to the fact that all parameters coefficients values have been scaled to the parameter with the highest coefficient value. From the first look at this tornado chart (Figure 5), one can generally conclude about the 
impact of all parameters at a certain time of production. i.e., parameters with a positive scaled value of the coefficient have a negative impact on the production and consequently as the parameter scaled value increases in the positive direction, GPL increases. Along the same line, parameters with a negative scaled value of the coefficient have a positive impact on gas production; therefore, as the parameter absolute scaled value increases in the negative direction, GPL decreases.

Considering the tornado chart, one can also notice the comparative significance of each parameter. i.e., the parameter that has the maximum absolute value has the most significant impact on the main response. Accordingly, it can be concluded that parameter (A) has a destructive impact on gas production (i.e., +0.5 , which means that the higher the parameter the higher the GPL). Conversely, the parameter (B) has a positive impact on gas production with a value of -0.7. Parameter (B) is more important than the parameter (A), as it has a higher absolute scaled value compared to that of the parameter (A).

Additionally, based on such tornado charts, one can define the worst and best case scenario for a combination of the pertinent parameters. i.e., the best case scenario with the lowest GPL is the one for which all parameters (with a positive scaled coefficient value) are set to the minimum limit of their variation range while all other parameters (with a negative scaled coefficient value) are set to the maximum limit of their variation range. Contrariwise, the worst case scenario with the highest GPL is the one for which all parameters (with a positive scaled coefficient value) are set to their maximum limit of range while all other parameters (with a negative scaled coefficient value) are set to their minimum limit of the range.

In this work, sometimes the saturation map of FF distribution in and around the fractures (Figure 6) is also produced and used to better interpret the results. It should be noted that the saturation map directly generated by Floviz (numerical simulator) cannot be used due to the grid refinements in the vicinity of fractures. Therefore, in order to have a better saturation map, which more clearly shows the effect of FF in/around the fracture, the output data for fracture grid blocks saturation and also adjacent grid blocks saturation were used in MATLAB software (The MathWorks, 2013) to develop a saturation map for the investigated case. Since we need to have all saturation maps consistent with respect to the number of grids, size and also colour distribution, a MATLAB code has been developed which uses the adjacent grid blocks saturation as input and give the map in a standardised format. It should be noted that to have a better visualisation of the saturation distribution, dimensions of grid blocks have not been selected to the same scale as those of the single-well model under study. To clarify the 
information on these plots, the fracture length in the X-direction and grid block sizes in the Ydirection has been added to these plots.

\section{Domain Change}

It should be highlighted that considerable efforts were dedicated to fit equations that are more representative of the trends observed in the performed simulations. In this exercise, the main dependent variable's (i.e. GPL) domain of the fitted response surface model (RSM) was changed. That is, without the domain change there were cases whereby the predicted GPL was very different from the actual value and sometimes giving unrealistic negative or greater than $100 \%$, GPL values. However, with the domain change, this issue was eliminated.

Figure 7 a shows that while real simulation results vary in the $0-100 \%$ range (x-axis), the calculated GPLs using normal RSM are in the range of $-30 \%$ to $120 \%$ (y-axis). To overcome this difficulty and to obtain more accurate RSM and benefiting from the support of MATLAB mathematical package technical support team, the GPL variable has been transferred to a different domain. That is, instead of defining the model with the output as GPL, the regression model has been defined in such a way that gives Log of (GPL/(101-GPL)) as the output. This ensures that GPL varies within the desired interval $[0,100]$. Figure $7 b$ shows the same real simulation results (x-axis) versus the calculated GPL (y-axis), after the GPL domain change. It is noted that calculated GPL values using RSM in new domain correctly vary in the 0 to $100 \%$ range.

\section{SFVW Base Reference Set}

Ranges of parameters corresponding to the best case and worst case scenarios of the Base Reference Set are tabulated in Table 5. The impact of pertinent parameters on GPL is shown in Figure 8. Two saturation maps corresponding to this set are shown in Figure 9 and Figure 10. The corresponding histogram chart demonstrating the GPL cumulative frequency is shown in Figure 11.

From data of Figure 8, it is noted that fracture permeability $\left(\mathrm{K}_{\mathrm{f}}\right)$, with the highest absolute coefficient value of 1 , the most important parameter in fracture cleanup, i.e. the larger the Kf, the lower the GPL. This observation is in line with having a high coefficient for the Corey exponent and endpoint for FF relative permeability curve ( $\mathrm{n}_{\mathrm{wf}}$ and $\mathrm{K}_{\operatorname{maxwf}}$ ), which are +0.63 and -0.61 , respectively. That is, they all show that cleanup efficiency is improved if fracture fluid mobility inside the fracture improves (10 days production period is considered). 
If the Corey exponent of gas relative permeability in the fracture and the matrix ( $\mathrm{n}_{\mathrm{gf}}$ and $\mathrm{n}_{\mathrm{gm}}$ ) increase it displays a destructive impact on the cleanup performance with their coefficients being +0.58 and +0.51 , respectively. That is, a reduction in gas mobility inside either the fracture or matrix causes an increase in GPL.

The impacts of surface tension (IFT), pore size distribution index ( $\lambda$ ) and Matrix permeability $(\mathrm{Km})$ with their coefficients being $-0.38,+0.3$ and -0.4 , respectively, have a moderate impact on GPL. Based on these coefficients, an increase in IFT or a decrease in $\lambda$ decreases GPL but based on the capillary pressure (Pc) equations, Equation (6) and (7), such changes increase Pc. Therefore, it can be concluded that both these two parameters are affecting the results such that if capillary pressure increases, there is a reduction in GPL or an improvement in the cleanup, as larger volume of FF is imbibed into matrix, leaving fracture clean for gas to flow. However, it should be noted that $\mathrm{km}$ also affects Pc, which is discussed below.

The Pc effect can be more clearly seen in the saturation map that has been created using the MATLAB code. The saturation map of the best and worst case scenarios after two days of the shut-in period are given in Figure 9 and Figure 10, respectively. As mentioned above, to have a better visualisation of the saturation distributions, dimensions of grid blocks have not been selected to the same scale as those of the single-well model under study. In the best case, maximum IFT and minimum $\lambda$, which tend to increase Pc have been considered. Figure 9 shows that in this set the fracture has low FF (defined as water) saturation, similarly to the uninvaded region, i.e. better cleanup. However, for the worst case scenario with the lowest IFT and highest $\lambda$, which tend to decrease Pc, FF saturation inside the fracture is still high, Figure 10 , i.e. poor cleanup.

Matrix permeability $\left(\mathrm{K}_{\mathrm{m}}\right)$ has a coefficient of -0.4 , suggesting that the higher the $\mathrm{Km}$ the lower GPL. An increase in matrix permeability $\left(\mathrm{K}_{\mathrm{m}}\right)$ influences GPL in two ways:

(i) It allows better mobility for fluids in the matrix during injection and production periods.

(ii) It reduces capillary pressure.

According to the points mentioned above, a decrease in Pc should increase GPL. Hence, it could be concluded that in this base reference set, the contribution of $\mathrm{Km}$ in improving fluid mobility, particularly that of the FF flowing into the matrix, results in the better cleanup, i.e. lowering GPL. This also impacts the Pc values of the best and worst case scenarios discussed above. That is, for the best case scenario and based on the impact of $\mathrm{km}$ in the Tornado chart; 
the highest km value (which reduces GPL) has been used. This suggests that because at this higher $\mathrm{km}$ value $\mathrm{Pc}$ is lower than that at the lower $\mathrm{km}$ value, $\mathrm{Pc}$ is not at its maximum for the best case. Conversely, for the worst case scenario, the lowest $\mathrm{km}$ value (which increase GPL) has been used, which suggests that the corresponding Pc is not at its minimum value. These trends also suggest that the impact of $\mathrm{km}$ on $\mathrm{Pc}$ is not important to the same extent as that of IFT and $\lambda$, both of which change in the direction of increasing Pc and decreasing GPL simultaneously.

These observations suggest that in SFVW-Set 1 base reference set, using chemicals (IFT reducing agents) to reduce Pc could increase GPL and impairs cleanup efficiency.

The impact of rest of pertinent parameters ( $\mathrm{K}_{\operatorname{maxgf}}, \mathrm{K}_{\operatorname{maxgm}}, \mathrm{K}_{\operatorname{maxwm}}$, and $\left.\mathrm{n}_{\mathrm{wm}}\right)$ is considered small since the absolute values of their coefficients are less than 0.2.

After 30 days of production, the same trends are still observed but the values of the coefficients are slightly greater for most of the parameters. This is due to having lower GPL, which exaggerates the impact of parameters. However, still, $\mathrm{K}_{\mathrm{f}}$, as well as nwf and Kmaxwf, are the leading parameters. The absolute values of $n_{\mathrm{gf}}, \mathrm{n}_{\mathrm{gm}}$, IFT and $\lambda$ coefficients are more or less similar to those of the early production period. The effect of $K_{\operatorname{maxgf}}, \mathrm{K}_{\operatorname{maxgm}}, \mathrm{K}_{\operatorname{maxwm}}$, and $\mathrm{n}_{\mathrm{wm}}$ are also small.

Comparison of results after 365 days with those of very early production stages (i.e., 10 days) shows an increase in coefficient of $n_{w f}$. This trend is due to a large reduction in FF which was removed from the fracture after one year of production, which makes the impact of FF relative permeability to be more noticed.

There is also a substantial decrease in the absolute value of the $\mathrm{K}_{\mathrm{m}}$ coefficient from -0.37 after 30 days to -0.096 after 1 year of production. This suggests that improved mobility of fracture fluid in the matrix, when $\mathrm{k}_{\mathrm{m}}$ is increased, does not significantly impact the results at low FF saturation.

From cumulative frequency data of histogram shown in Figure 11, it is noted that during the first 10 days of production, over $83 \%$ of simulation runs have GPL larger than $20 \%$, $\mathrm{GPL}_{20}=17 \%$. It is evident that GPL decreases significantly at longer production time. That is, the frequency of runs with GPL more than $20 \%$ is about $68 \%$ and $28 \%$ after 30 days and 1 year of production, correspondingly, i.e., the longer the production time the cleaner the fracture and consequently the lower the GPL.

The main observation is that FF mobility in the fracture is the most important parameter; therefore, to increase the cleanup efficiency, creating highly conductive fractures, .e., high 
permeability fractures, is strongly recommended. This can also be accomplished by improving kf, by reducing nwf or increasing Kmaxwf. Moreover, high Pc owing to higher IFT reduces GPL, in other words, two general practical guidelines can be drawn (i). Enhancement in fracture conductivity and mobility of FF within the fracture results in an improved cleanup efficiency (ii) retaining high Pc by maintaining high IFT results in a cleaner fracture and higher cleanup efficiency.

\section{SFVW-Set with increased soaking time $(\mathrm{ST}=20)$}

In SFVW-Set 3, the shut-in time (i.e., soaking time or ST) was increased from 2 in the base reference set to 20 days to give sufficient time for Pc to allow more FF to be imbibed into the matrix. This would result in a cleaner fracture for gas to flow. If the tornado chart of this set with extended ST, Figure 12, is compared with that of the base reference set, Figure 8, it is noted that despite longer shut-in period, the results seem more or less similar, i.e., most coefficients have approximately the same values. The exceptions are variables affecting Pc (i.e. IFT, $\lambda$ and $\mathrm{K}_{\mathrm{m}}$ ), which express some differences, mainly at the early production stage. That is, at early production stage (10 day), there is a rise in the absolute value of the IFT coefficient from 0.38 in the base reference set to 0.56 in this set. For $\lambda$, it has increased from 0.3 to 0.41 and for $\mathrm{K}_{\mathrm{m}}$, it has changed from 0.4 to 0.28 . All these confirm the greater importance of Pc on improving fracture cleanup and reducing GPL in the set with increased ST. In other words, extending ST gives more time to FF to imbibe deeper into the matrix resulting in more distributed FF saturation inside the matrix. However, it seems this is limited only to the early production time.

Almost the same observation is noted when looking at the cumulative frequency of runs with a given GPL, Figure 13. That is, the corresponding curves for the base reference set and this set are almost overlapping except for 10 days of production. It suggests that the extended shut-in time improves the cleanup efficiency only at the early production time.

It was mentioned that the extended ST results in more FF imbibing into the matrix which makes the impact of Pc parameters to be more important than that of the base reference set. It is clearly observed in the FF saturation map of the best case after twenty days of shut-in, Figure 14. Comparing data of this Figure with those of Figure 9 in the base reference set, it is noted that the FF saturation in the fracture and matrix is considerably smaller than that of the base case. Similarly, the saturation of the FF in the matrix and fracture in the worst case, Figure 14, is smaller than that of the base case, Figure 10. In other words, extending ST from 2 days in 
the base reference set, SFVW-Set1, to 20 days in SFVW-Set 3 results in more distributed FF in the matrix and also cleaner fracture and consequently better cleanup.

\section{SFVW-Sets with reduced $\mathrm{Km}$ range $(\mathrm{Kmr}=10$ and 100$)$}

In these sets, the range of matrix permeability variation was lowered from $1 \mu \mathrm{D}-100 \mu \mathrm{D}$ $(\mathrm{Kmr}=1)$ in the base reference set to $0.1 \mu \mathrm{D}-10 \mu \mathrm{D}$ in SFVW-Set 4, i.e. $\mathrm{Kmr}=10$, and to 0.01 $\mu \mathrm{D}-1 \mu \mathrm{D}$ in SFVW-Set 25, i.e. $\mathrm{Kmr}=100$. The aim was to compare the results of these sets with the base reference set, SFVW-Set 1, with the only difference being a tighter/tightest formation by a factor of 10 and 100 in SFVW-Sets 4 and 25, to see the effect of Km reduction in moderate DP sets. Comparing the tornado charts of these sets with each other, Figure 16a and b, and also with that of the base reference set, Figure 8, demonstrates that most of the pertinent parameters show more or less the same trends in terms of direction of impact but, in these tight sets, the effect of fluid mobility in the matrix (i.e., $K_{m}, K_{\operatorname{maxwm}}, n_{w m}, K_{\operatorname{maxgm}}$ and $n_{g m}$ ) is more important than that in the base reference set. From data of Figure 16 a and b, it is noted that as the formation becomes tighter/tightest in SFVW-Set 4 and 25 respectively, the coefficient values of $\mathrm{K}_{\mathrm{m}}, \mathrm{K}_{\mathrm{maxwm}}, \mathrm{n}_{\mathrm{wm}} \mathrm{K}_{\operatorname{maxgm}}, \mathrm{n}_{\mathrm{gm}}$ become larger and also the most important affecting GPL in SFVW-Set 25, i.e. cleanup performance is better if fluid mobility (FF and Gas) inside the matrix improves. This observation highlights the fact that in tight formations, fluid mobility in matrix plays a very important role in the cleanup. Similarly, from data of Figure 16b, it is noted that fracture permeability has a moderate impact on GPL.

The saturation map of best and worst case scenarios of SFVW-Set 25 with Kmr=100 after two days of the shut-in period are shown in Figure 17 and Figure 18, respectively.

If one compares these saturation maps, with those of the base reference set, SFVW-Set 1, Figure 9 and Figure 10, it is noted that the fracturing fluid has gone deeper in the matrix (in Y direction) in SFVW-Set 1 than 25 due to larger value for Km in SFVW-Set 1 as a result of higher mobility. In other words, in tighter formations, due to having less FF mobility in the Y direction a bit more FF saturation in the $\mathrm{X}$ direction alongside the fracture is observed.

Figure 19 is the histogram chart that compares the GPL cumulative frequency of the runs in SFVW-Sets 25, 4 and, the base reference, SFVW-Set 1 . It is noted that a decrease in matrix permeability variation range increases GPL and causes a slower cleanup.

\section{SFVW-Sets with reduced/increased DP (DP=100 and 4000 psi)}


In these sets, the applied pressure drawdown (DP) during the production period of the base reference set was reduced \& increased from 1000 to 100 psi \& 4000 psi, respectively. The aim was to compare the impact of changing DP on cleanup.

Comparing the tornado charts of these set, i.e., SFVW-Set 6 with DP=100 and SFVW-Set 7 with $\mathrm{DP}=4000$ with each other, Figure 20 and Figure 21 respectively, and also with that of the base reference set, Figure 8, highlights that still the same three main important parameters (i.e. Kf, Kmaxwf and nwf), overwhelmingly control the cleanup performance. However, in the SFVW-Set 6 with reduced DP (DP=100 psi), Figure 20, the impact of IFT and $\lambda$ on GPL is more pronounced with greater coefficients than those of the base reference set, Figure 8, indicating the greater significance of Pc on the cleanup efficiency in low DP SFVW-Sets. This trend emphasises that a decrease of GPL can be obtained by increasing IFT or decreasing $\lambda$. Similarly, it is in agreement with the direction of the impact of the Km coefficient, which, opposite to the base reference set, is now positive, that is, an increase in Km increases GPL. In other words, in this SFVW-Set, the contribution of an increase in Km, which reduces Pc and increases GPL, is more dominant than that of improving fluid mobility and reducing GPL. This effect is more pronounced at later production periods when more of FF is produced. This trend is mainly due to the relative increase of Pc contribution when drawdown is decreased. In other words, it is more difficult for FF remaining inside matrix to flow out, hence, an increase in Pc, results in the larger amount of FF to be imbibed deeper into the matrix and, the slighter the confrontation for gas production within the fracture. It is also noted that compared to the base reference set (Figure 8), here the absolute values of Kmaxwm and nwm coefficients have increased especially after 370 production days (Figure 20). In line with the explanations given above, this is because, at this low pressure drop, FF mobility in the matrix is more important.

In SFVW-Set 7, DP was fixed at $4000 \mathrm{psi}$, instead of the $1000 \mathrm{psi}$ used for the base reference set. As noted in the corresponding tornado chart, Figure 21, and compared to the base reference set, increasing DP in this set has not resulted in major changes in the trends of data except for the more reduced impact of Pc. That is, here the absolute values of the IFT and $\lambda$ coefficients are smaller. The negative effect of an increase in $\mathrm{Km}$ on Pc is also smaller as the absolute value of its coefficient is higher. As mentioned above, an increase in $\mathrm{Km}$ influences GPL in two ways: (i) it allows better mobility for fluids and (ii) it reduces Pc. Considering that reduction of Pc should increase GPL, it is concluded that in this set, the contribution of $\mathrm{Km}$ in improving fluid mobility, particularly that of fracture fluid flowing into the matrix, results in better cleanup and consequently lower GPL. 
The histogram of cumulative GPL frequency for these SFVW-Sets, Figure 22, shows that the cleanup process is relatively slower in the low DP set (SFVW-Set 6). This shows that the cleanup process is severely delayed when DP is reduced. However, due to higher DP in SFVWSet 7, greater reduction in GPL is observed as demonstrated by the histogram of cumulative GPL frequency.

\section{SFVW-Sets with low Km range and different DPs and STs}

In this section, the cleanup efficiency of FF in formations with very low matrix permeability while changing other pertinent parameters like DP and ST was investigated. 13 sets were simulated considering different applied DP during production, shut-in soaking time periods and Km range, i.e., SFVW-Sets 4, 14, 15, 16, 17, 23, 24, 25, 26, 27, 64, 65 \& 66.

\subsection{Lower Km range (Kmr=10) \& low DP (100psi) SFVW-Sets with different ST}

In SFVW-Sets 14 and 15, the Km variation range was lowered from $1 \mu \mathrm{D}-100 \mu \mathrm{D}$ in the base reference set to $0.1 \mu \mathrm{D}-10 \mu \mathrm{D}(\mathrm{Kmr}=10)$ and DP also decreased from 1000 psi in the base reference set to 100 psi. the only difference between the SFVW-Set 14 and 15 is ST, with its higher value allocated in SFVW-Set 15.

From data of SFVW-Set 14, Figure 23, it is noted that $\mathrm{K}_{\mathrm{f}}$ with its coefficient values varying between -0.45 and -0.35 at the three production periods, is not as important as the base reference set. However, still, it can be concluded that the larger the fracture permeability, the lower the GPL. This observation agrees with a relatively high coefficient for $n_{w f}$ and $K_{\text {maxwf. }}$. That is, these observations show that cleanup efficiency is improved if mobility of FF within the fracture increases. In this set, the gas mobility in the matrix is the most important parameter. That is, $\mathrm{n}_{\mathrm{gm}}$ has a positive coefficient of around 1 at all three production periods. This is because of reduced Km and DP. Furthermore, in this set, the effect of Pc on the imbibition of the FF into the matrix is an important factor due to the relatively high coefficient of IFT and $\lambda$, pertinent parameters affecting Pc.

If the tornado chart of SFVW-Set 14 shown in Figure 23 is compared with that of the previously reported SFVW-Set 6 , with the higher Km variation range of $1 \mu \mathrm{D}-100 \mu \mathrm{D}$, shown in Figure 20, it is noted that in the SFVW-Set $14, \mathrm{~K}_{\mathrm{f}}$ is less and $\mathrm{Km}$ is more important. Similarly, the absolute values of the $K_{\operatorname{maxgf}}, \mathrm{n}_{\mathrm{gf}}, \mathrm{K}_{\operatorname{maxwf}}$ and $\mathrm{n}_{\mathrm{wf}}$ coefficients of this set appear to be slightly lower than those of set 6 . This means that GPL is less affected by gas and FF relative permeability inside the fracture. Due to having lower $\mathrm{K}_{\mathrm{m}}$ values, which leads to the more 
important effect of fluid flow in the matrix, the absolute values of the $n_{g m}$ and $n_{w m}$ coefficients shown in Figure 23 are much higher, i.e. the impact of mobility of gas and FF in the matrix permeability is more pronounced here.

In order to study the impact of ST in sets with low Km range and low DP SFVW-Sets, the ST was extended from 2 days in SFVW-Set 14 to 20 days in SFVW-Set 15. In other words, SFVW-Set 14 and 15 are similar sets with the only difference being a longer ST of 20 days applied in SFVW-Set 15.

From data of Figure 24, corresponding to SFVW-Set 15, it is noted that IFT, $\lambda$ and $\mathrm{K}_{\mathrm{f}}$ with the coefficients of $-1,+0.58$ and -0.56 after 10 days of production, respectively, are relatively the most important parameters. That is, they all show that cleanup performance is improved if FF imbibition into the matrix and also mobility inside the fracture is improved. The gas mobility in the matrix is also important ( $\mathrm{n}_{\mathrm{gm}}$ with an absolute coefficient of +0.62 ) because the matrix permeability $(\mathrm{km})$ is reduced by a factor of 10 . This agrees with what was shown earlier for the previous SFVW-Set 14. If the tornado chart of this set, Figure 24, is compared with that of the previous set 14 with ST=2 days, Figure 23 , it is noted that in this set IFT and $\lambda$ are more important due to longer soaking time.

Looking at the histogram chart of the GPL cumulative frequency of SFVW-Sets $6,14 \& 15$, Figure 25, slightly more severe GPL is observed at all production periods for set 14 compared to set 6 with the higher $\mathrm{Km}$ range. This increase in GPL is more pronounced at a later production period of 370 days. In other words, it is noted that the negative impact of reduced $\mathrm{Km}$ and DP in increasing the severity of gas production loss is small in this set. It is also noted that slightly less severe GPL is observed at early production periods for SFVW-Set 15 with longer ST compared to SFVW-Set 14. In other words, it seems at longer production period, this small difference is diminished.

\subsection{Lower Km range \& high DP SFVW-Sets with different ST}

In SFVW-Set 16, the Km variation range was lowered from $1 \mu \mathrm{D}-100 \mu \mathrm{D}$ in the base reference set to $0.1 \mu \mathrm{D}-10 \mu \mathrm{D}$ (i.e. $\mathrm{kmr}=10$ ) and DP increased from 1000 psi in the base reference set to 4000 psi.

Comparing the tornado chart of SFVW-set 16 shown in Figure 26 with that of SFVW-Set 4 with lower DP of 1000 psi shown in Figure 16a, it can be concluded that as DP is increased the impact of fracture and its relevant parameters are much higher due to the good delivery of fluids from the matrix to the fracture. It can also be concluded that the effect of $\mathrm{Km}$ in this set is more 
pronounced than that of set 4 because higher DP in this set enables easier delivery of fluids from the matrix to fracture than before. If the absolute coefficients for $\lambda$ and IFT for these two sets are compared, it is noted that the effect of these parameters is less pronounced for this set 16, with lower absolute values, confirming that the effect of Pc is much more important in lower DP sets. In other words, the higher the DP, the lower the impact of Pc on cleanup efficiency and vice versa.

When the ST was extended from 2 days in set 16 to 20 days in set 17, the observation was the same as that noted by comparing set 15 and set 14, i.e. the impact of IFT and $\lambda$ is more important for longer ST. In other words, when ST is increased by a factor of ten, the fracturing fluid imbibition into the matrix is more effective and the parameters pertinent to capillary pressure, i.e. IFT and $\lambda$, have higher absolute coefficient values. The histogram chart of the GPL cumulative frequency also confirmed that this effect is limited only to early production periods.

\subsection{The Lowest Km range \& low DP SFVW-Sets with different ST}

In this SFVW-Set 23, Kmr was 100 and DP was reduced to 100 psi compared to the corresponding base reference set values of $\mathrm{Kmr}=1$ and $\mathrm{DP}=1000 \mathrm{psi}$, respectively.

The trends of parameters in the tornado chart of this set, Figure 27, contradict previous observations, i.e. increasing $\mathrm{K}_{\mathrm{f}}$ increases GPL at early times. This trend suggested that there was an inconsistency in the results. After an extensive investigation, it was noted that this is due to negative GPLs obtained for many simulation runs of this significantly low Km and low DP set. It should be noted that these negative GPLs, due to overpressure effect, were excluded when fitting the RSM equation. This resulted in a poor surface model and inaccurate calculated results. It should be highlighted that according to the definition of GPL, negative GPL, as per Equation (11), means that there is more cumulative gas production in the unclean case than the clean one with FF presence, which is not possible.

The investigations indicated that these negative GPLs were due to over-pressurizing of fluids (typically up to 900 psi higher than the average reservoir pressure, Figure 28) in the grids adjacent to the fracture while injecting the fracturing fluid at the end of shut-in time. On the other hand, the resultant FF saturation increase in the matrix did not impair the gas relative permeability much, i.e. Less than $10 \%$. Hence, at this low DP of 100 psi, a higher GPT, total cumulative gas production, compared to the clean case was recorded, resulting in negative GPL. 
In order to further confirm this, the clean case was re-run using the saturation map (Figure 29) at the end of soaking time for the unclean case, in this case, the overpressure effect in grids adjacent to the fracture was eliminated. Figure 30 shows that by removing this synthetic overpressure effect from the model and using the unclean saturation map, positive GPLs are obtained. In other words, some runs have more cumulative gas production for the clean case than the unclean one.

In order to ensure that this synthetic over-pressure effect, created by my simulation method, did not have any adverse effect on other sets results, an extensive investigation, was performed, which confirmed the effect was limited only to this set. If ST was extended from 2 days in SFVW-Set 23 to 20 days SFVW-Set 24, it was noted that by extending ST the overpressure effect was alleviated, which indicates that impact of ST is more important at this lower $\mathrm{Km}$, DP set. In the next section, a solution to the over-pressure effect will be investigated.

\subsection{SFVWs with Permeability Enhancement, SFVW-Sets 64, 65 and 66}

In the previous section (Section 11.3), numerical issues were reported for SFVW-Sets when $\mathrm{Km}$ and applied DP were small. The impact of synthetic over-pressure created during the injection period was particularly pronounced for SFVW-Sets with $\mathrm{Kmr}=100$ when applied DP was 100 psi, compared to the base reference set. SFVW-Set 23, with $\mathrm{Kmr}=100$ and DP=100 psi, was considered unreliable.

It was discussed that during FF injection, to honour the assumed injected FF volume, injection pressure was increased to unrealistically high values. The resultant overpressure effect in matrix grids adjacent to the fracture did not dissipate completely during the shut-in time. This overpressure effect resulted in negative GPL especially when the DP and Km were low. According to the definition of GPL, a negative GPL means that total cumulative gas production for the unclean case is higher than that of the clean one, Equation (11). This occurred because in cases with negative GPL, and at the start of the production period, the overpressure value was added to the imposed DP, mostly at early production periods and at the same time, the presence of FF did not reduce Krg significantly. These two effects result in higher FGPT than that for the clean case.

In order to mitigate the overpressure effect, a model for stress dependent permeability changes was considered for modelling of FF injection but only during the hydraulic fracturing stage (i.e., FF injection). This allowed the pressure to fall to the initial field pressure. It should 
be noted that no permeability modification was applied to pressures less than the original field pressure (through the production stage).

The stress dependent transmissibility model was considered for fracture and matrix grids, i.e. identical permeability enhancement factor $(\mathrm{m})$ was used for matrix grids (in $\mathrm{x}$ and $\mathrm{y}$ directions) and for fracture grids. As described earlier, FF is injected in a pre-fractured model and hence the fracture initiation and propagation is not simulated.

As mentioned, stress dependent permeability was considered to apply permeability enhancement in the regions in the vicinity of the fracture for the duration of FF injection allowing dissipation of the unrealistically high pressures reported previously. A model available in the literature (Jurus et al., 2013) to describe permeability enhancement as a function of variations of stress was applied. In the suggested model the ratio of the existing permeability (k) to initial permeability (ko) is expressed by a power function of stress (s), Equation (12). one can use the increase of net pore pressure instead of absolute stress. Net pore pressure is considered as the difference between the current pressure and initial reservoir pressure. An increase in net pore pressure is identical to the reduction of rock effective stress, i.e, $s=-p_{\text {net }}=$ pRi-pgrid.

The function is expressed by a straight line plot of $\log (\mathrm{k} / \mathrm{ko})$ versus stress, with a slope defined by m (Permeability Enhancement Factor).

$$
\frac{K}{K_{o}}=10^{-m * s}=10^{m * p_{n e t}}
$$

Where:

- $\mathrm{K}$ : enhanced permeability due to injection, md

- Ko: original permeability, md

- $\mathrm{m}$ : permeability enhancement factor, $\mathrm{Psi}^{-1}$, in this work $\mathrm{m}$ is considered to be $10^{-3}$ $\mathrm{psi}^{-1}$

As mentioned earlier, stress dependent changes of permeability is modelled only for pressures higher than the original pressure, i.e., during the FF injection period. For the duration of the production stage, the permeability is considered constant and equivalent to the original value.

To evaluate the effect of permeability enhancement on cleanup efficiency, three SFVW-Sets of long SFVW base reference set (SFVW-Set 64), long SFVW with Kmr=100 and DP=100 psi (SFVW-Set 65) and long SFVW with Kmr=100 (SFVW-Set 66) were studied, these SFVW- 
Sets are here compared to their relevant SFVW-Sets without permeability enhancement respectively (i.e., SFVW-Sets 1, 23 and 25).

Comparing the tornado chart of SFVW-Sets 1 and 64, Figure 8 and Figure 31, with each other with the only difference being inclusion of permeability enhancement in SFVW-Set 64, it is noted that the impact of some of the parameters are slightly different but the overall observed trends of all parameters in SFVW-Sets 1 and 64 are more or less the same. Figure 32 shows the histogram chart that compares the GPL cumulative frequency of the runs in SFVWSets 1 and 64. It is noted that the GPL cumulative frequency of both SFVW-Sets are almost the same (only the histogram charts for GPL-10 days are slightly different). These two observations (comparison of tornado charts and histogram charts of SFVW-Sets 1 and 64) indicate that the effect of considering permeability enhancement in the SFVW base reference set is minimal, this is in line with the fact that in SFVW-Set 1 very few negative GPL values were observed due to relatively high permeability range $(\mathrm{Kmr}=1)$ and moderate DP.

Permeability enhancement was considered in two more SFVW-Sets with (Kmr=100) and with either DP=100psi (SFVW-Set 65) or DP=1000 psi (SFVW-Set 66). The impact of overpressure effect in SFVW-Set 65 was maximum due to the very tight formation and very low DP. The aim was to compare the results of the SFVW-Set 23 with those of the SFVW-Set 65, with the only difference being the inclusion of permeability enhancement in SFVW-Set 65 . The tornado chart for SFVW-Set 23, Figure 27, suggested an inconsistency in results. This was due to several negative GPLs obtained for many simulation runs of this low permeability low pressure drawdown SFVW-Set. The tornado chart for SFVW-Set 65, Figure 33, on the other hand, suggests that the inclusion of permeability enhancement can mitigate the overpressure effect and significantly improve the LRSM and resulting tornado chart. It is noted from Figure 33 that the effect of Pc pertinent parameters is most important for this low DP, low-k SFVWSet, a trend which was also observed in other SFVW-Sets with either low DP or low-k (Sections 11.1 and 11.3).

Figure 34 shows the histogram chart that compares the GPL cumulative frequency of the runs in SFVW-Sets 23 and 65. If one considers the histogram chart for SFVW-Set 23, it is noted that the cumulative frequency for 1 year falls below those for 10 and 30 days. This was due to having many runs with negative GPL, which have not been included in this Figure since the histogram chart takes only positive GPL values into account. But this issue has been sorted in SFVW-Set 65 with the inclusion of permeability enhancement. 
Figure 35 and Figure 36 also indicate an improvement in trends of LRSM and Histogram chart for SFVW-Set 66 compared to those for SFVW-Set 25.

Based on the results observed in these new SFVW-Sets with permeability enhancement (SFVW-Sets 64, 65 and 66), it is noted that although the effect of considering permeability enhancement in high permeability high/moderate DP SFVW-Sets was minimal, it significantly alleviated the overpressure effect in low permeability moderate/low DP SFVW-Sets.

\section{SFVW-Sets with short fracture length}

In this section, the results of 13 new SFVW-Sets (i.e., SFVW-Sets 10, 18-19, 21-22, 46, 55 $61)$ are presented. These SFVW sets were performed to investigate the cleanup efficiency when fracture length was decreased. it was mentioned previously that the fracture length was either 50, 100 or 400 metres representing very short, short and long fracture SFVW-Sets, respectively.

Figure 37 and Figure 20 show the tornado charts of two relevant SFVW-Sets with different fracture lengths, SFVW-Set 18 (100 m short fracture) and SFVW-Set 6 (400 m long fracture) respectively both with $\mathrm{DP}=100 \mathrm{psi}$, these two tornado charts are compared in order to observe how the effect of pertinent parameters on GPL changes with the hydraulic fracture length.

It is noted that in SFVW-Set 18 , similar to the long fracture SFVW-Set6, $\mathrm{K}_{\mathrm{f}}, \mathrm{K}_{\text {maxwf }}$ and $\mathrm{n}_{\mathrm{gf}}$ coefficients have high values indicating that the cleanup performance is enhanced if FF mobility inside the fracture improves. Furthermore, as production time increases the impact of all pertinent parameters on GPL declines except for water mobility pertinent parameters at 30 days of production .

Another significant observation is that the $\mathrm{Km}$ fluid mobility effect is more dominant than its effect on Pc, i.e. increasing km, whilst reducing Pc, decreases GPL whilst the opposite trend was observed in long fracture SFVW-Set 6, this shows that in shorter fracture SFVW-Set, fluid mobility within the matrix is more important.

The results of short and long fractures in Figure 37 and Figure 20 show that as the length of fracture increases, the impact of fracture pertinent parameters (i.e., $K_{f}, K_{\operatorname{maxwf}}, K_{\operatorname{maxgf}}, \mathrm{n}_{\mathrm{wf}}$ and $\left.\mathrm{n}_{\mathrm{gf}}\right)$ on GPL reduction increases whereas the impact of the matrix pertinent parameters $\left(\mathrm{K}_{\mathrm{m}}\right.$, $\mathrm{K}_{\operatorname{maxwm}}, \mathrm{K}_{\operatorname{maxgm}}, \mathrm{n}_{\mathrm{wm}}$ and $\mathrm{n}_{\mathrm{gm}}$ ) on GPL reduction decreases. In other words, for longer fractures, fluid mobility within fracture is more important whilst for shorter fracture, fluid mobility within the matrix is more dominant. It is also noted that having a shorter fracture reduces the impact of Pc on GPL, i.e. the absolute values of IFT and $\lambda$ coefficients are smaller. 
Figure 38 compares the histogram charts of two other relevant SFVW-Sets, i.e., Set 28 $(\mathrm{xf}=100 \mathrm{~m})$ and Set $8(\mathrm{xf}=400 \mathrm{~m})$ with $\mathrm{Kmr}=100$ and $\mathrm{DP}=4000$ psi. This Figure similar to that for SFVW-Sets 18 and 6, indicates that the longer the fracture, the slower the cleanup, that is due to injecting higher FF volume, which requires more time to cleanup.

In the other 19 SFVW-Sets of simulations, the effect of pertinent parameters in the lower matrix permeability range (tighter formation), extended soaking time, low/moderate/high DP and different fracture lengths $(100 \mathrm{~m}$ and $400 \mathrm{~m})$ have been studied and compared. In these SFVW-Sets, observations similar to those of the above SFVW-Sets were noted (i.e. the impact of fracture (and matrix) pertinent parameters on GPL reduction increases (and decreases) as fracture length increases). In the higher DP SFVW-Sets, the effect of fracture mobility parameters was more pronounced. This is because, at higher DP, the impact of matrix and Pc parameters are less. However, in high DP short fracture SFVW-Sets, as formation became tighter, the effect of matrix mobility parameters ( $K_{m}, K_{\operatorname{maxwm}}, \mathrm{K}_{\operatorname{maxgm}}, \mathrm{n}_{\mathrm{wm}}$ and $\left.\mathrm{n}_{\mathrm{gm}}\right)$ were more important. This is because in tighter formation fluid mobility in the matrix is more difficult and hence the improvement at higher pressure is more evident.

\section{Conclusions}

An extensive investigation on the cleanup efficiency of SFVWs was conducted to further improve the current understanding of hydraulic fracturing treatment for practical field applications.

In this study, the results of a total of 35 different sets for Long fracture SFVW, 400m, and Short fracture SFVW, 100m, were analysed. The results have been compared with those of a base reference set and other similar SFVW-Sets. These numerical models have similar geometry as those of the SFVW reference set but are different in the shut-in time period (ST), matrix permeability variation range $(\mathrm{Kmr})$, pressure drawdown (DP) and length of the hydraulic fracture.

A summary of the key conclusions is given below:

1. Fracture permeability and FF mobility pertinent parameters were the main drivers of GPL improvement during production and for all cases studied apart from SFVW sets with very low $\mathrm{Km}$ range (i.e. SFVW-Set 25 ), SFVW sets with very low $\mathrm{Km}$ range and low DP (i.e. SFVW-Set 14, 15, 63). 
2. Additionally, matrix permeability $(\mathrm{Km})$ displayed a positive impact on GPL, i.e. an increase in km reduced GPL and improved fracture cleanup for all SFVW-Sets apart from SFVW-Sets with reduced pressure drawdown of 100 psi described below.

3. The coefficients of interfacial tension (IFT) and pore size index $(\lambda)$ parameters controlling capillary pressure indicated that an improvement of cleanup efficiency is attained when capillary pressure $(\mathrm{Pc})$ is increased. This is achieved when IFT is increased and/or $\lambda$ is decreased except for sets with very low $\mathrm{km}$ range. In other words, the use of IFT reducing agent in the formations with Km within $1 \mu \mathrm{D}-100 \mu \mathrm{D}$ is not recommended whilst for tighter formations, i.e., $0.1 \mu \mathrm{D}-10 \mu \mathrm{D}$ and $0.01 \mu \mathrm{D}$ $1 \mu \mathrm{D}$, the use of IFT reducing agent in the FF could improve the post fracturing production.

4. As soaking time was extended from 2 to 20 days, more FF invaded further and deeper into the matrix, leaving the fracture cleaner for improved gas production. On the other hand, the favourable result lasted only in early production periods. i.e., no improvement of GPL was observed after 30 days and beyond. At the same early time, variables related to capillary pressure (IFT, $\lambda$ and $\mathrm{Km}$ ) also showed the more noticeable effect of $\mathrm{Pc}$ in improving the cleanup performance. The more pronounced effect of Pc affected by coefficient values of IFT and $\lambda$ was also noticed in sets with matrix permeability variation range reduced by a factor of 10 . The impact of ST was more important in lower Km, DP sets.

5. When the pressure drawdown was reduced from 1000 to 100 psi, the impact of Pc became more pronounced. The contribution of an increase in $\mathrm{Km}$, which reduces $\mathrm{Pc}$ and increases GPL, was evident, i.e. the Km coefficient was positive. This trend, which is in line with increased absolute values of IFT and $\lambda$ coefficients resulting in higher Pc, was opposite to what was observed in the previous cases where the $\mathrm{Km}$ coefficient was negative.

6. Increasing the pressure drawdown, resulted in the faster cleanup.

7. The high applied pressure drawdown resulted in the lower effect of capillary pressure and the more pronounced effect of $\mathrm{Km}$ on mobility.

8. Once pressure drawdown became very low and/or soaking time was prolonged, the effect of capillary pressure on GPL decrease was more pronounced.

9. As the formation becomes tighter, in general larger GPL and slower cleanup were detected. 
10. There were inconsistencies in SFVW-Set 23 with low DP=100 psi \& low Km. After an extensive investigation, this was attributed to removing many negative GPL cases present in these very low DP and Km simulations. Negative GPL occurred because, in our simulation method, the fluid in grids adjacent to fracture was over-pressurized during FF injection. It was confirmed that this effect was limited only to this set.

11. The inclusion of permeability enhancement in very low DP and Km simulations could alleviate the over-pressure effect with minimal effect in high $\mathrm{Km}$ range high/moderate DP sets.

12. As length of fracture reduced, the effect of fracture pertinent parameters on GPL decreased and the effect of matrix pertinent parameters on GPL increased.

13. The effect of capillary pressure in decreasing GPL was less noticeable in shorter fractures.

14. In shorter fractures, faster fracture cleanup was observed.

15. In the short fracture set with higher injected FF, the effect of matrix pertinent parameters (Km, Kmaxwm, Kmaxgm, nwm and ngm) on GPL was more pronounced.

16. In the higher DP sets, the effect of fracture mobility parameters was more pronounced. However, in high DP short fracture sets as formation became tighter, the effect of matrix parameters (Km, Kmaxwm, Kmaxgm, nwm and ngm) were more significant.

\section{Acknowledgements}

The above study was conducted as a part of the Gas-condensate Recovery Project at HeriotWatt University. This research project is sponsored by Daikin, DongEnergy, Ecopetrol/Equion, ExxonMobil, GDF, INPEX, JX-Nippon, Petrobras, RWE, Saudi-Aramco and TOTAL, whose contribution is gratefully acknowledged.

\section{Nomenclature}

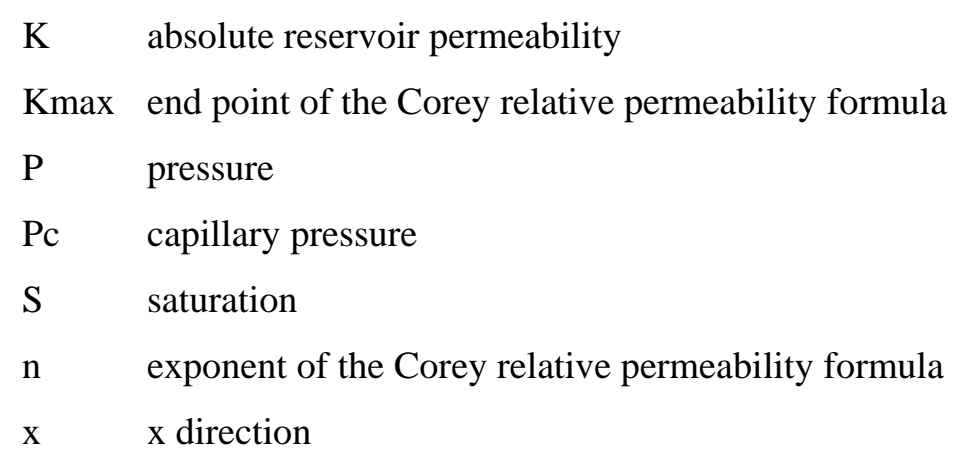




$$
\begin{array}{ll}
\mathrm{y} & \mathrm{y} \text { direction } \\
\mathrm{z} & \mathrm{z} \text { direction }
\end{array}
$$

\section{Subscript}

$\begin{array}{ll}\mathrm{g} & \text { gas } \\ \mathrm{w} & \text { water } \\ \mathrm{r} & \text { residual } \\ \mathrm{f} & \text { fracture } \\ \mathrm{m} & \text { matrix }\end{array}$

\section{Abbreviations}

LRSM linear response surface model

ILRSM linear response surface model with interaction

FVR the ratio of injected fracture fluid to fracture volume

IFT interfacial tension

FF fracture fluid

DP Pressure drawdown

GPL gas production loss

$\mathrm{Kmr}$ Matrix Permeability Ratio, i.e., if $\mathrm{Kmr}=10$ mean the $\mathrm{Km}$ variation range is reduced by factor of 10

ST Shut-in/Soaking time

VW Vertical Well

HF Hydraulic Fracturing

\section{References}

Ahmed, U., Abou-Sayed, A. and Jones, A., 1979. Experimental Evaluation of Fracturing Fluid Interaction with Tight Reservoir Rocks and Propped Fractures.

ALAJMI, E 2012 ' Modelling of Gas-Condensate Flow around Complex Well Geometries and Cleanup Efficiency in Heterogeneous Systems' PhD thesis, Heriot-Watt University Petroleum Engineering, Edinburgh, UK

Bazin, B. et al., 2009. In Situ Water Blocking Measurements and Interpretation Related to Fracturing in tight gas reservoirs.

Bennion, D., Thomas, F. and Bietz, R., 1996. Water and hydrocarbon phase trapping in porous mediadiagnosis, prevention and treatment. Journal of Canadian Petroleum Technology, 35(10).

BROOKS, R.H. \& COREY, A.T., 1966. Properties of porous media affecting fluid flow. Journal of the Irrigation and Drainage Division, 92(2), pp.61-90.

Cooke Jr, C., 1972. Conductivity of fracture proppants in multilayers, Esso Production Res Co.

Cooke Jr, C., 1974. Effect of fracturing fluids on fracture conductivity, Exxon Production Res Co. 
Gdanski, R., Fulton, D. and Shen, C., 2006. Fracture Face Skin Evolution During Cleanup.

Gdanski, R. and Walters, H., 2010. Impact of Fracture Conductivity and Matrix Relative Permeability on Load Recovery.

Ghahri, P., Jamiolahmady, M. and Sohrabi, M., 2011. A Thorough Investigation of Cleanup Efficiency of Hydraulic Fractured Wells Using Response Surface Methodology, SPE 144114

GHAHRI, P 2010 'Modelling of Gas-condensate flow around horizontal and deviated wells and cleanup efficiency of hydraulically fractured wells' PhD thesis, Heriot-Watt University Petroleum Engineering, Edinburgh, UK

Ghahri, P., Jamiolahmady, M. and Sohrabi, M., 2009. Investigation of Cleanup Efficiency of Hydraulically Fractured Wells in Gas Condensate Reservoirs.

Jamiolahmady, M., Sohrabi, M., Ganesh, D. and Danesh, A., 2007. Impact of fracture clean up on productivity of gas-condensate wells.

Jamiolahmady, M., Alajmi, E., Nasriani, H. R., Ghahri, P. and Pichestapong, K., 2014. A Thorough Investigation of Clean-up Efficiency of Hydraulic Fractured Wells Using Statistical Approaches, SPE 170862

JURUS, W. J., WHITSON, C. H. \& GOLAN, M. 2013. Modeling Water Flow in HydraulicallyFractured Shale Wells. Society of Petroleum Engineers..

Mahadevan, J. and Sharma, M., 2005. Factors Affecting Clean-up of Water-Blocks: A Laboratory Investigation. SPE Journal, 10(3): 238-246.MATLAB Refrence Manual, 2010.

Montgomery, K. and Berthelot, J., 1990. Effects of Fracture Fluid Invasion on Cleanup Behavior and Pressure Buildup Analysis.

MORADIDOWLATABAD, M. (2016) New Approaches for Performance Evaluation and Design of Well Completions in Horizontal Wells. Heriot-Watt University.

Nasriani, H. R., Jamiolahmady, M. and Alajmi, E., 2014. An Integrated Study of Cleanup Efficiency of Short Hydraulic Fractured Vertical Wells Using Response Surface Methodology, 76th EAGE Conference \& Exhibition 2014.

NEW-COIN (2015) 'Near Wellbore Coupling INertial (NEW-COIN) Version 3.7 Build 5609'. Gas Condensate Recovery (GCR) Team, Heriot-Watt University.

SCHLUMBERGER (2015) 'Geoquest, ECLIPSE 100, Version 2015.1.0.0', Simulation Launch Management Utility.

Tannich, J.D., 1975. Liquid Removal From Hydraulically Fractured Gas Wells, Journal of Petroleum Technology, Volume 27, Number 11, Pages 1309-1317.

THE MATHWORKS (2013) 'MATLAB and Statistics Toolbox Release 2014b (8.4.0.150421)', Natick Inc. Massachusetts, United States.

THOMAS, L. K., KATZ, D. L. and TEK, M. R. (1968) 'Threshold pressure phenomena in porous media', Society of Petroleum Engineers Journal. Society of Petroleum Engineers, 8(2), pp. 174-184. 


\section{Tables}

Table 1 Basic properties of the SFVW (Xf is fracture half length) model

\begin{tabular}{|c|c|c|c|c|}
\hline $\mathbf{X}_{\mathbf{f}}(\mathbf{m})$ & $\mathbf{w}_{\mathbf{f}}(\mathbf{m})$ & $\mathbf{X r e s}(\mathbf{m})$ & $\mathbf{Y r e s}(\mathbf{m})$ & $\operatorname{Zres}(\mathbf{m})$ \\
\hline 100 or 400 & 0.004 & 2000 & 2000 & 40 \\
\hline
\end{tabular}

Table 2 Fluid properties of gas used in this study.

\begin{tabular}{|c|c|c|}
\hline $\mathbf{P}(\mathbf{p s i})$ & $\mathbf{B g}$ & $\mu(c p)$ \\
\hline 14.65 & 260.21 & 0.0147 \\
\hline 400 & 9.4295 & 0.0149 \\
\hline 600 & 6.2505 & 0.015 \\
\hline 800 & 4.6658 & 0.0152 \\
\hline 1000 & 3.7189 & 0.0154 \\
\hline 1500 & 2.4673 & 0.016 \\
\hline 2000 & 1.8527 & 0.0168 \\
\hline 2500 & 1.492 & 0.0177 \\
\hline 3000 & 1.2574 & 0.0187 \\
\hline 3500 & 1.0942 & 0.0198 \\
\hline 4000 & 0.9749 & 0.021 \\
\hline 5000 & 0.8137 & 0.0235 \\
\hline 6000 & 0.7109 & 0.026 \\
\hline 7000 & 0.6401 & 0.0283 \\
\hline 7500 & 0.6124 & 0.0295 \\
\hline 8000 & 0.5886 & 0.0306 \\
\hline 8500 & 0.5677 & 0.0317 \\
\hline & & \\
\hline
\end{tabular}


Table 3 The range of variation of uncertain parameters after fracturing.

\begin{tabular}{|c|c|c|c|}
\hline & Parameter & Min & Max \\
\hline Fracture Permeability & $\mathrm{K}_{\mathrm{f}}(\mathrm{D})$ & 1 & 30 \\
\hline Matrix Permeability & $\mathrm{K}_{\mathrm{m}}$ & $1 \mu \mathrm{D}$ & $100 \mu \mathrm{D}$ \\
\hline Matrix capillary pressure curve (Pc) & Pore size index $\lambda$ & 1 & 4 \\
\hline Matrix capillary pressure curve (Pc) & Threshold pressure & Eq. $(11)$ & Eq. $(11)$ \\
\hline Matrix capillary pressure curve (Pc) & $\begin{array}{c}\text { Interfacial Tension } \\
(\mathrm{mNm} / \mathrm{m})\end{array}$ & 2 & 50 \\
\hline Matrix Krg curve & $\mathrm{n}_{\mathrm{gm}}$ & 1.5 & 5 \\
\hline Matrix Krw curve & $\mathrm{n}_{\mathrm{wm}}$ & 1.2 & 4 \\
\hline Matrix Krg curve & $\mathrm{K}_{\operatorname{maxg}}(\mathrm{end}$ point $)$ & 0.5 & 1.0 \\
\hline Matrix Krw curve & $\mathrm{K}_{\operatorname{maxw}}(\mathrm{end}$ point $)$ & 0.05 & 0.6 \\
\hline Fracture Krg curve & $\mathrm{n}_{\mathrm{gf}}$ & 1.5 & 5 \\
\hline Fracture Krw curve & $\mathrm{n}_{\mathrm{wf}}$ & 1.2 & 4 \\
\hline Fracture Krg curve & $\mathrm{K}_{\operatorname{maxg}}(\mathrm{end}$ point $)$ & 0.5 & 1.0 \\
\hline Fracture Krw curve & $\mathrm{K}_{\operatorname{maxw}}(\mathrm{end}$ point $)$ & 0.1 & 0.75 \\
\hline Pressure Drawdown & $\Delta \boldsymbol{p}(\mathrm{psi})$ & 1000 & 1000 \\
\hline Porosity & $\boldsymbol{\phi}$ & 0.15 & 0.15 \\
\hline Matrix Krg curve & $\mathrm{S}_{\mathrm{grm}}$ & 0.1 & 0.1 \\
\hline Matrix Krw curve & $\mathbf{S}_{\mathrm{wrm}}$ & 0.15 & 0.15 \\
\hline Fracture Krg curve & $\mathrm{S}_{\mathrm{grf}}$ & 0.1 & 0.1 \\
\hline Fracture Krw curve & $\mathrm{S}_{\mathrm{wrf}}$ & 0.15 & 0.15 \\
\hline & & & \\
\hline & & & \\
\hline & & & \\
\hline
\end{tabular}


Table 4a SFVW-Sets analysed

\begin{tabular}{|c|c|c|c|c|c|c|c|c|c|c|c|c|c|c|c|c|}
\hline 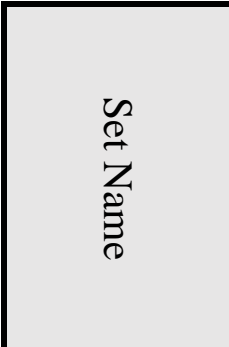 & $\begin{array}{l}\vartheta \\
\vartheta \\
\theta \\
\theta \\
0\end{array}$ & $\stackrel{\pi}{\lambda}$ & 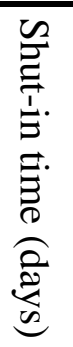 & 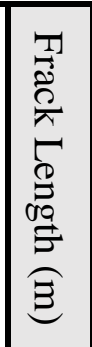 & 胥 & 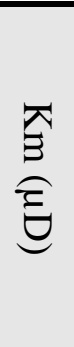 & $\overline{\tilde{z}}$ & 武 & 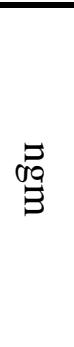 & $\stackrel{\Xi}{\Xi}$ & $\begin{array}{c}\text { 胥 } \\
\text { 离 } \\
\text { og } \\
\end{array}$ & 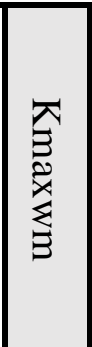 & $\stackrel{\overrightarrow{9}}{\rightarrow 0}$ & 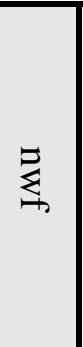 & 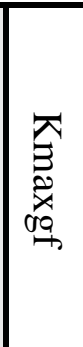 & 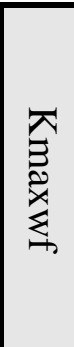 \\
\hline $\begin{array}{l}\text { Default } \\
\text { Values }\end{array}$ & $\overline{8}$ & N & $N$ & 8 & 它 & $\overline{8}$ & $\overrightarrow{+}$ & 峁 & $\overline{\dot{u}}$ & $\dot{i}$ & $\dot{\varphi}$ & $\begin{array}{l}\stackrel{P}{0} \\
\dot{u} \\
\dot{y} \\
a\end{array}$ & $\overline{i r}$ & $\dot{\tilde{n}}$ & $\dot{0}$ & $\begin{array}{l}\stackrel{\circ}{0} \\
\stackrel{0}{u} \\
u\end{array}$ \\
\hline SFVW-Set 1 & $\checkmark$ & $\checkmark$ & $\checkmark$ & $\checkmark$ & $\checkmark$ & $\checkmark$ & $\checkmark$ & $\checkmark$ & $\checkmark$ & $\checkmark$ & $\checkmark$ & $\checkmark$ & $\checkmark$ & $\checkmark$ & $\checkmark$ & $\checkmark$ \\
\hline SFVW-Set 3 & $\checkmark$ & $\checkmark$ & 20 & $\checkmark$ & $\checkmark$ & $\checkmark$ & $\checkmark$ & $\checkmark$ & $\checkmark$ & $\checkmark$ & $\checkmark$ & $\checkmark$ & $\checkmark$ & $\checkmark$ & $\checkmark$ & $\checkmark$ \\
\hline SFVW-Set 4 & $\checkmark$ & $\checkmark$ & $\checkmark$ & $\checkmark$ & $\checkmark$ & : & $\checkmark$ & $\checkmark$ & $\checkmark$ & $\checkmark$ & $\checkmark$ & $\checkmark$ & $\checkmark$ & $\checkmark$ & $\checkmark$ & $\checkmark$ \\
\hline SFVW-Set 5 & $\checkmark$ & $\checkmark$ & 20 & $\checkmark$ & $\checkmark$ & $\stackrel{0}{\frac{1}{0}}$ & $\checkmark$ & $\checkmark$ & $\checkmark$ & $\checkmark$ & $\checkmark$ & $\checkmark$ & $\checkmark$ & $\checkmark$ & $\checkmark$ & $\checkmark$ \\
\hline SFVW-Set 6 & 100 & $\checkmark$ & $\checkmark$ & $\checkmark$ & $\checkmark$ & $\checkmark$ & $\checkmark$ & $\checkmark$ & $\checkmark$ & $\checkmark$ & $\checkmark$ & $\checkmark$ & $\checkmark$ & $\checkmark$ & $\checkmark$ & $\checkmark$ \\
\hline SFVW-Set 7 & 8 & $\checkmark$ & $\checkmark$ & $\checkmark$ & $\checkmark$ & $\checkmark$ & $\checkmark$ & $\checkmark$ & $\checkmark$ & $\checkmark$ & $\checkmark$ & $\checkmark$ & $\checkmark$ & $\checkmark$ & $\checkmark$ & $\checkmark$ \\
\hline SFVW-Set 8 & 㕝 & $\checkmark$ & $\checkmark$ & $\checkmark$ & $\checkmark$ & : & $\checkmark$ & $\checkmark$ & $\checkmark$ & $\checkmark$ & $\checkmark$ & $\checkmark$ & $\checkmark$ & $\checkmark$ & $\checkmark$ & $\checkmark$ \\
\hline $\begin{array}{c}\text { SFVW-Set } \\
10\end{array}$ & $\checkmark$ & $\checkmark$ & $\checkmark$ & 100 & $\checkmark$ & $\checkmark$ & $\checkmark$ & $\checkmark$ & $\checkmark$ & $\checkmark$ & $\checkmark$ & $\checkmark$ & $\checkmark$ & $\checkmark$ & $\checkmark$ & $\checkmark$ \\
\hline $\begin{array}{c}\text { SFVW-Set } \\
12\end{array}$ & 100 & $\checkmark$ & 20 & $\checkmark$ & $\checkmark$ & $\checkmark$ & $\checkmark$ & $\checkmark$ & $\checkmark$ & $\checkmark$ & $\checkmark$ & $\checkmark$ & $\checkmark$ & $\checkmark$ & $\checkmark$ & $\checkmark$ \\
\hline $\begin{array}{c}\text { SFVW-Set } \\
13\end{array}$ & ठे & $\checkmark$ & 20 & $\checkmark$ & $\checkmark$ & $\checkmark$ & $\checkmark$ & $\checkmark$ & $\checkmark$ & $\checkmark$ & $\checkmark$ & $\checkmark$ & $\checkmark$ & $\checkmark$ & $\checkmark$ & $\checkmark$ \\
\hline $\begin{array}{c}\text { SFVW-Set } \\
14\end{array}$ & $\vec{\circ}$ & $\checkmark$ & $\checkmark$ & $\checkmark$ & $\checkmark$ & $\begin{array}{l}\stackrel{0}{\overrightarrow{1}} \\
\stackrel{\overrightarrow{0}}{0}\end{array}$ & $\checkmark$ & $\checkmark$ & $\checkmark$ & $\checkmark$ & $\checkmark$ & $\checkmark$ & $\checkmark$ & $\checkmark$ & $\checkmark$ & $\checkmark$ \\
\hline $\begin{array}{c}\text { SFVW-Set } \\
15\end{array}$ & $\overrightarrow{8}$ & $\checkmark$ & 20 & $\checkmark$ & $\checkmark$ & $\begin{array}{l}\stackrel{0}{\overrightarrow{1}} \\
\stackrel{\overrightarrow{0}}{2}\end{array}$ & $\checkmark$ & $\checkmark$ & $\checkmark$ & $\checkmark$ & $\checkmark$ & $\checkmark$ & $\checkmark$ & $\checkmark$ & $\checkmark$ & $\checkmark$ \\
\hline $\begin{array}{c}\text { SFVW-Set } \\
16\end{array}$ & हे & $\checkmark$ & $\checkmark$ & $\checkmark$ & $\checkmark$ & $\begin{array}{l}\stackrel{0}{\overrightarrow{1}} \\
\dot{\overrightarrow{0}}\end{array}$ & $\checkmark$ & $\checkmark$ & $\checkmark$ & $\checkmark$ & $\checkmark$ & $\checkmark$ & $\checkmark$ & $\checkmark$ & $\checkmark$ & $\checkmark$ \\
\hline
\end{tabular}


Table 4b SFVW-Sets analysed

\begin{tabular}{|c|c|c|c|c|c|c|c|c|c|c|c|c|c|c|c|c|}
\hline 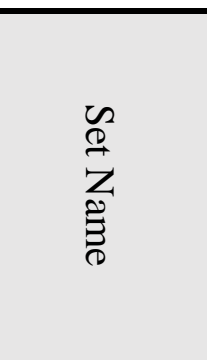 & 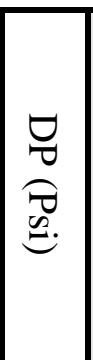 & $\underset{\lambda}{T}$ & 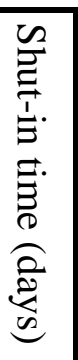 & 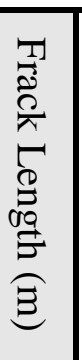 & 胥 & 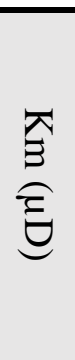 & $\overrightarrow{\tilde{B}}$ & 켝 & $\stackrel{\substack{g \\
\Xi}}{\Xi}$ & E & 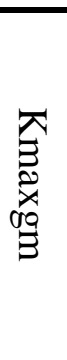 & 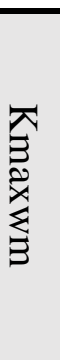 & $\stackrel{\overrightarrow{\sigma 0}}{\rightarrow}$ & $\underset{\not}{\Xi}$ & 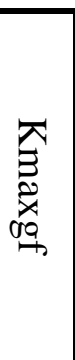 & 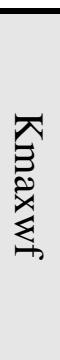 \\
\hline $\begin{array}{l}\text { Default } \\
\text { Values }\end{array}$ & ஓ & $N$ & $N$ & 8 & 产 & $\frac{7}{8}$ & $\vec{t}$ & $\begin{array}{l}N \\
\ddot{2}\end{array}$ & $\overline{u ̈}$ & $\stackrel{i}{\dot{1}}$ & $\stackrel{0}{\dot{1}}$ & $\begin{array}{l}0 \\
0 \\
\text { ب̂. } \\
0 \\
0 \\
0\end{array}$ & $\dot{u}$ & $\ddot{i}$ & î & $\begin{array}{l}0 \\
\dot{1} \\
\stackrel{0}{0} \\
\text { ur }\end{array}$ \\
\hline $\begin{array}{c}\text { SFVW-Set } \\
17\end{array}$ & $\begin{array}{l}8 \\
8\end{array}$ & $\checkmark$ & 20 & $\checkmark$ & $\checkmark$ & $\begin{array}{l}\stackrel{0}{\overrightarrow{1}} \\
\dot{\overrightarrow{0}}\end{array}$ & $\checkmark$ & $\checkmark$ & $\checkmark$ & $\checkmark$ & $\checkmark$ & $\checkmark$ & $\checkmark$ & $\checkmark$ & $\checkmark$ & $\checkmark$ \\
\hline $\begin{array}{c}\text { SFVW-Set } \\
18\end{array}$ & 100 & $\checkmark$ & $\checkmark$ & 100 & $\checkmark$ & $\checkmark$ & $\checkmark$ & $\sqrt{ }$ & $\checkmark$ & $\checkmark$ & $\checkmark$ & $\checkmark$ & $\checkmark$ & $\checkmark$ & $\checkmark$ & $\checkmark$ \\
\hline $\begin{array}{c}\text { SFVW-Set } \\
19 \\
\end{array}$ & 100 & $\checkmark$ & 20 & 100 & $\checkmark$ & $\checkmark$ & $\sqrt{ }$ & $\checkmark$ & $\checkmark$ & $\checkmark$ & $\checkmark$ & $\checkmark$ & $\checkmark$ & $\checkmark$ & $\checkmark$ & $\checkmark$ \\
\hline $\begin{array}{c}\text { SFVW-Set } \\
21\end{array}$ & 옹 & $\checkmark$ & $\checkmark$ & 100 & $\checkmark$ & $\checkmark$ & $\checkmark$ & $\checkmark$ & $\checkmark$ & $\checkmark$ & $\checkmark$ & $\checkmark$ & $\checkmark$ & $\checkmark$ & $\checkmark$ & $\checkmark$ \\
\hline $\begin{array}{c}\text { SFVW-Set } \\
22\end{array}$ & 용 & $\checkmark$ & $\checkmark$ & 100 & $\checkmark$ & $\begin{array}{l}\stackrel{\circ}{\overrightarrow{1}} \\
\dot{\overrightarrow{0}}\end{array}$ & $\checkmark$ & $\checkmark$ & $\checkmark$ & $\checkmark$ & $\checkmark$ & $\checkmark$ & $\checkmark$ & $\checkmark$ & $\checkmark$ & $\checkmark$ \\
\hline $\begin{array}{c}\text { SFVW-Set } \\
23\end{array}$ & $\overrightarrow{8}$ & $\checkmark$ & $\checkmark$ & $\checkmark$ & $\checkmark$ & $\begin{array}{l}\stackrel{0}{0} \\
\stackrel{9}{\lrcorner} \\
\end{array}$ & $\checkmark$ & $\checkmark$ & $\checkmark$ & $\checkmark$ & $\checkmark$ & $\checkmark$ & $\checkmark$ & $\checkmark$ & $\checkmark$ & $\checkmark$ \\
\hline $\begin{array}{c}\text { SFVW-Set } \\
24\end{array}$ & $\overrightarrow{8}$ & $\checkmark$ & 20 & $\checkmark$ & $\checkmark$ & $\begin{array}{l}\stackrel{0}{0} \\
\stackrel{0}{9} \\
\\
\end{array}$ & $\checkmark$ & $\checkmark$ & $\checkmark$ & $\checkmark$ & $\checkmark$ & $\checkmark$ & $\checkmark$ & $\checkmark$ & $\checkmark$ & $\checkmark$ \\
\hline $\begin{array}{c}\text { SFVW-Set } \\
25\end{array}$ & $\checkmark$ & $\checkmark$ & $\checkmark$ & $\checkmark$ & $\checkmark$ & $\begin{array}{l}\stackrel{0}{0} \\
\stackrel{9}{9} \\
\dot{1}\end{array}$ & $\checkmark$ & $\checkmark$ & $\checkmark$ & $\checkmark$ & $\checkmark$ & $\checkmark$ & $\checkmark$ & $\checkmark$ & $\checkmark$ & $\checkmark$ \\
\hline $\begin{array}{c}\text { SFVW-Set } \\
26\end{array}$ & $\checkmark$ & $\checkmark$ & 20 & $\checkmark$ & $\checkmark$ & $\begin{array}{l}\stackrel{0}{0} \\
\stackrel{0}{1} \\
\dot{1}\end{array}$ & $\checkmark$ & $\checkmark$ & $\checkmark$ & $\checkmark$ & $\checkmark$ & $\checkmark$ & $\checkmark$ & $\checkmark$ & $\checkmark$ & $\checkmark$ \\
\hline $\begin{array}{c}\text { SFVW-Set } \\
27\end{array}$ & 용 & $\checkmark$ & 20 & $\checkmark$ & $\checkmark$ & $\begin{array}{l}\circ \\
\stackrel{0}{9} \\
\dot{1}\end{array}$ & $\checkmark$ & $\checkmark$ & $\checkmark$ & $\checkmark$ & $\checkmark$ & $\checkmark$ & $\checkmark$ & $\checkmark$ & $\checkmark$ & $\checkmark$ \\
\hline $\begin{array}{c}\text { SFVW-Set } \\
28\end{array}$ & 용 & $\checkmark$ & $\checkmark$ & $\checkmark$ & $\checkmark$ & $\begin{array}{l}\circ \\
\stackrel{0}{\circ} \\
\stackrel{+}{1} \\
-1\end{array}$ & $\checkmark$ & $\checkmark$ & $\checkmark$ & $\sqrt{ }$ & $\checkmark$ & $\checkmark$ & $\checkmark$ & $\checkmark$ & $\checkmark$ & $\checkmark$ \\
\hline $\begin{array}{c}\text { SFVW-Set } \\
46\end{array}$ & $\checkmark$ & $\checkmark$ & $\checkmark$ & 50 & $\checkmark$ & $\checkmark$ & $\checkmark$ & $\checkmark$ & $\checkmark$ & $\checkmark$ & $\checkmark$ & $\checkmark$ & $\checkmark$ & $\checkmark$ & $\checkmark$ & $\checkmark$ \\
\hline
\end{tabular}


Table 4c SFVW-Sets analysed

\begin{tabular}{|c|c|c|c|c|c|c|c|c|c|c|c|c|c|c|c|c|}
\hline 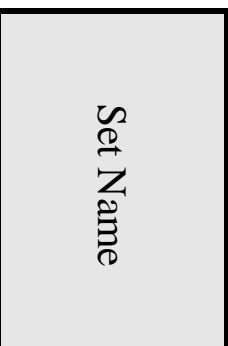 & $\begin{array}{l}\vartheta \\
\vartheta \\
\vartheta \\
0 \\
0\end{array}$ & $\sum_{\lambda}^{T}$ & 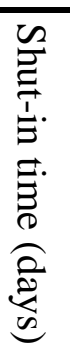 & 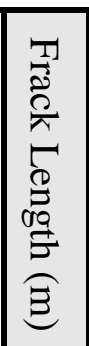 & 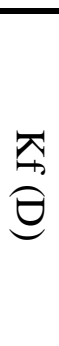 & 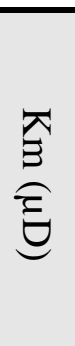 & $\vec{\Xi}$ & 곡 & $\stackrel{\substack{90 \\
g}}{g}$ & 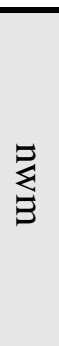 & 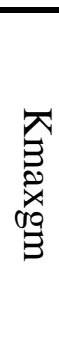 & 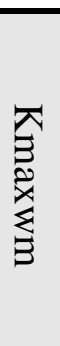 & 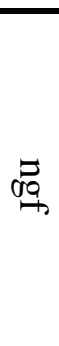 & $\underset{\infty}{E}$ & 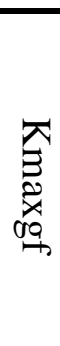 & 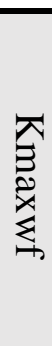 \\
\hline $\begin{array}{l}\text { Default } \\
\text { Values }\end{array}$ & 8 & $N$ & $N$ & 8 & $\stackrel{\bar{\omega}}{0}$ & $\frac{7}{8}$ & $\vec{p}$ & $\stackrel{N}{\check{o}}$ & úr & $\vec{i}$ & í & $\begin{array}{l}0 \\
0 \\
\text { ù } \\
0 \\
0\end{array}$ & í & $\vec{i}$ & í & $\begin{array}{l}0 \\
\dot{1} \\
\dot{0} \\
\text { ù }\end{array}$ \\
\hline $\begin{array}{c}\text { SFVW-Set } \\
55\end{array}$ & 100 & $\checkmark$ & $\checkmark$ & 100 & $\checkmark$ & $\stackrel{0}{\rightarrow}$ & $\checkmark$ & $\checkmark$ & $\checkmark$ & $\checkmark$ & $\checkmark$ & $\checkmark$ & $\checkmark$ & $\checkmark$ & $\checkmark$ & $\checkmark$ \\
\hline $\begin{array}{c}\text { SFVW-Set } \\
56\end{array}$ & 용 & $\checkmark$ & 20 & 100 & $\checkmark$ & $\checkmark$ & $\checkmark$ & $\checkmark$ & $\checkmark$ & $\checkmark$ & $\checkmark$ & $\checkmark$ & $\checkmark$ & $\checkmark$ & $\checkmark$ & $\checkmark$ \\
\hline $\begin{array}{c}\text { SFVW-Set } \\
57\end{array}$ & $\checkmark$ & $\checkmark$ & $\checkmark$ & 100 & $\checkmark$ & $\begin{array}{l}\stackrel{0}{\overrightarrow{1}} \\
\stackrel{\overrightarrow{0}}{0}\end{array}$ & $\checkmark$ & $\checkmark$ & $\checkmark$ & $\checkmark$ & $\checkmark$ & $\checkmark$ & $\checkmark$ & $\checkmark$ & $\checkmark$ & $\checkmark$ \\
\hline $\begin{array}{c}\text { SFVW-Set } \\
58\end{array}$ & 100 & $\checkmark$ & 20 & 100 & $\checkmark$ & $\begin{array}{l}\stackrel{0}{\overrightarrow{1}} \\
\frac{1}{0}\end{array}$ & $\checkmark$ & $\checkmark$ & $\checkmark$ & $\checkmark$ & $\checkmark$ & $\checkmark$ & $\checkmark$ & $\checkmark$ & $\checkmark$ & $\checkmark$ \\
\hline $\begin{array}{c}\text { SFVW-Set } \\
59\end{array}$ & 8े & $\checkmark$ & 20 & 100 & $\checkmark$ & $\begin{array}{l}\stackrel{0}{\overrightarrow{1}} \\
\stackrel{\overrightarrow{0}}{0}\end{array}$ & $\checkmark$ & $\checkmark$ & $\checkmark$ & $\checkmark$ & $\checkmark$ & $\checkmark$ & $\sqrt{ }$ & $\sqrt{ }$ & $\checkmark$ & $\checkmark$ \\
\hline $\begin{array}{c}\text { SFVW-Set } \\
60\end{array}$ & $\checkmark$ & $\checkmark$ & 20 & 100 & $\checkmark$ & $\begin{array}{l}\stackrel{0}{\overrightarrow{1}} \\
\stackrel{\overrightarrow{0}}{0}\end{array}$ & $\checkmark$ & $\checkmark$ & $\checkmark$ & $\checkmark$ & $\checkmark$ & $\checkmark$ & $\checkmark$ & $\sqrt{ }$ & $\checkmark$ & $\checkmark$ \\
\hline $\begin{array}{c}\text { SFVW-Set } \\
61\end{array}$ & 용 & $\checkmark$ & 20 & 100 & $\checkmark$ & $\begin{array}{l}\circ \\
\stackrel{0}{+} \\
\stackrel{1}{+}\end{array}$ & $\checkmark$ & $\checkmark$ & $\checkmark$ & $\checkmark$ & $\checkmark$ & $\checkmark$ & $\checkmark$ & $\checkmark$ & $\checkmark$ & $\checkmark$ \\
\hline \begin{tabular}{|c|} 
SFVW-Set \\
64, with \\
Permeability \\
Enhancement
\end{tabular} & $\checkmark$ & $\checkmark$ & $\checkmark$ & $\checkmark$ & $\sqrt{ }$ & $\checkmark$ & $\checkmark$ & $\checkmark$ & $\checkmark$ & $\sqrt{ }$ & $\checkmark$ & $\checkmark$ & $\sqrt{ }$ & $\checkmark$ & $\checkmark$ & $\checkmark$ \\
\hline \begin{tabular}{|c|} 
SFVW-Set \\
65, with \\
Permeability \\
Enhancement
\end{tabular} & 100 & $\checkmark$ & $\checkmark$ & $\checkmark$ & $\checkmark$ & $\begin{array}{l}\stackrel{0}{0} \\
\stackrel{0}{1} \\
\end{array}$ & $\sqrt{ }$ & $\checkmark$ & $\checkmark$ & $\checkmark$ & $\checkmark$ & $\checkmark$ & $\checkmark$ & $\checkmark$ & $\checkmark$ & $\checkmark$ \\
\hline $\begin{array}{c}\text { SFVW-Set } \\
66, \text { with } \\
\text { Permeability } \\
\text { Enhancement }\end{array}$ & $\sqrt{ }$ & $\checkmark$ & $\checkmark$ & $\checkmark$ & $\checkmark$ & $\begin{array}{l}\circ \\
\stackrel{0}{+} \\
\stackrel{1}{-}\end{array}$ & $\checkmark$ & $\checkmark$ & $\checkmark$ & $\checkmark$ & $\checkmark$ & $\checkmark$ & $\checkmark$ & $\checkmark$ & $\checkmark$ & $\checkmark$ \\
\hline
\end{tabular}


Table 5 Parameters for the worst and the best scenarios for the Base Reference Set, Set 1 .

\begin{tabular}{|c|c|c|c|c|}
\hline \multirow{2}{*}{ No. } & \multirow{2}{*}{\multicolumn{2}{|c|}{ Parameter }} & \multicolumn{2}{|l|}{ Case } \\
\hline & & & Worst & Best \\
\hline 1 & Fracture Permeability & $\mathrm{K}_{\mathrm{f}}(\mathrm{D})$ & 1 & 30 \\
\hline 2 & Matrix Permeability & $\mathrm{K}_{\mathrm{m}}(\mu \mathrm{D})$ & 1 & 100 \\
\hline 3 & \multirow[b]{2}{*}{ Matrix Capillary Pressure } & Pore Size Index, $\lambda$ & 4 & 1 \\
\hline 4 & & $\begin{array}{l}\text { Interfacial Tension, } \\
\text { IFT }(\mathrm{mNm} / \mathrm{m})\end{array}$ & 2 & 50 \\
\hline 5 & $\begin{array}{l}\text { Exponent of the Corey gas relative } \\
\text { permeability curve in matrix }\end{array}$ & $\mathrm{n}_{\mathrm{gm}}$ & 5 & 1.5 \\
\hline 6 & $\begin{array}{l}\text { Exponent of the Corey fracture fluid } \\
\text { (water) relative permeability curve in } \\
\text { matrix }\end{array}$ & $\mathrm{n}_{\mathrm{wm}}$ & 4 & 1.2 \\
\hline 7 & $\begin{array}{l}\text { End point of Corey gas relative } \\
\text { permeability curve in matrix }\end{array}$ & $\mathrm{K}_{\operatorname{maxgm}}$ & 0.5 & 1.0 \\
\hline 8 & $\begin{array}{l}\text { End point of Corey fracture fluid (water) } \\
\text { relative permeability curve in matrix }\end{array}$ & $\mathrm{K}_{\operatorname{maxwm}}$ & 0.05 & 0.6 \\
\hline 9 & $\begin{array}{l}\text { Exponent of the Corey gas relative } \\
\text { permeability curve in fracture }\end{array}$ & $\mathrm{n}_{\mathrm{gf}}$ & 5 & 1.5 \\
\hline 10 & $\begin{array}{l}\text { Exponent of the Corey fracture fluid } \\
\text { (water) relative permeability curve in } \\
\text { fracture }\end{array}$ & $\mathrm{n}_{\mathrm{wf}}$ & 4 & 1.2 \\
\hline 11 & $\begin{array}{l}\text { End point of Corey gas relative } \\
\text { permeability curve in fracture }\end{array}$ & $\mathrm{K}_{\operatorname{maxgf}}$ & 0.5 & 1.0 \\
\hline 12 & $\begin{array}{l}\text { End point of Corey fracture fluid (water) } \\
\text { relative permeability curve in fracture }\end{array}$ & $\mathrm{K}_{\operatorname{maxwf}}$ & 0.1 & 0.75 \\
\hline 13 & Porosity & $\phi$ & 0.15 & \\
\hline 14 & Residual water saturation in fracture & $S_{\mathrm{wrf}}$ & 0.15 & \\
\hline 15 & Residual water saturation in matrix & $\mathrm{S}_{\mathrm{wrm}}$ & 0.15 & \\
\hline 16 & Residual gas saturation in fracture & $S_{\text {grf }}$ & 0.1 & \\
\hline 17 & Residual gas saturation in matrix & $\mathrm{S}_{\mathrm{grm}}$ & 0.1 & \\
\hline
\end{tabular}




\section{Figures}

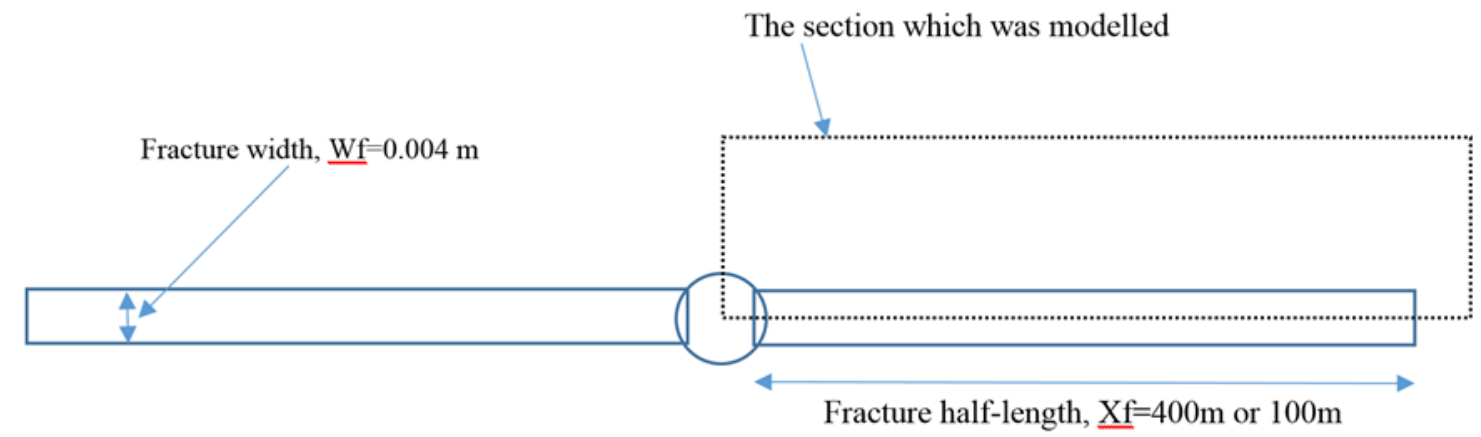

Figure 1 The section that is modelled for SFVW sets.

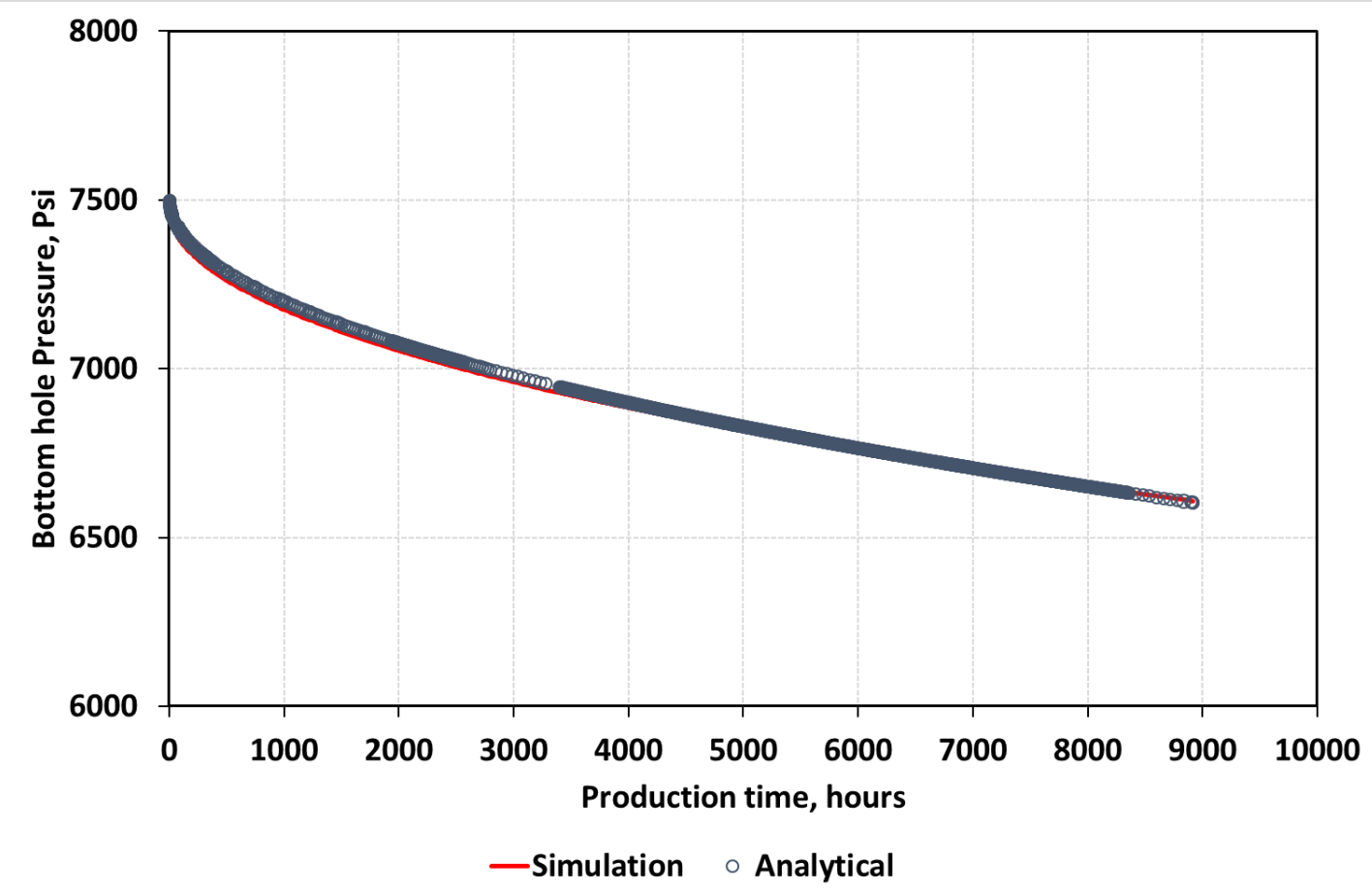

Figure 2 Predicated bottom hole pressure by simulation model and analytical model (Equation (2)) versus production time. 


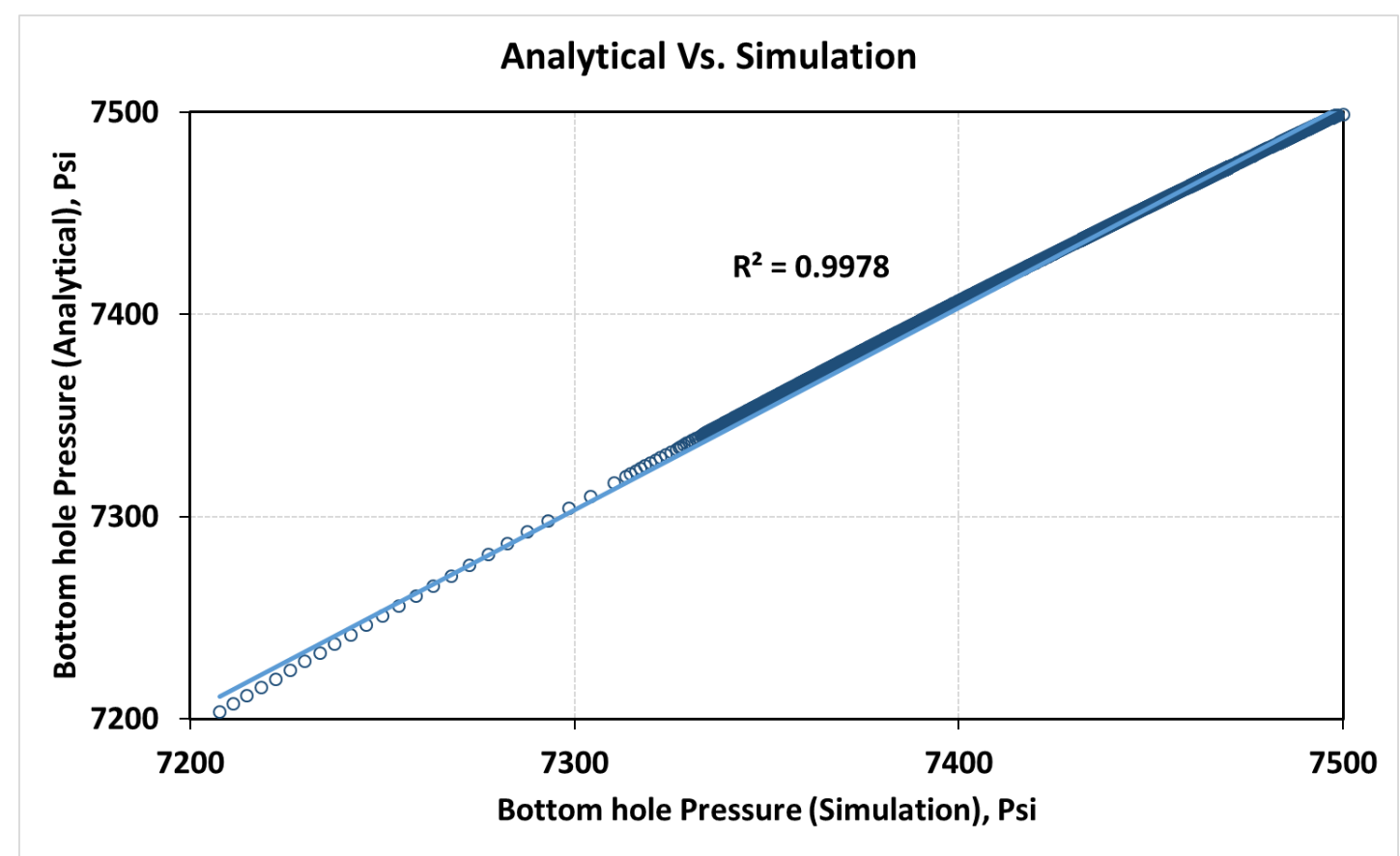

- Analytical Vs. Simulation - Linear (Analytical Vs. Simulation)

Figure 3 Predicated bottom hole pressure by analytical model (Equation (2)) vs the simulation model.

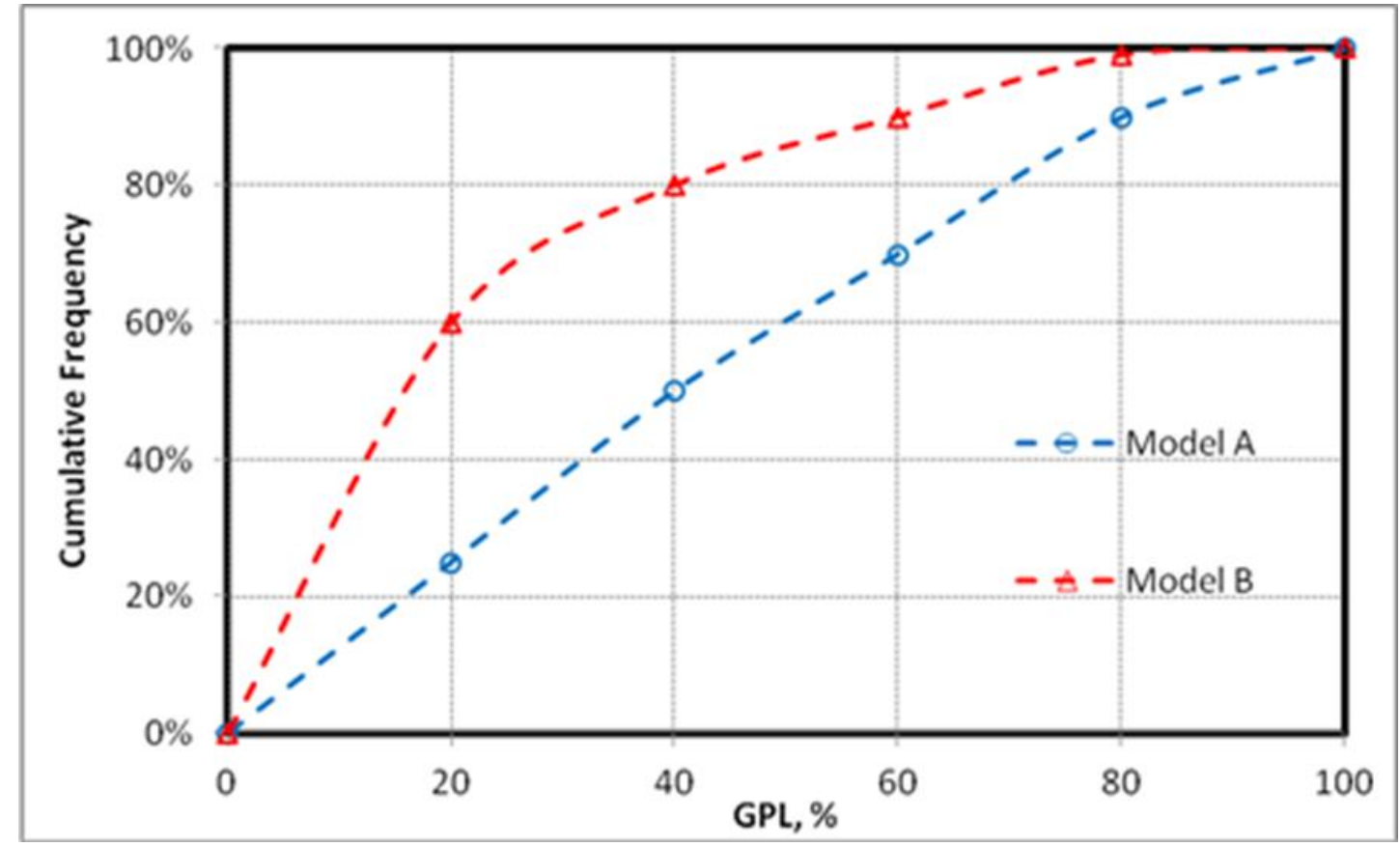

Figure 4 Histogram chart demonstrating the percentage of the cumulative frequency of the runs for (model A and B) versus GPL\%. (For demonstration purposes). 


\section{Gas Production Loss-10Days (GPL)}

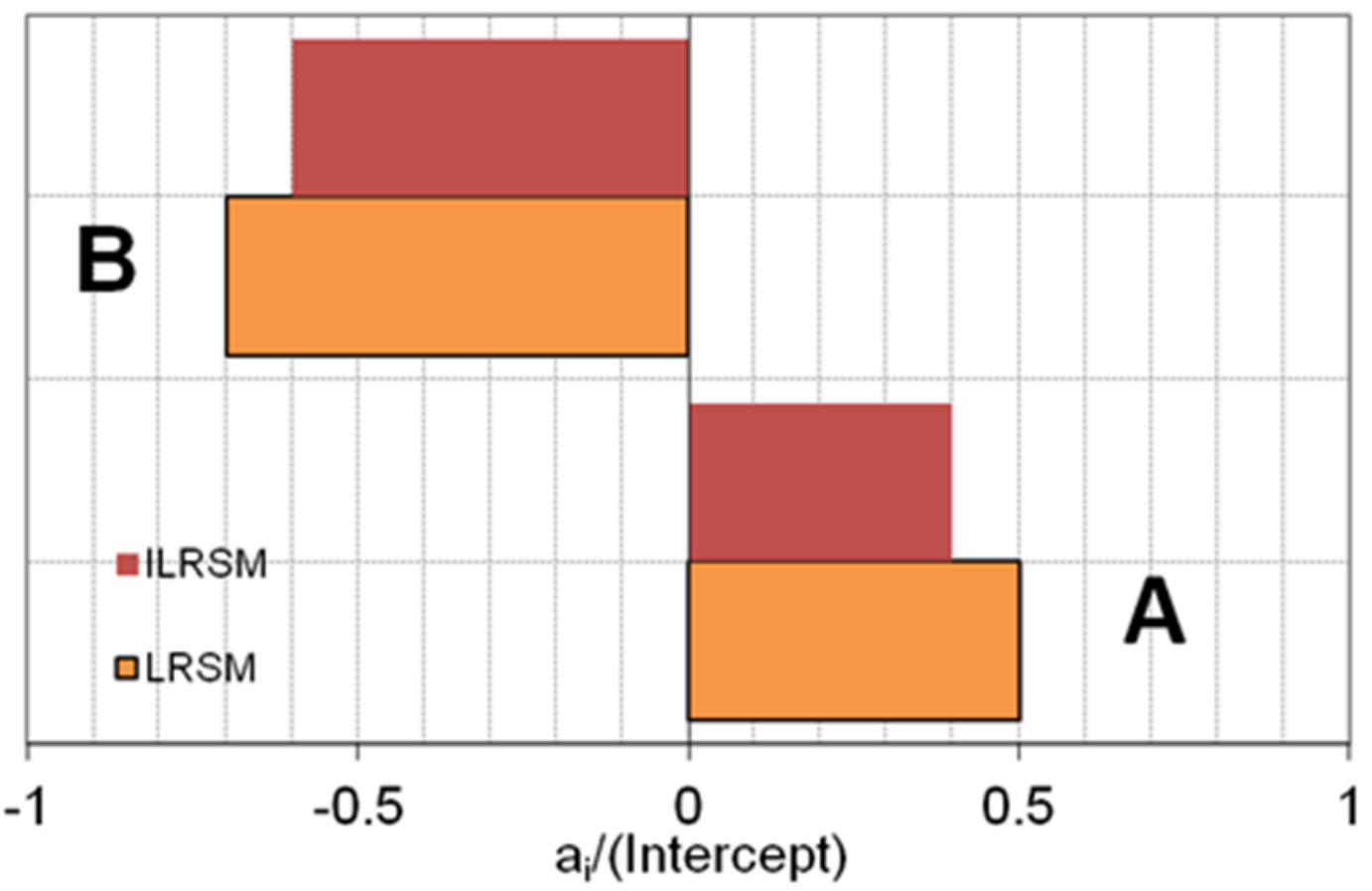

Figure 5 Tornado chart of primary coefficients of all pertinent parameters on gas production loss (Linear Response Surface Model, without interaction) for (Model A and B). (For demonstration purposes).

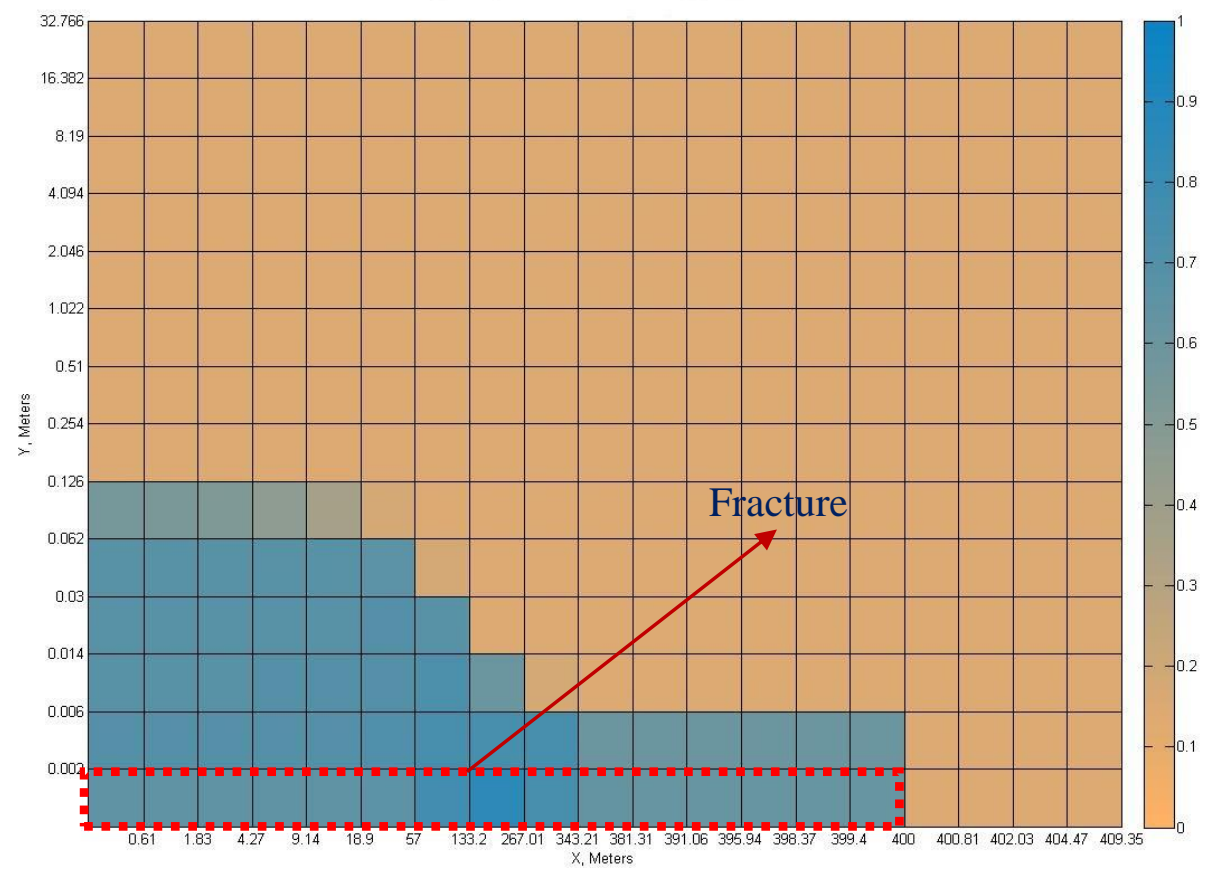

Figure 6 The saturation map of FF distribution in and around the fractures. 
a. Normal RSM

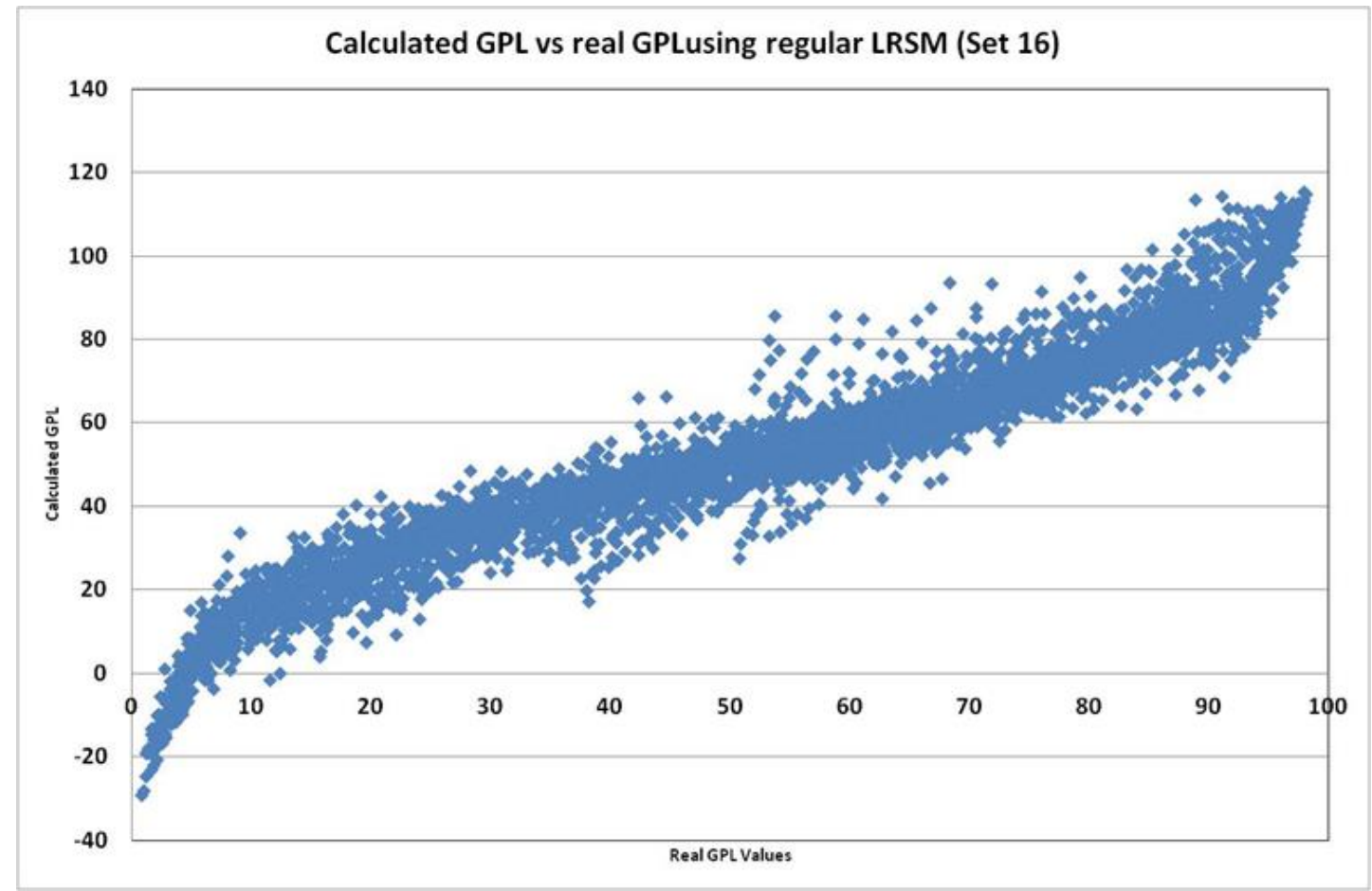

b. RSM with Domain change

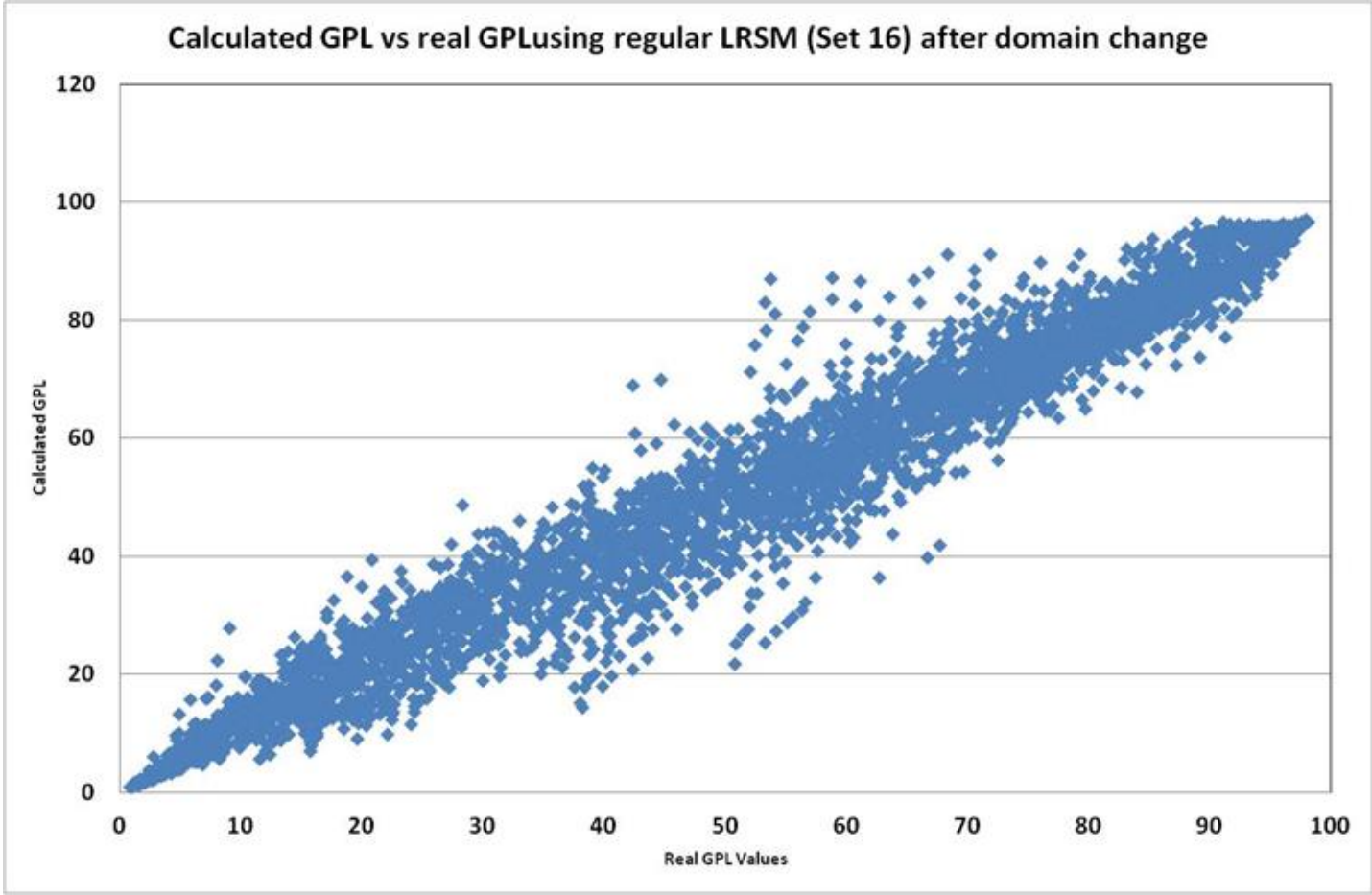

Figure 7 Calculated GPL using RSM versus real GPL results, a. Normal RSM, b. RSM with a domain change. 
Base Reference Set, SFVW-Set 1, Long Fracture, Gas Production Loss - LRSM

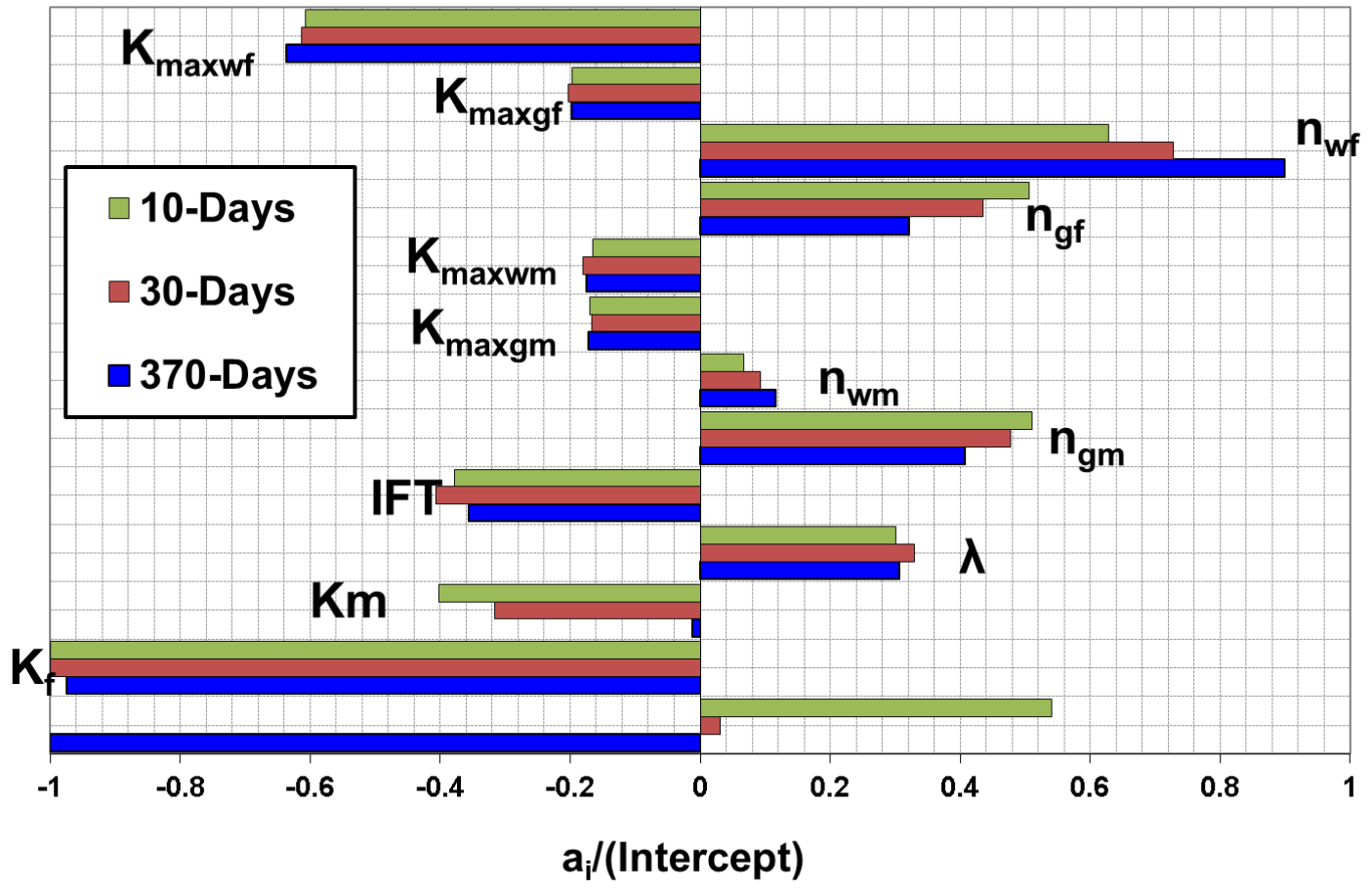

Figure 8 Tornado chart showing LRSM coefficients of all pertinent parameters in the Base Reference Set $(\mathrm{BC})$ at three production stages, $(\mathrm{FVR}=2, \mathrm{DP}=1000 \mathrm{psi}, \mathrm{ST}=2$ days and $\mathrm{Kmr}=1$ ).

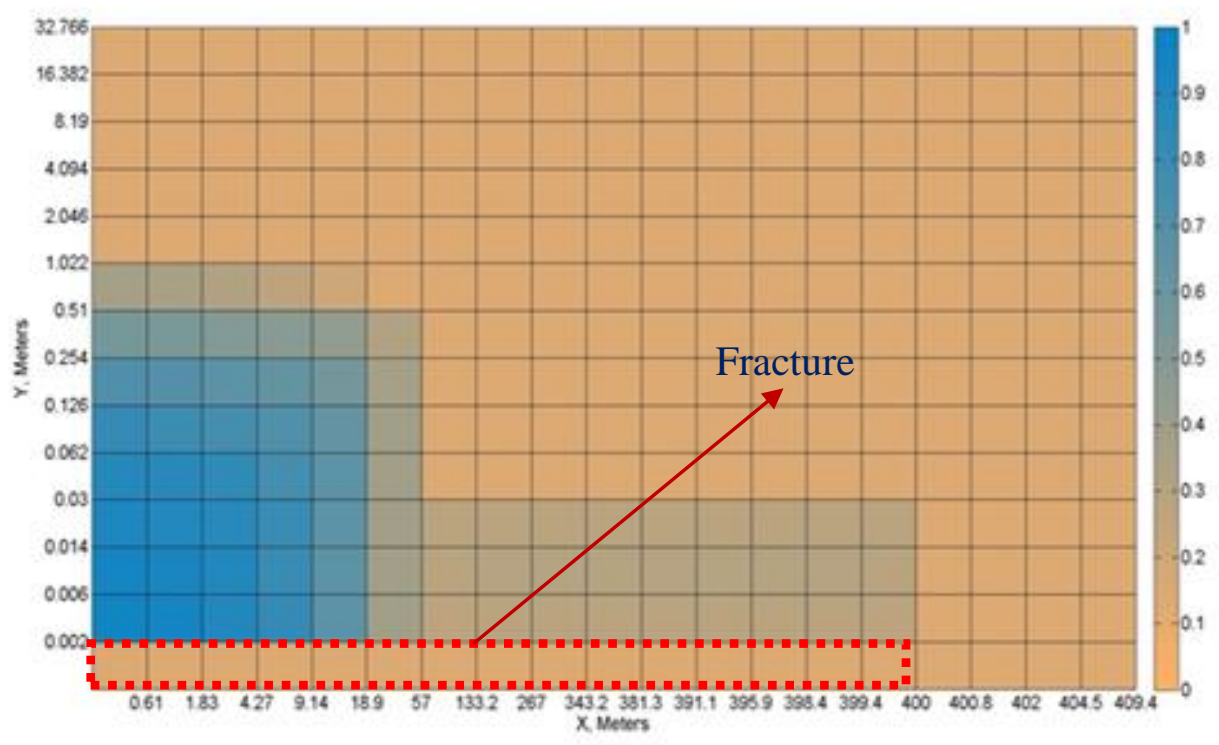

Figure 9 Fracturing Fluid saturation map of the best scenario of the Base Reference Set after 2 days of the shut-in period. 


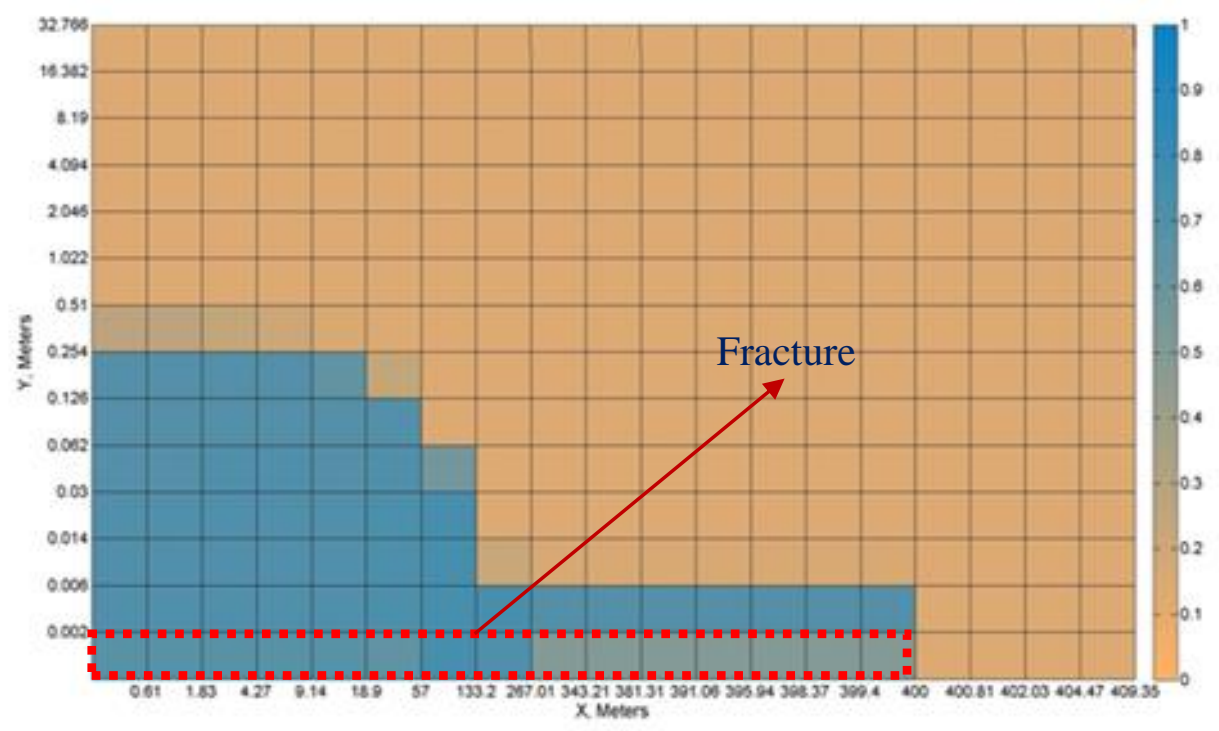

Figure 10 Fracturing Fluid saturation map of the worst scenario of the Base Reference Set after 2 days of the shut-in period.

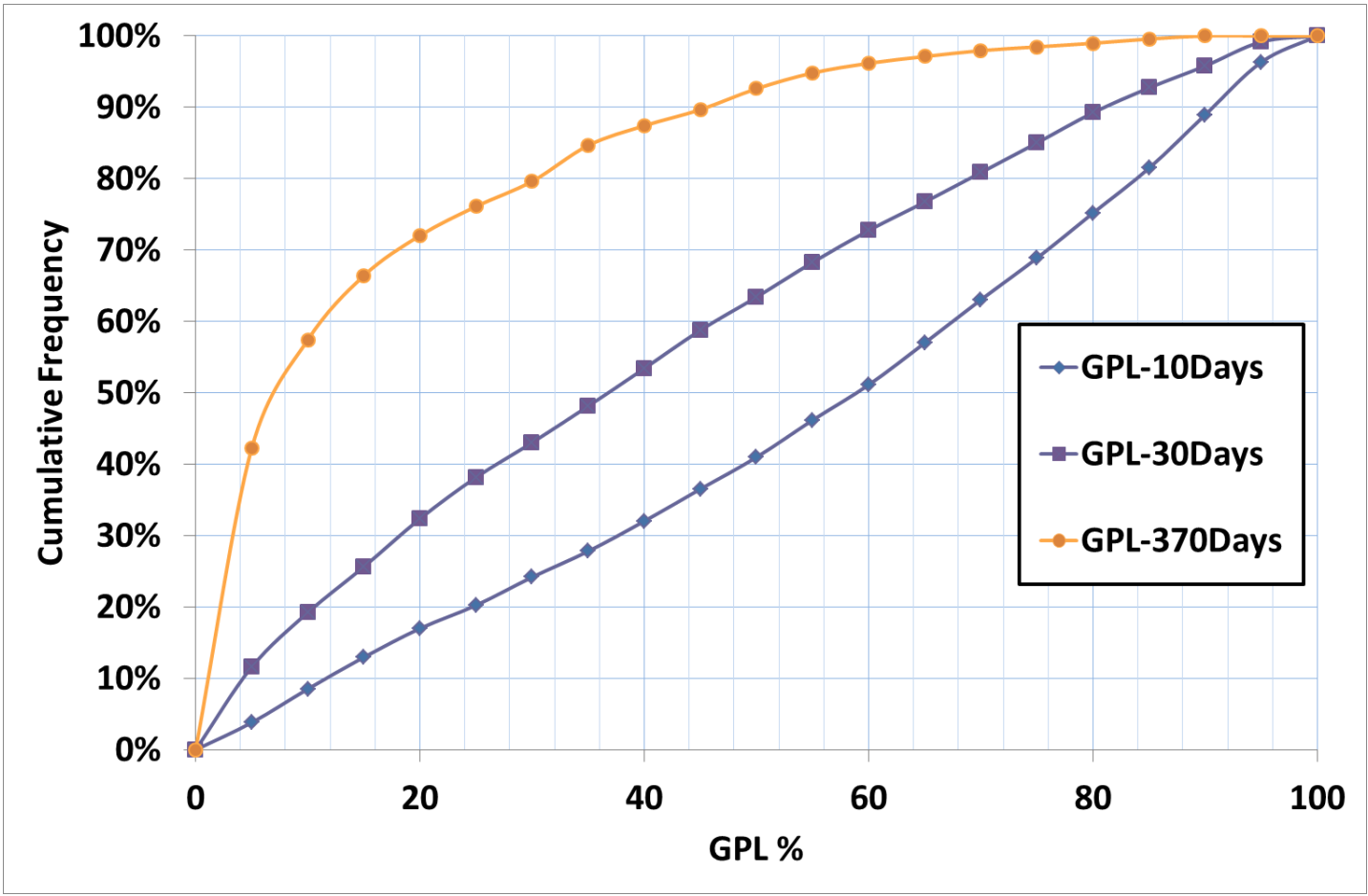

Figure 11 Histogram chart displaying cumulative frequency of the Base Reference Set (BC) at three production stages. 
SFVW-Set 3, Long Fracture, Gas Production Loss (GPL) - LRSM

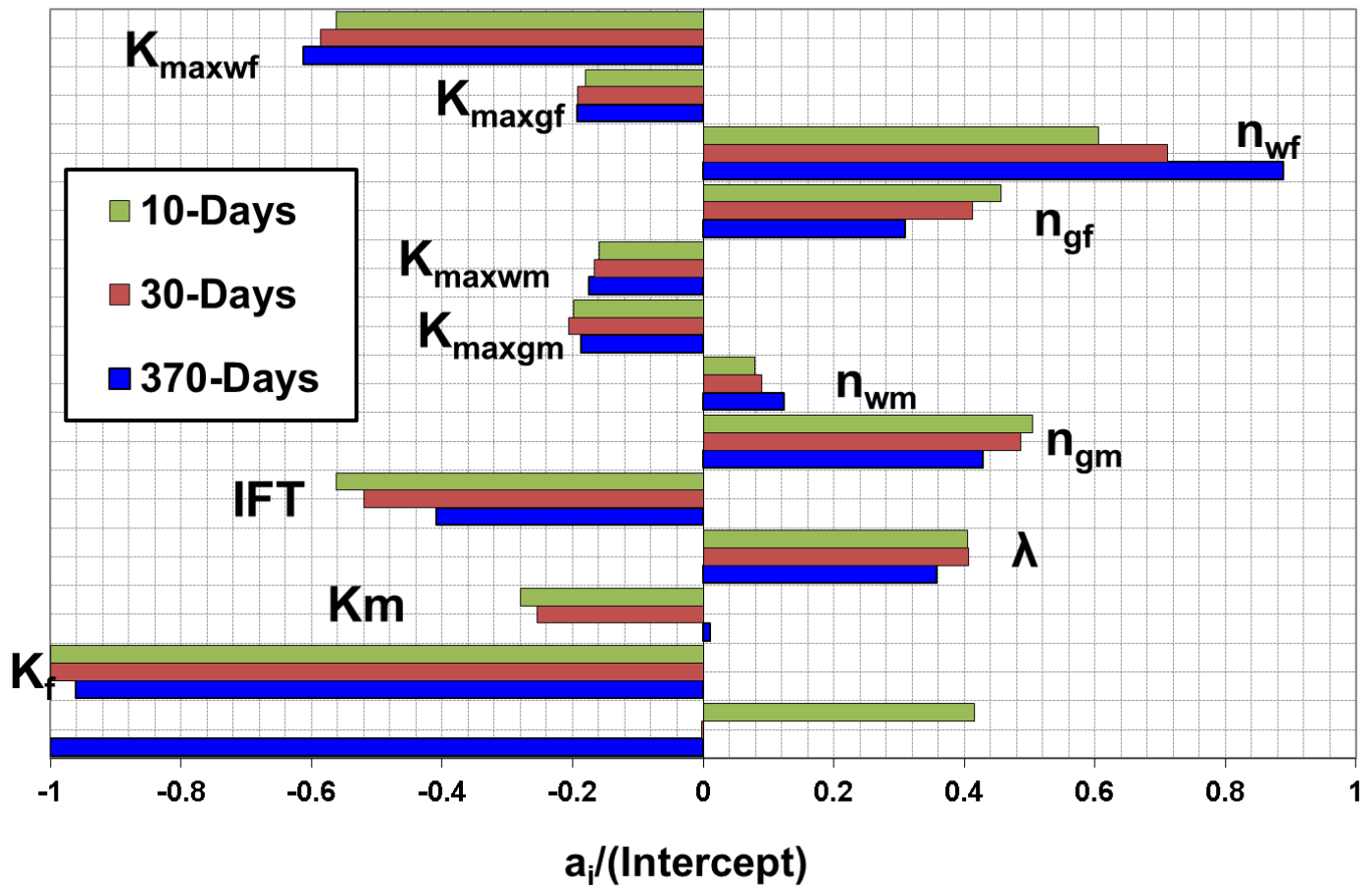

Figure 12 Tornado chart comparing LRSM coefficients of all pertinent parameters at three production stages, in the SFVW- Set with ST=20 days, Long Fracture.

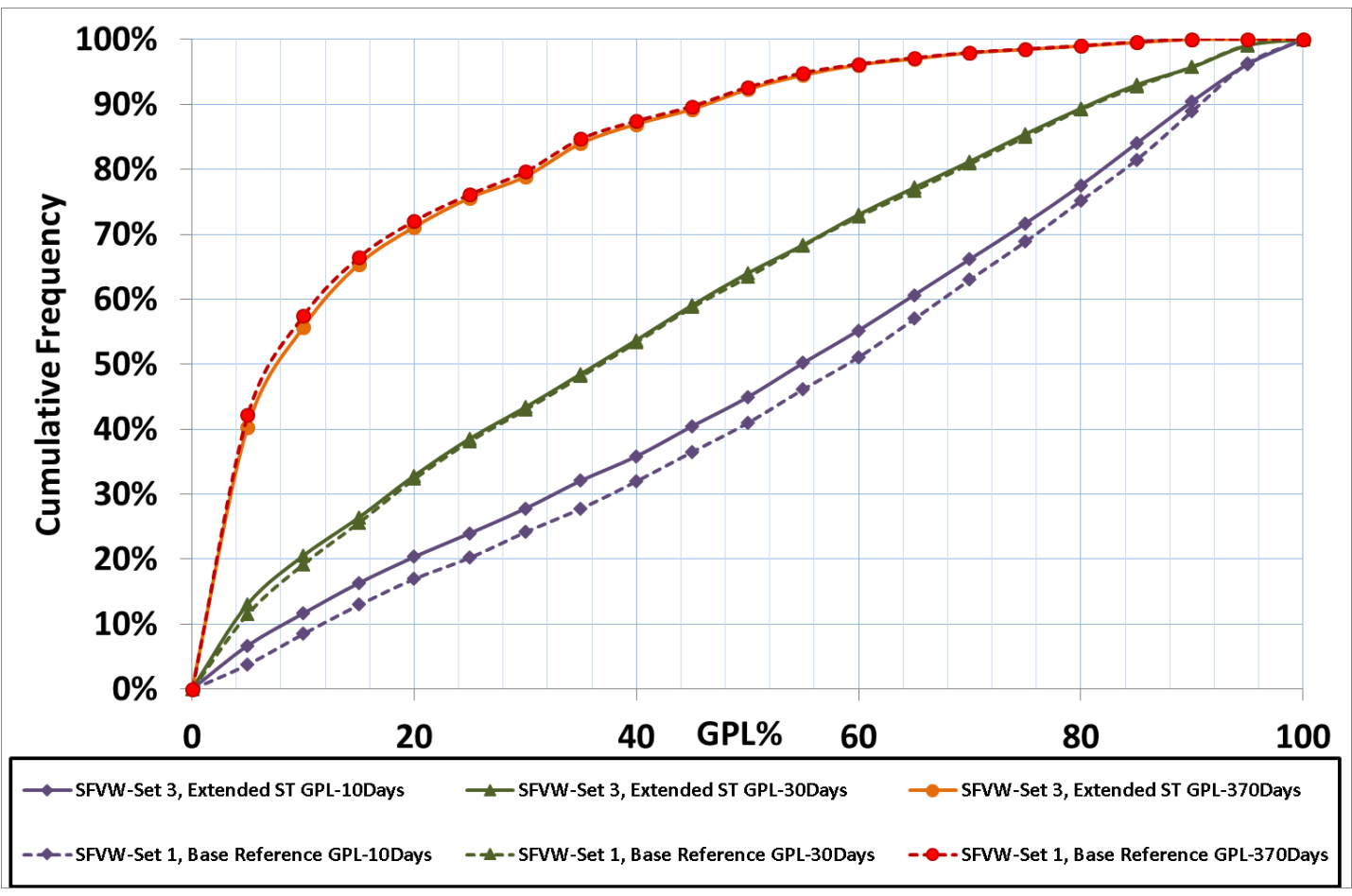

Figure 13 Histogram chart comparing the cumulative frequency of SFVW-Set 3 with ST=20, and SFVW-Set 1 base reference set at three production periods. 


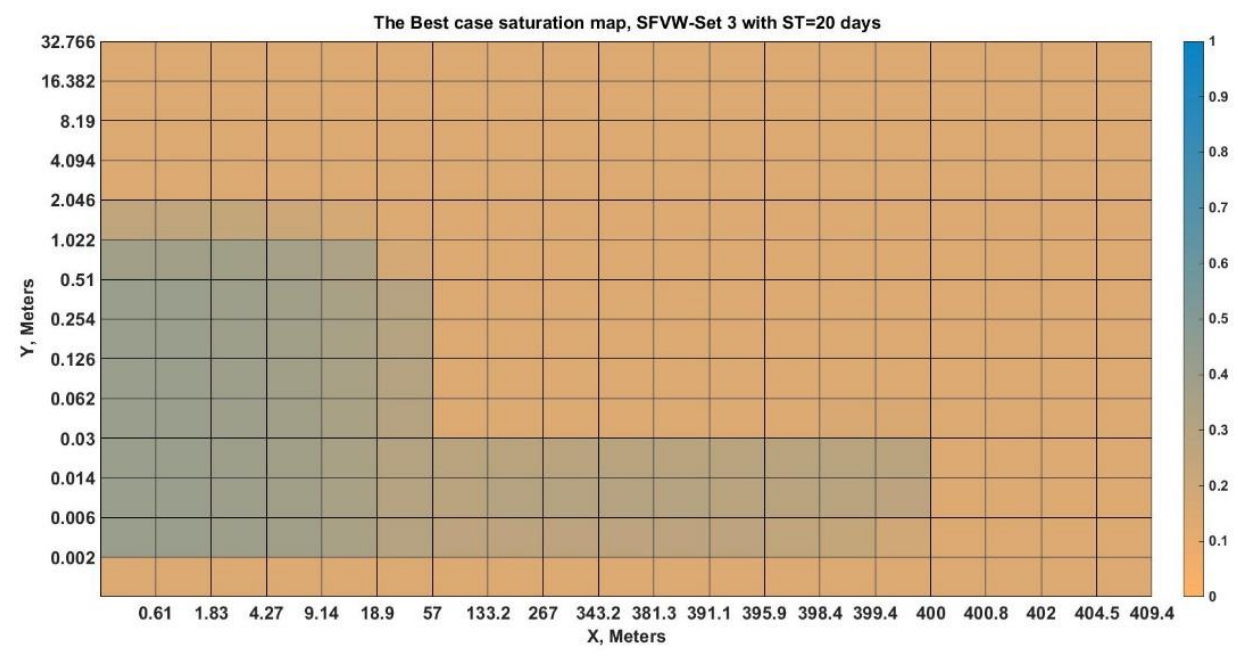

Figure 14 Fracturing Fluid saturation map of the best scenario of the SFVW-Set 3 after 20 days of the shut-in period.

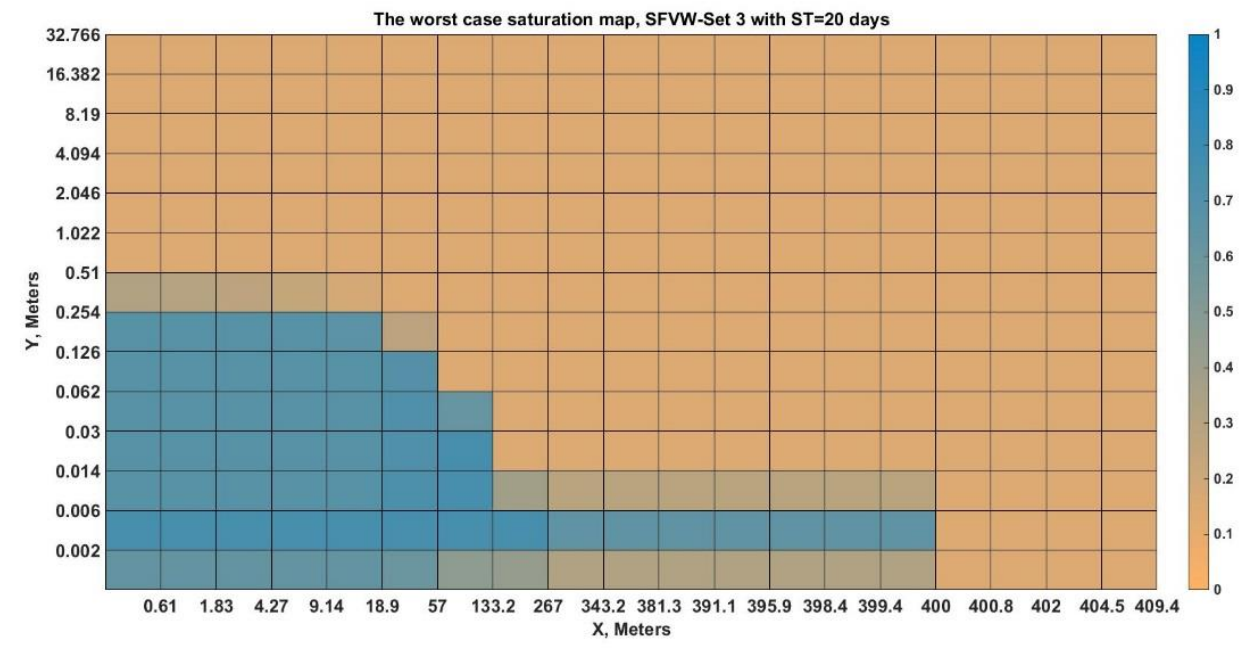

Figure 15 Fracturing Fluid saturation map of the worst scenario of the SFVW-Set 3 after 20 days of the shut-in period. 
a. SFVW-Set 4, Kmr=10

SFVW-Set 4, Kmr=10, Long Fracture, Gas Production Loss (GPL) - LRSM

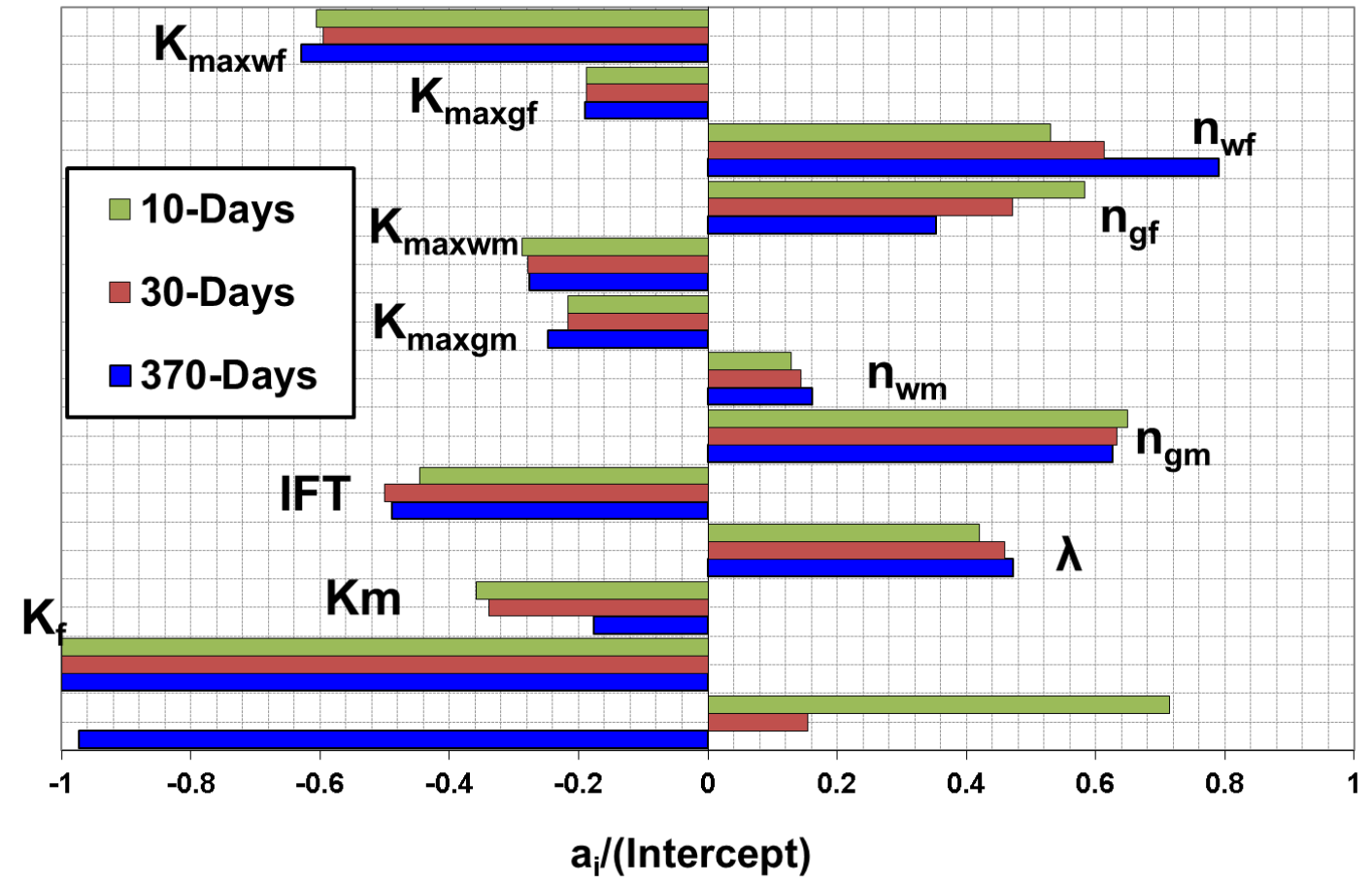

b. SFVW-Set $25, \mathrm{Kmr}=100$

SFVW-Set 25, Kmr=100, Long Fracture, Gas Production Loss (GPL) - LRSM

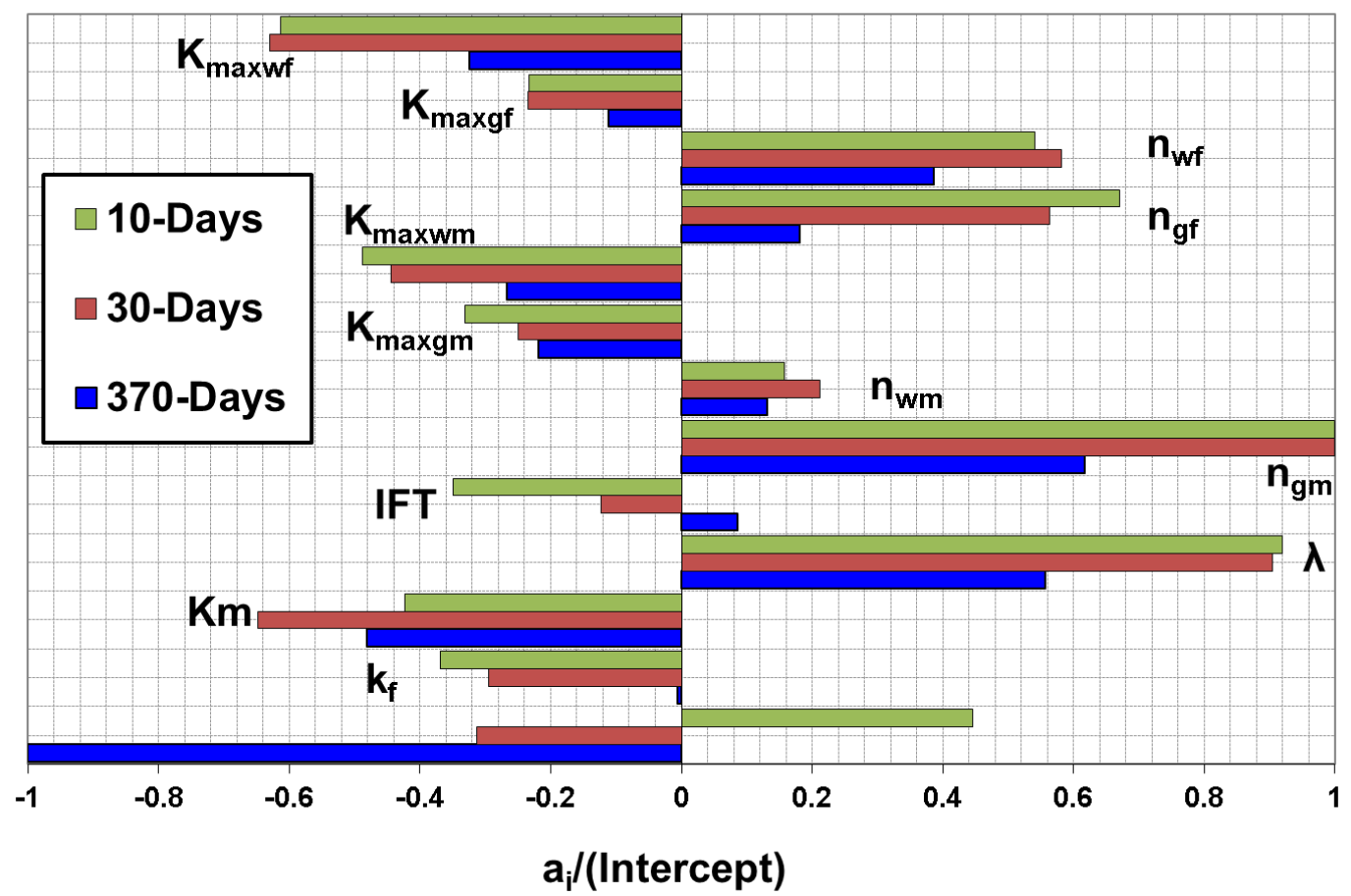

Figure 16 Tornado chart comparing LRSM coefficients of all pertinent parameters at three production stages, in a. SFVW-Set 4 with $\mathrm{Kmr}=10$ and b. SFVW-Set 25 with $\mathrm{Kmr}=100$., Long Fracture. 


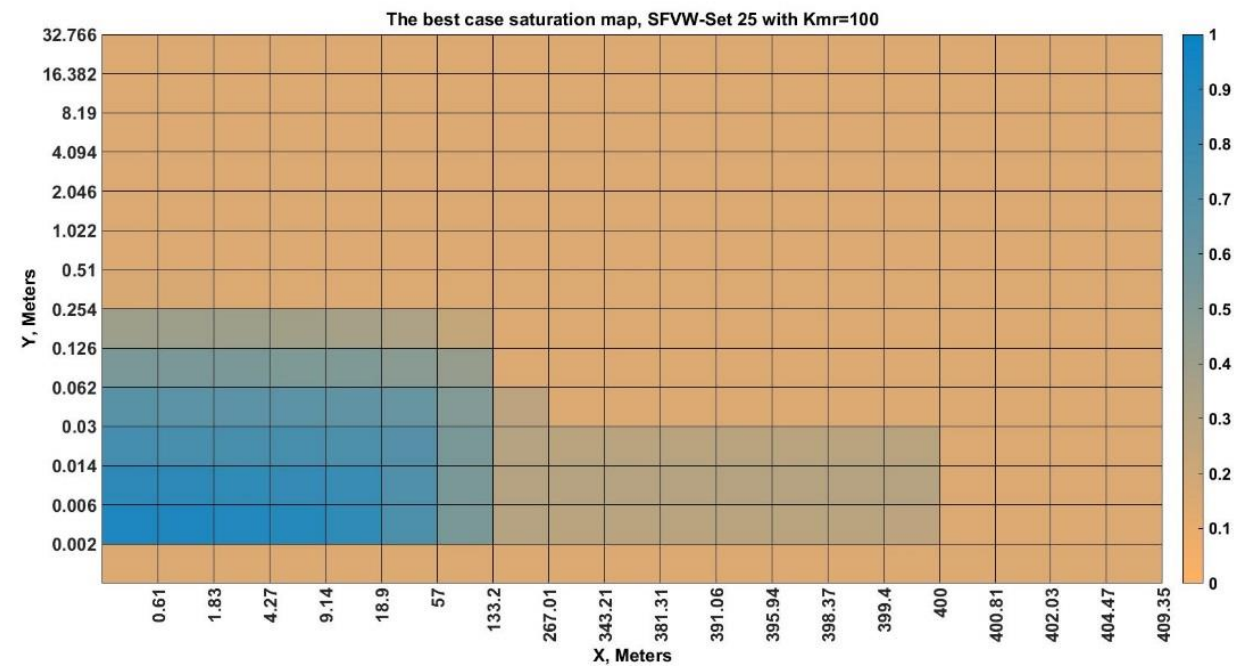

Figure 17 Fracturing Fluid saturation map of the best scenario of the SFVW-Set 25 after 2 days of the shut-in period.

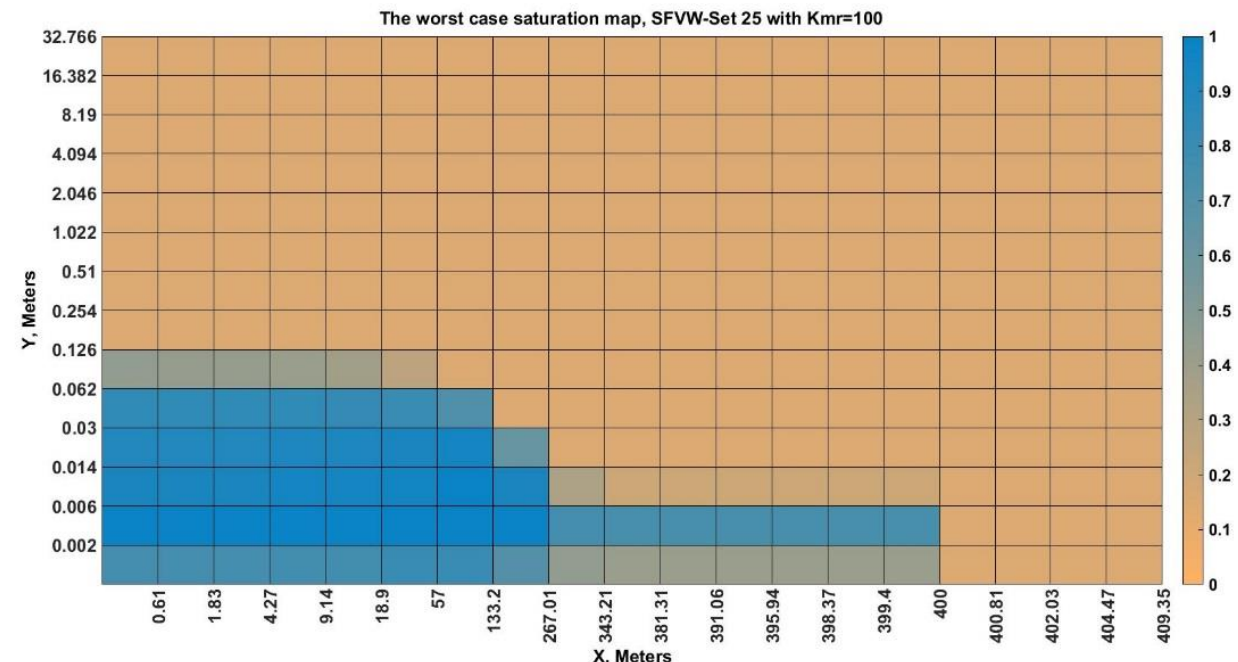

Figure 18 Fracturing Fluid saturation map of the worst scenario of the SFVW-Set 25 after 2 days of the shut-in period. 


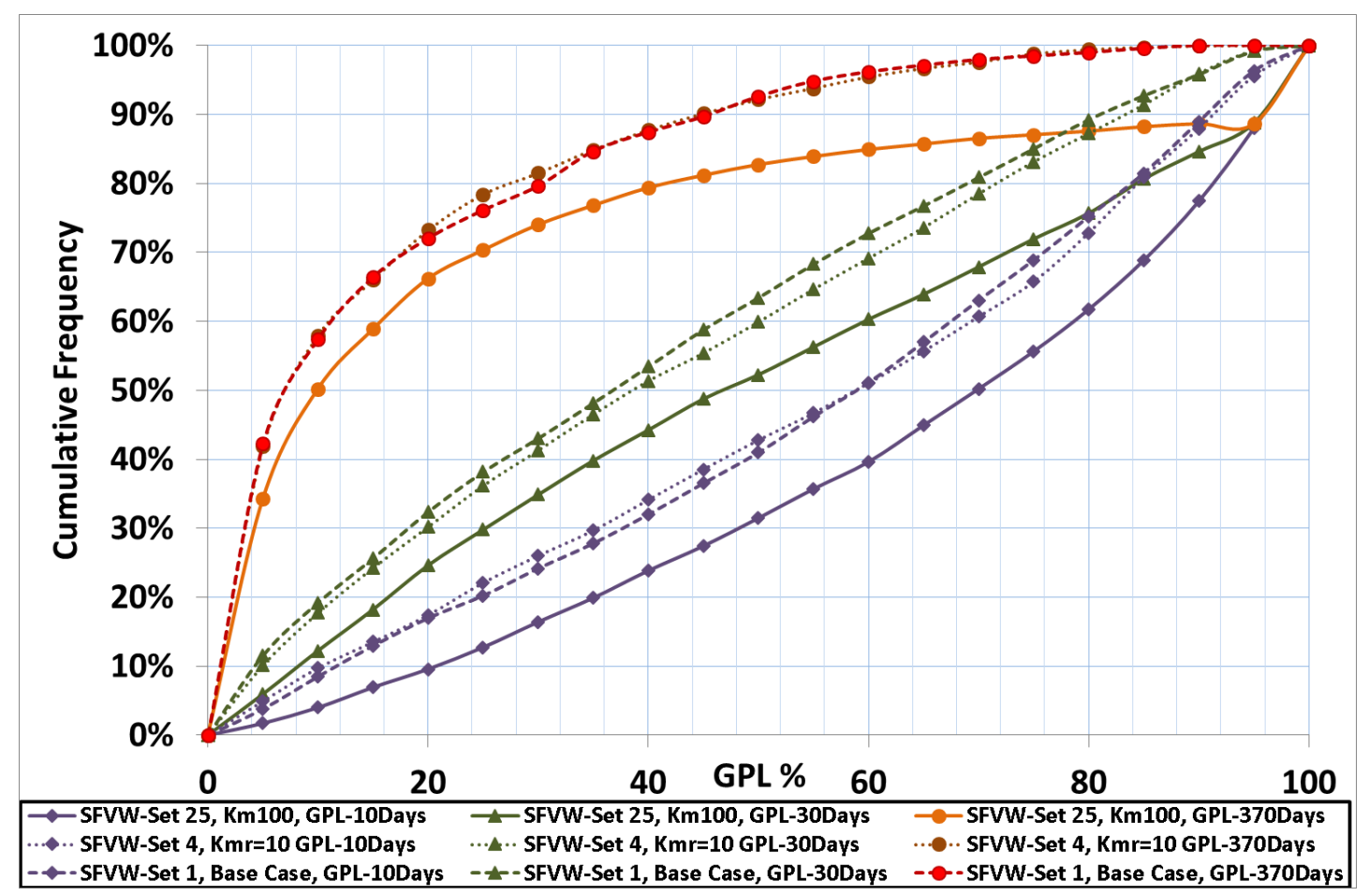

Figure 19 Histogram chart comparing the cumulative frequency of SFVW-Set 25, 4 and 1 with $\mathrm{Kmr}=100,10$ and 1 respectively at three production periods.

SFVW-Set 6, DP=100, Long Fracture , Gas Production Loss (GPL) - LRSM

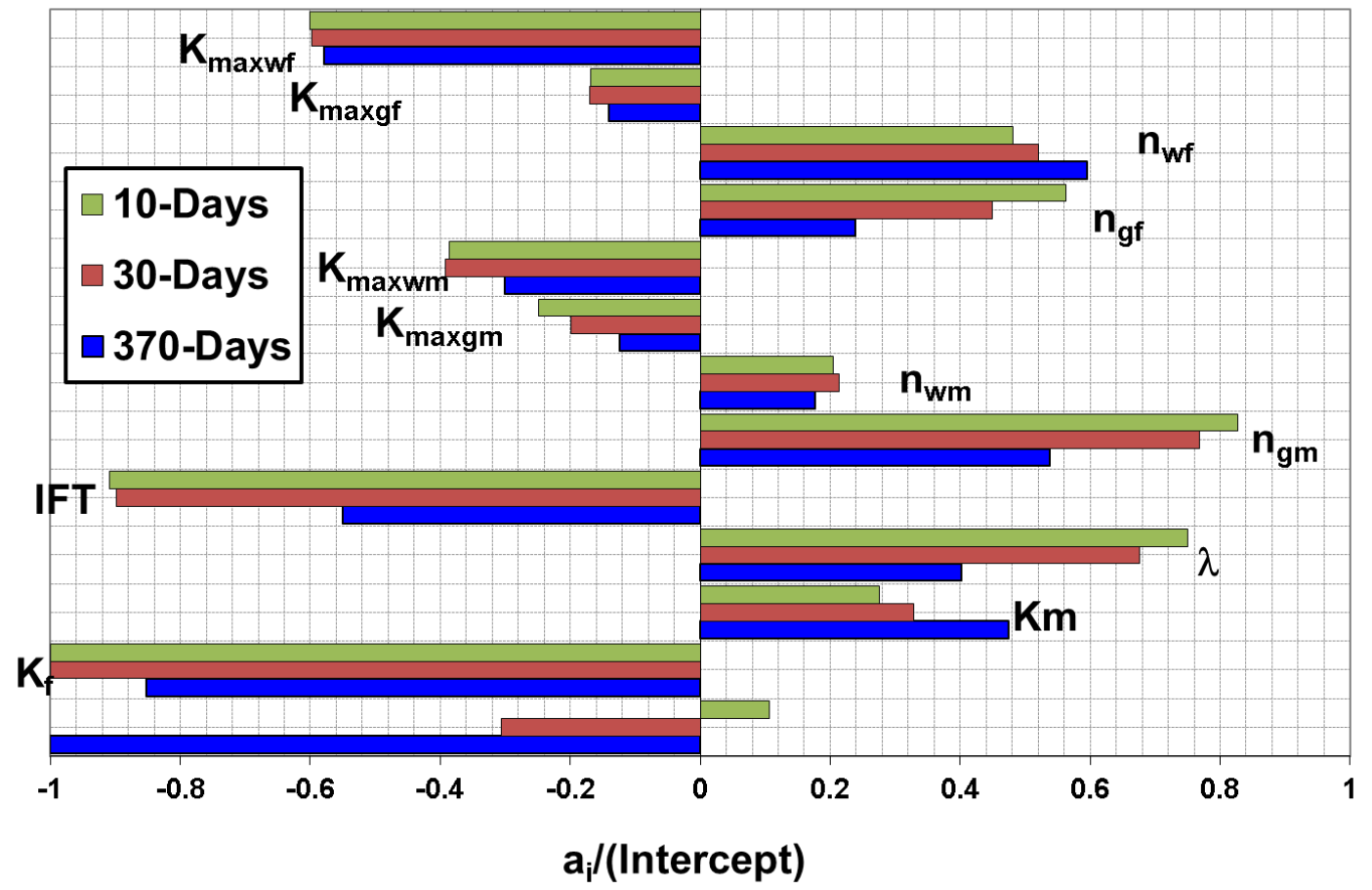

Figure 20 Tornado chart comparing LRSM coefficients of all pertinent parameters at three production stages, in SFVW-Set 6 with DP=100 psi, Long Fracture. 
SFVW-Set 7, DP=4000 psi, Long Fracture, Gas Production Loss (GPL)-LRSM

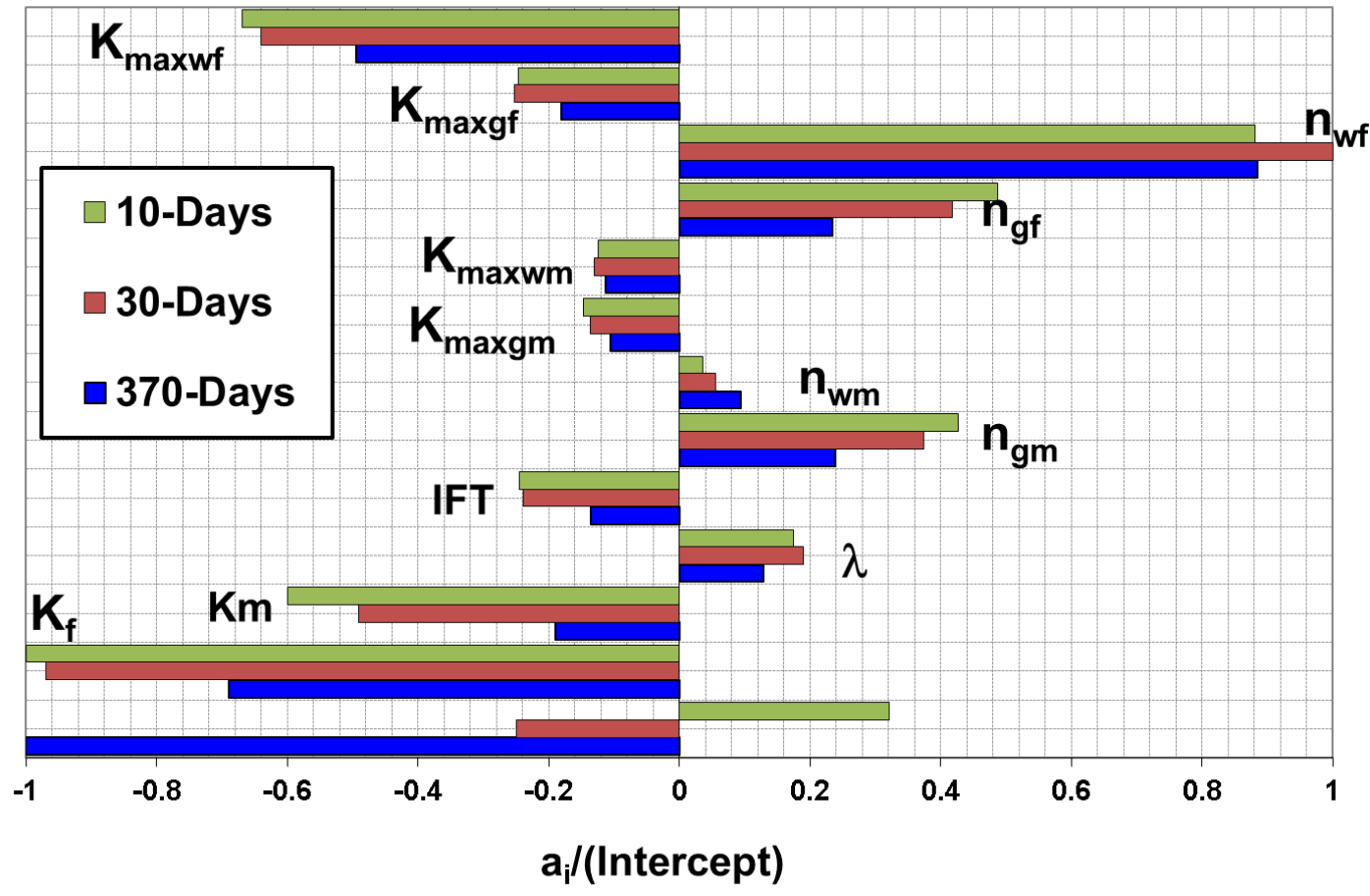

Figure 21 Tornado chart comparing LRSM coefficients of all pertinent parameters at three production stages, in SFVW-Set 7 with DP=4000 psi, Long Fracture.

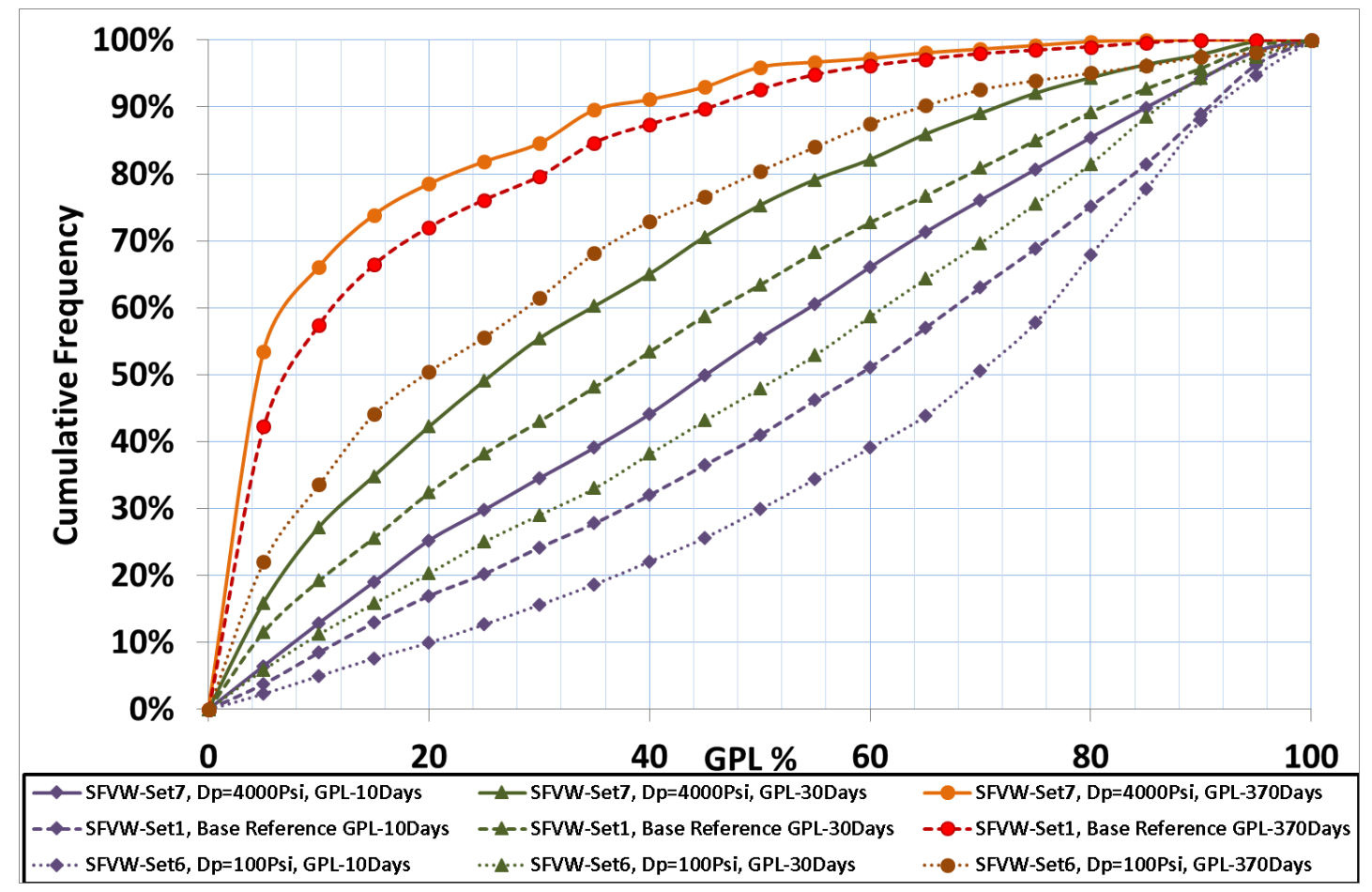

Figure 22 Histogram chart comparing the cumulative frequency of SFVW-Set 6, 1 and 7 with $\mathrm{DP}=100,1000$ and 4000 respectively at three production periods. 
SFVW-Set 14, Kmr=10 \& DP=100psi, GPL - LRSM

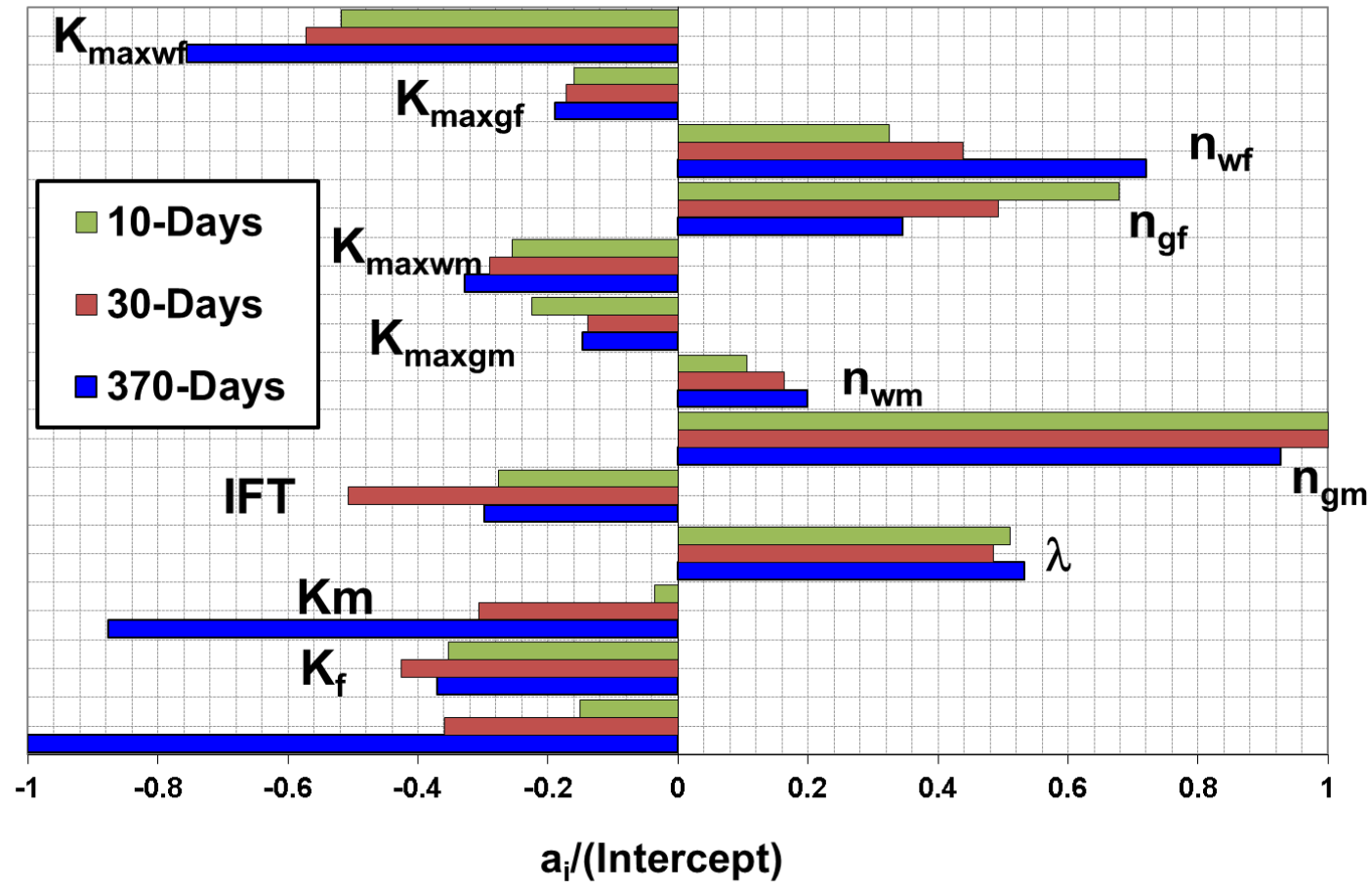

Figure 23 Tornado chart comparing LRSM coefficients of all pertinent parameters at three production stages, in SFVW-Set 14 with $\mathrm{Kmr}=10$ \&DP=100 psi, Long Fracture.

SFVW-Set 15, Kmr=10, DP=100 psi \& ST=20 days, GPL - LRSM

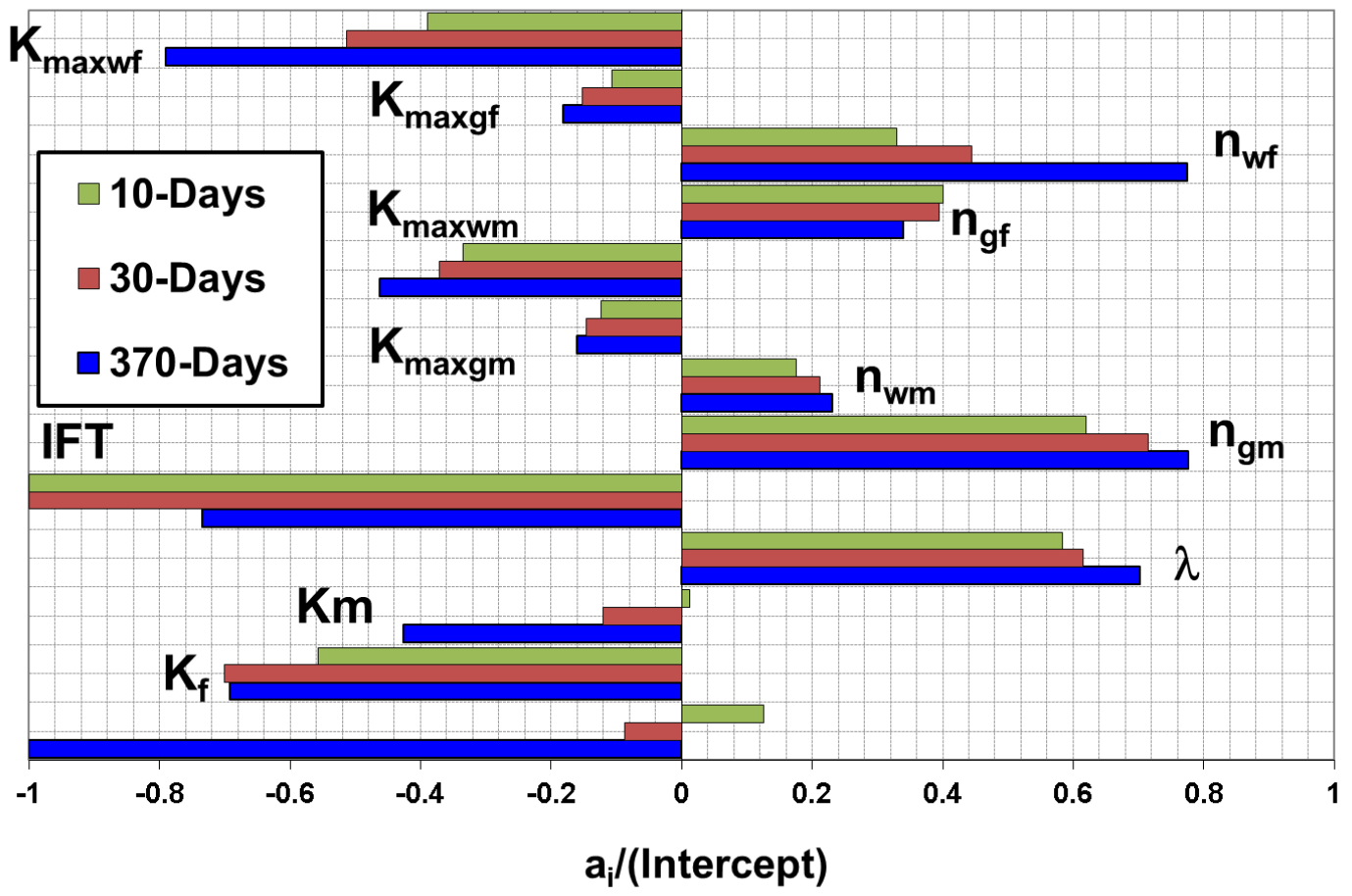

Figure 24 Tornado chart comparing LRSM coefficients of all pertinent parameters at three production stages, in SFVW-Set 15 with $\mathrm{Kmr}=10, \mathrm{DP}=100$ psi \& ST=20 days, Long Fracture. 


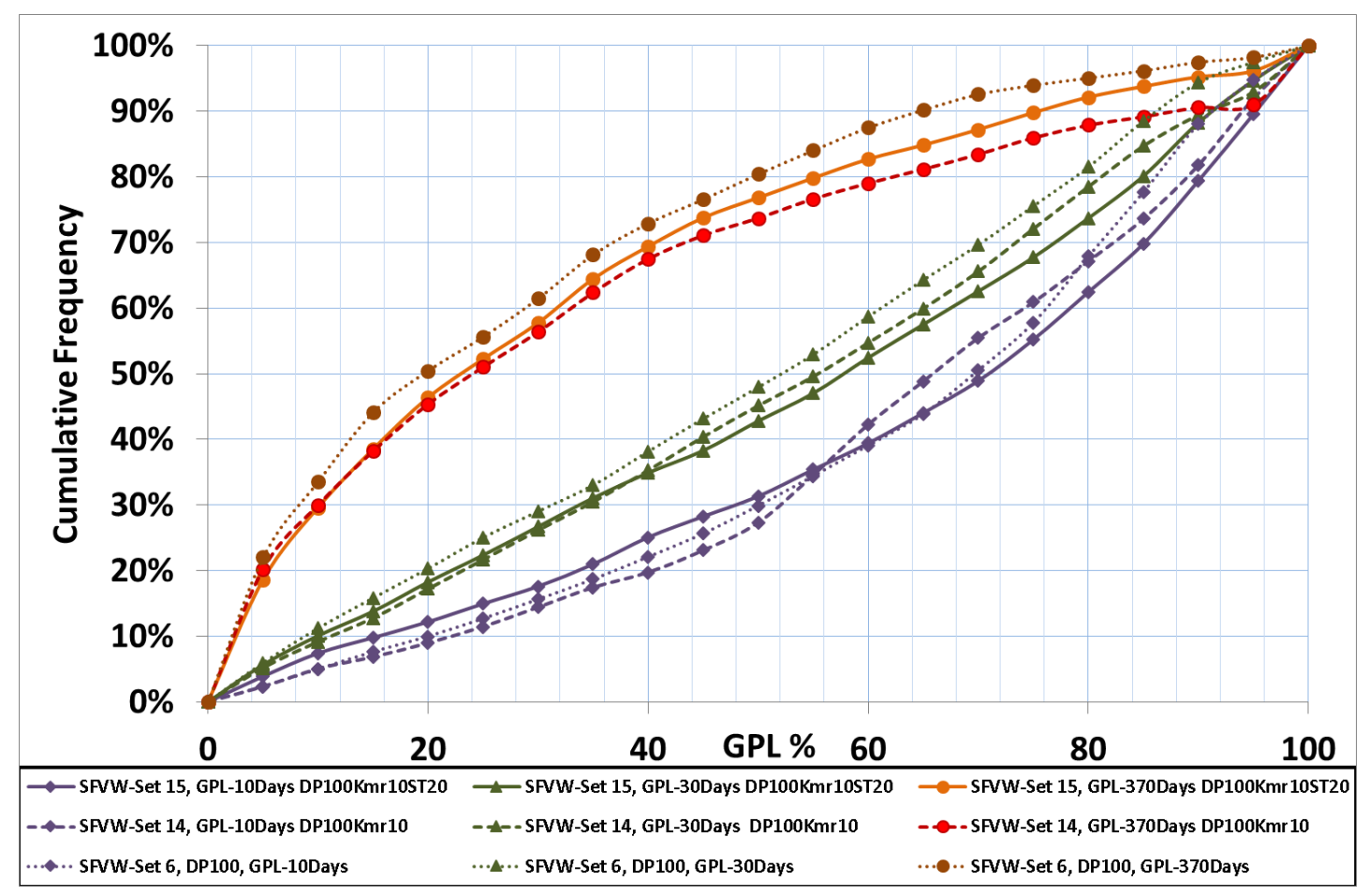

Figure 25 Histogram chart comparing cumulative frequency of SFVW-Set 6, 14 and 15 with $\mathrm{DP}=100, \mathrm{Kmr}=10 \& \mathrm{DP}=100$ and $\mathrm{Kmr}=10, \mathrm{DP}=100$ psi \& $\mathrm{ST}=20$ respectively at three production periods

SFVW-Set 16, Kmr=10 \& DP=4000psi, GPL - LRSM

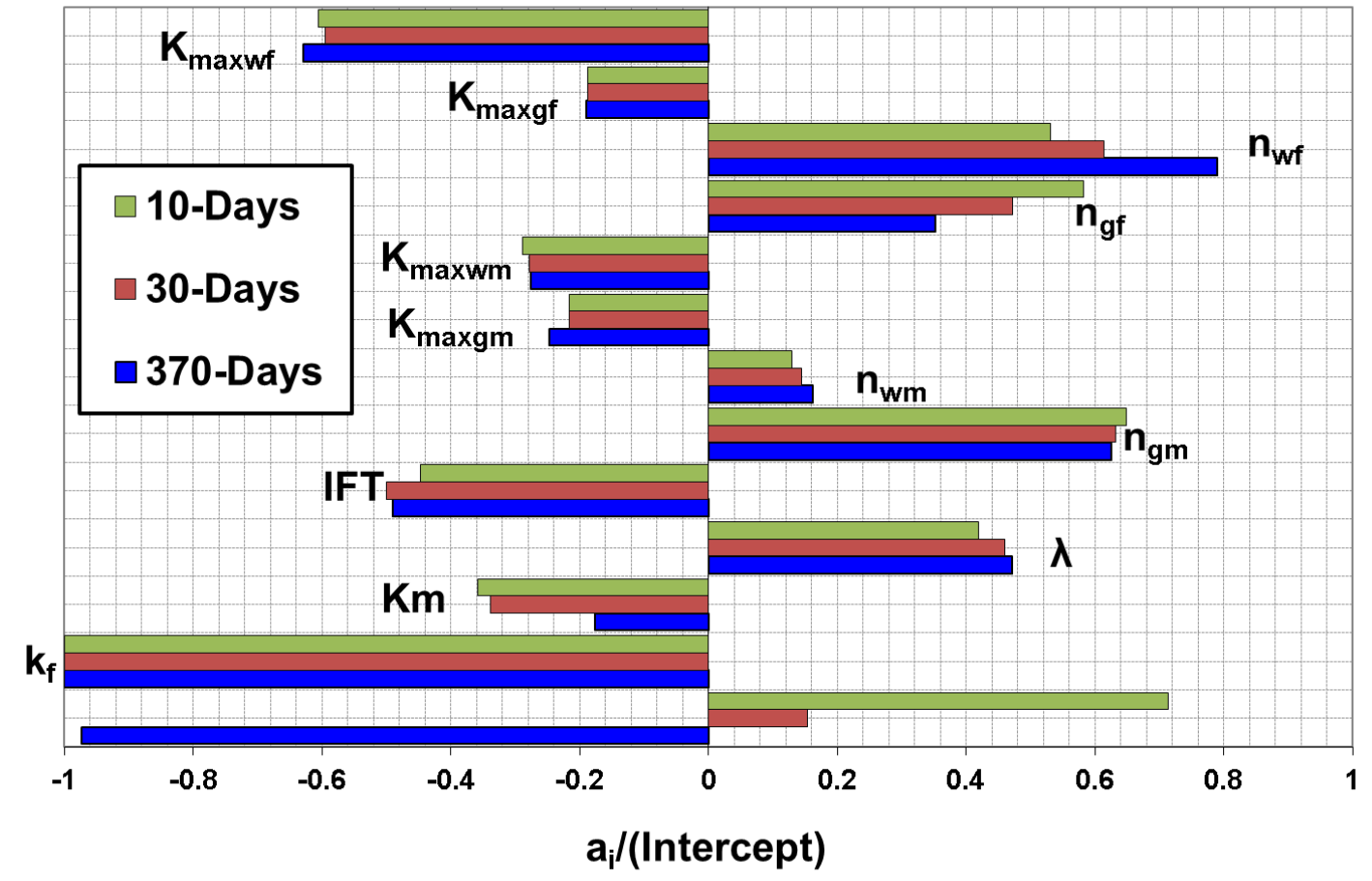

Figure 26 Tornado chart comparing LRSM coefficients of all pertinent parameters at three production stages, in SFVW-Set 16 with $\mathrm{Kmr}=10$ \& DP=4000, Long Fracture. 
SFVW-Set 23, Kmr=100 \& DP=100 psi, GPL - LRSM

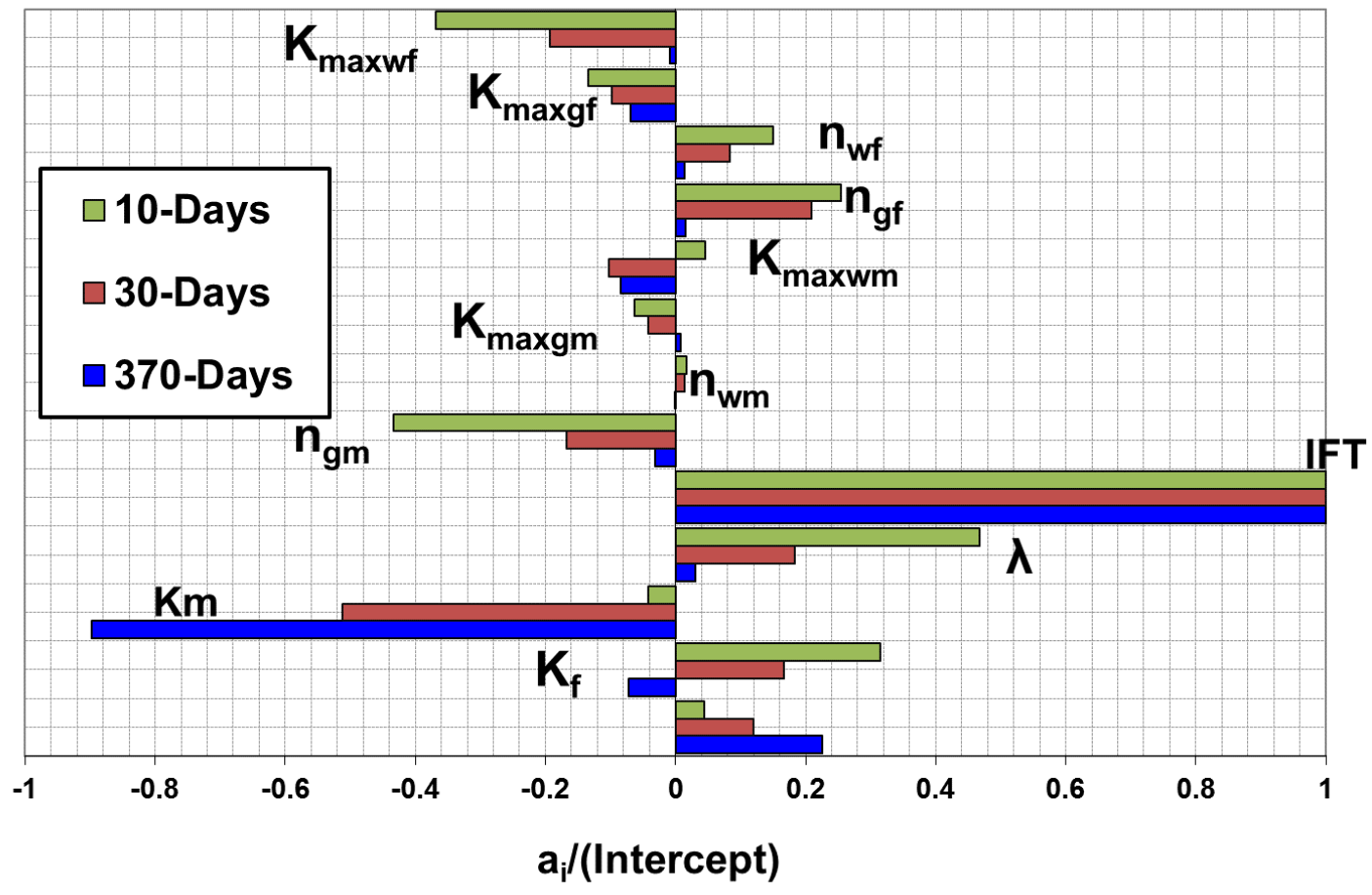

Figure 27 Tornado chart comparing LRSM coefficients of all pertinent parameters at three production stages, in SFVW-Set 23 with Kmr=100 \& DP=100, Long Fracture.

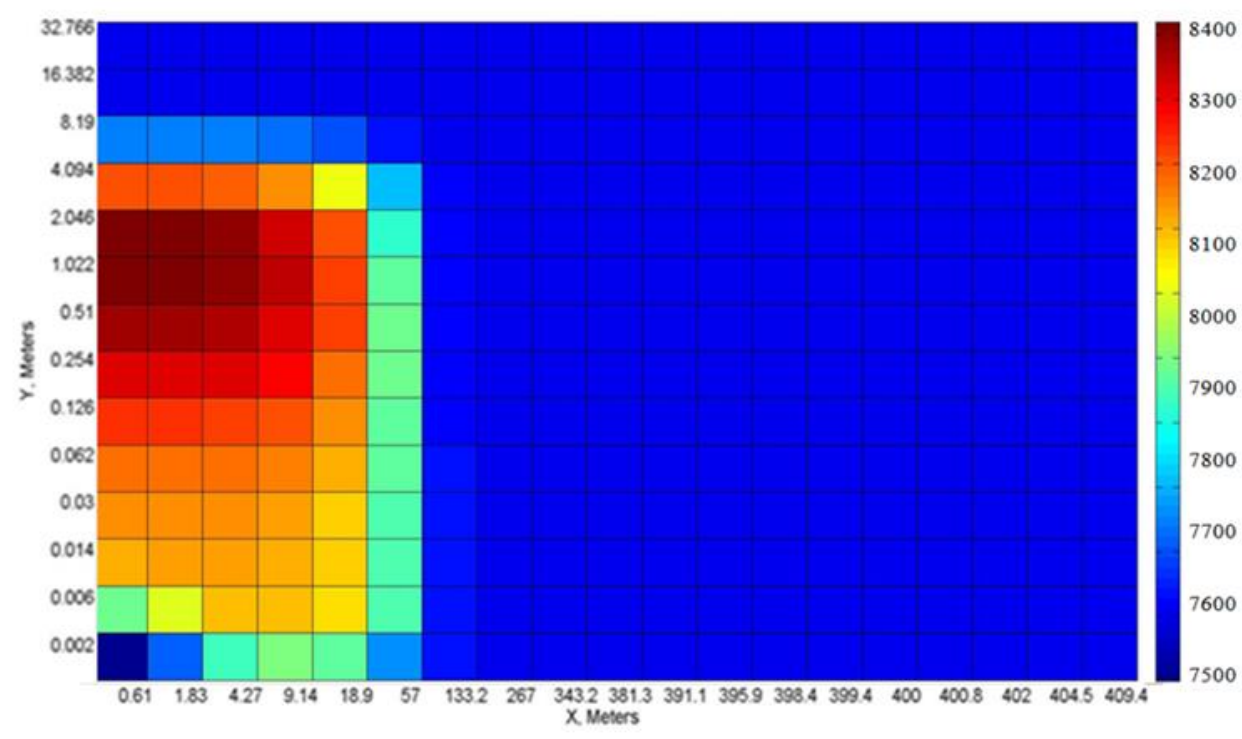

Figure 28 Pressure distribution Map at the End of Soaking time for SFVW-Set 23. 


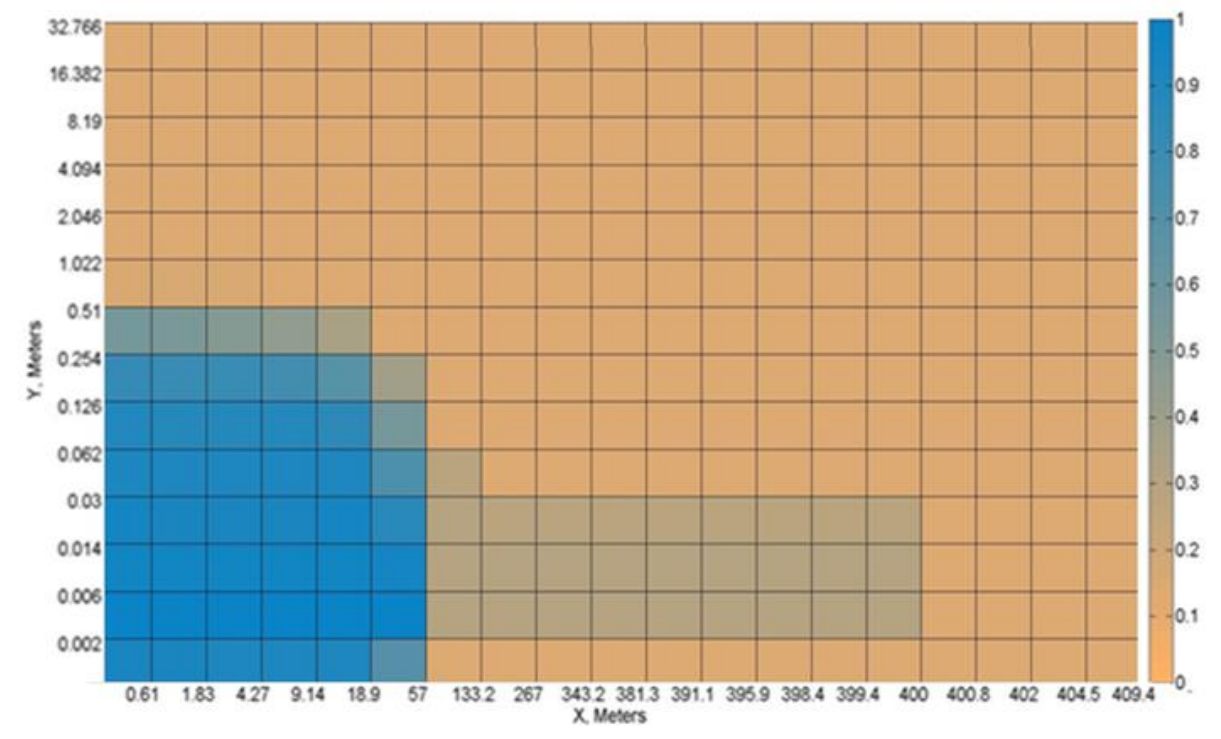

Figure 29 FF Saturation distribution Map at the End of Soaking time for SFVW-Set 23.

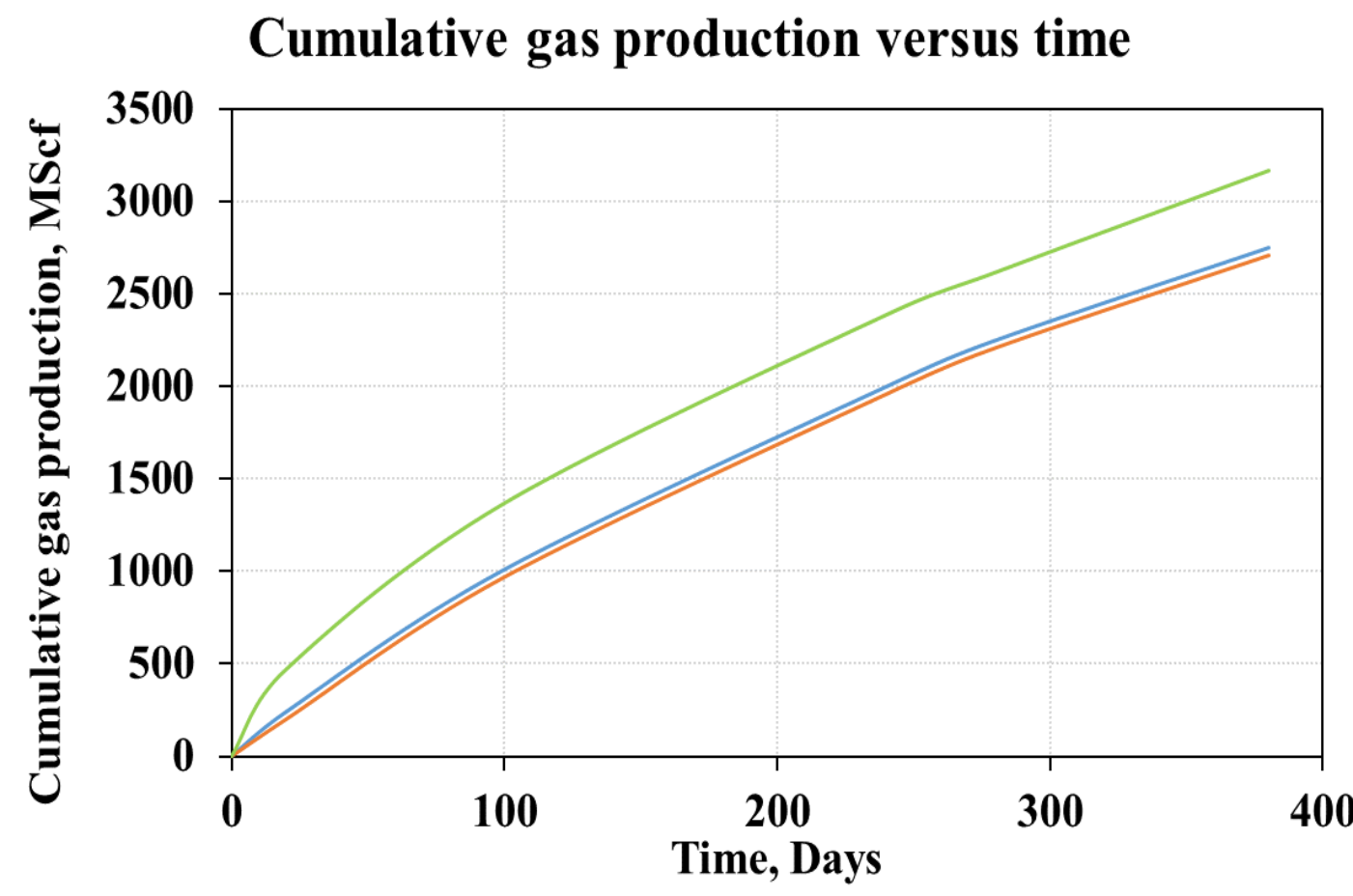

—Clean Case — Clean case using unclean saturation map — Unclean Case

Figure 30 GPT (total cumulative gas production) plot for the three cases, clean, unclean and clean with unclean saturation map 
SFVW-Set 64 Base Reference Set with Km Enhancement, GPL - LRSM

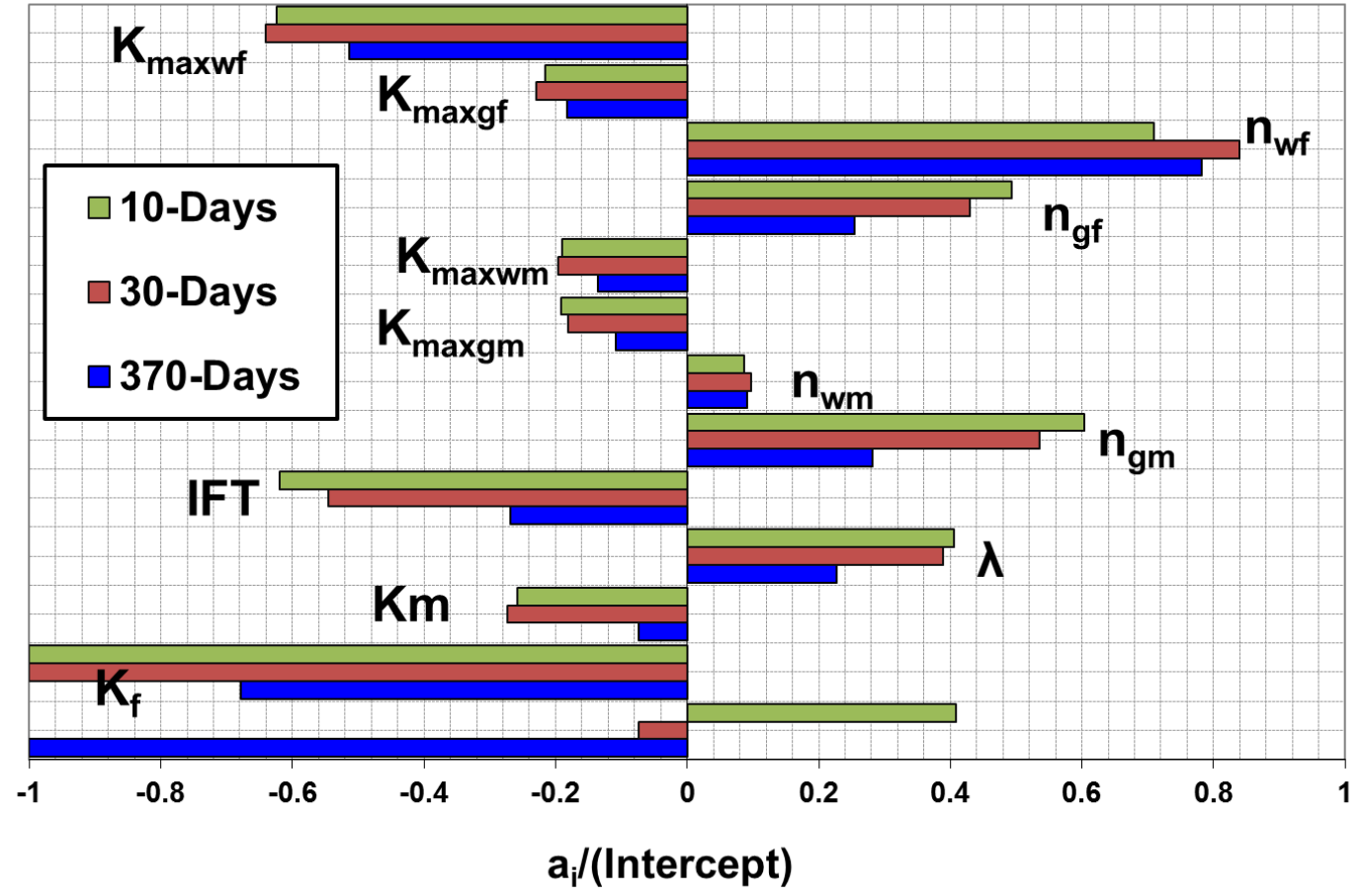

Figure 31 Tornado chart comparing LRSM coefficients of all pertinent parameters at three production stages, in SFVW-Set 64 base reference set with K enhancement, Long Fracture.

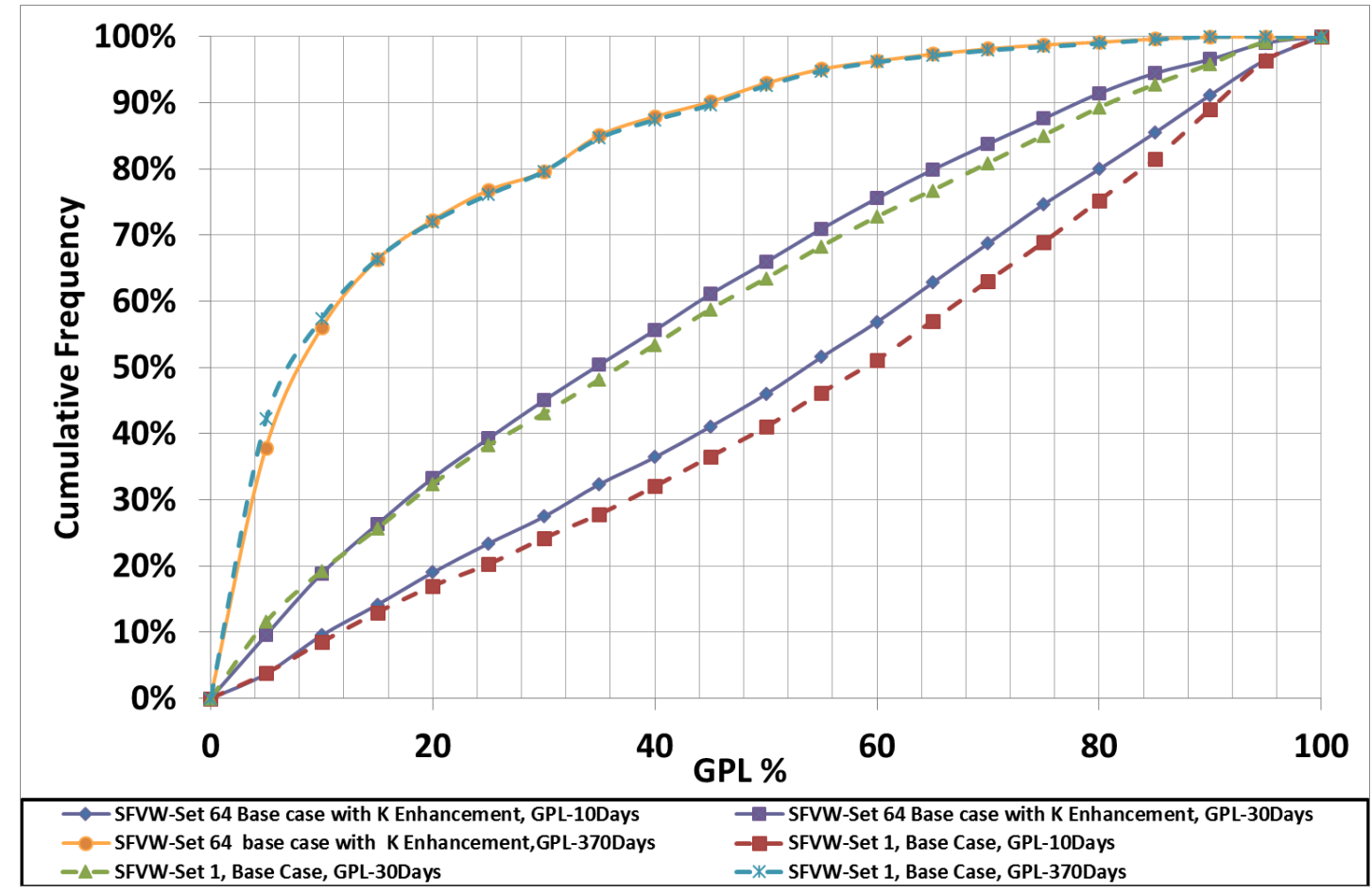

Figure 32 Histogram chart comparing cumulative frequency of SFVW-Set 64 and 1 with the only difference being inclusion of K enhancement in SFVW-Set 64 at three production periods 
SFVW-Set 65, Kmr=100 \& DP=100 psi, K Enhancement, GPL- LRSM

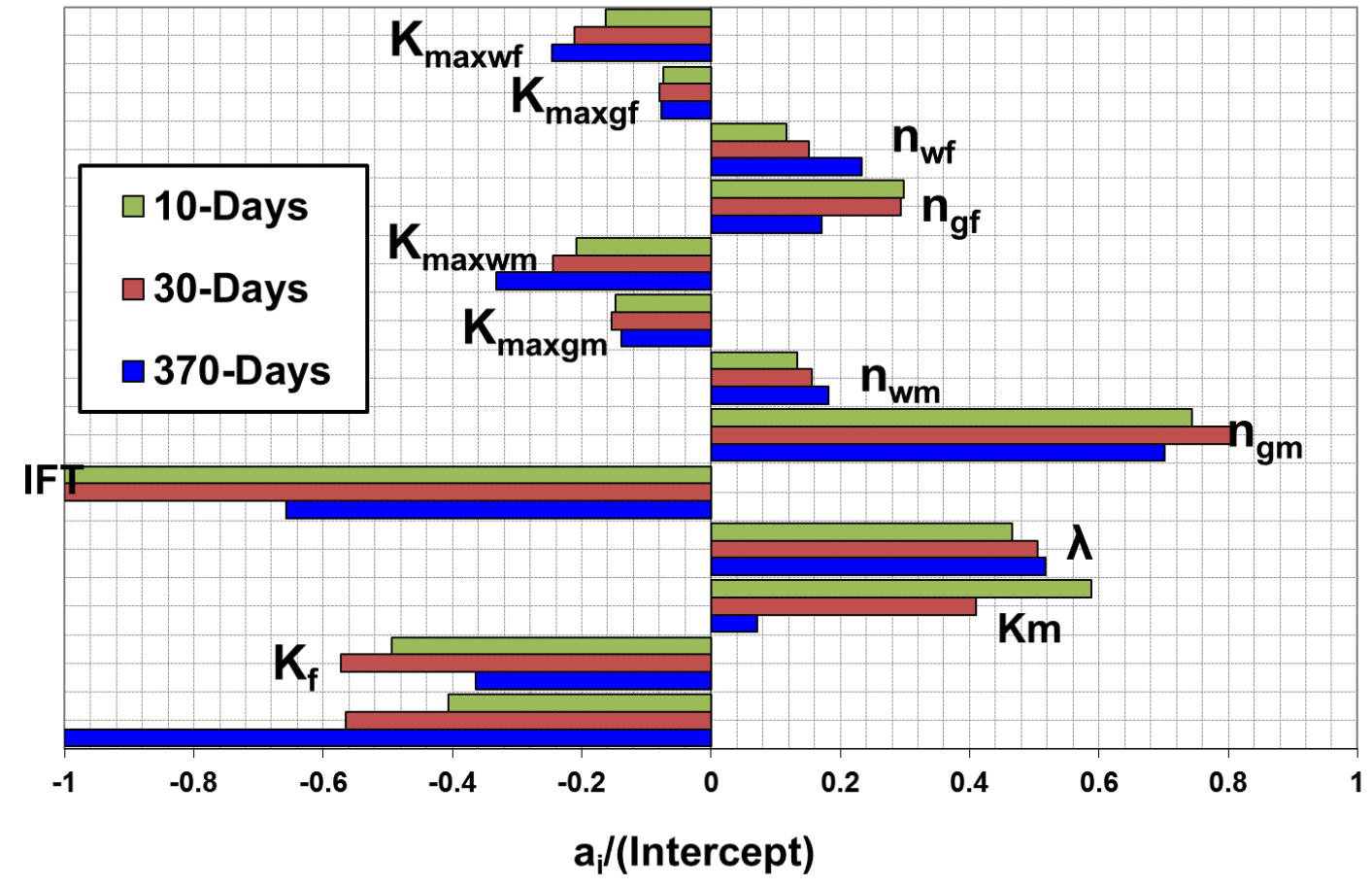

Figure 33 Tornado chart comparing LRSM coefficients of all pertinent parameters at three production stages, in SFVW-Set 65 (Kmr=100 \& DP=100 psi) with $\mathrm{K}$ enhancement, Long Fracture.

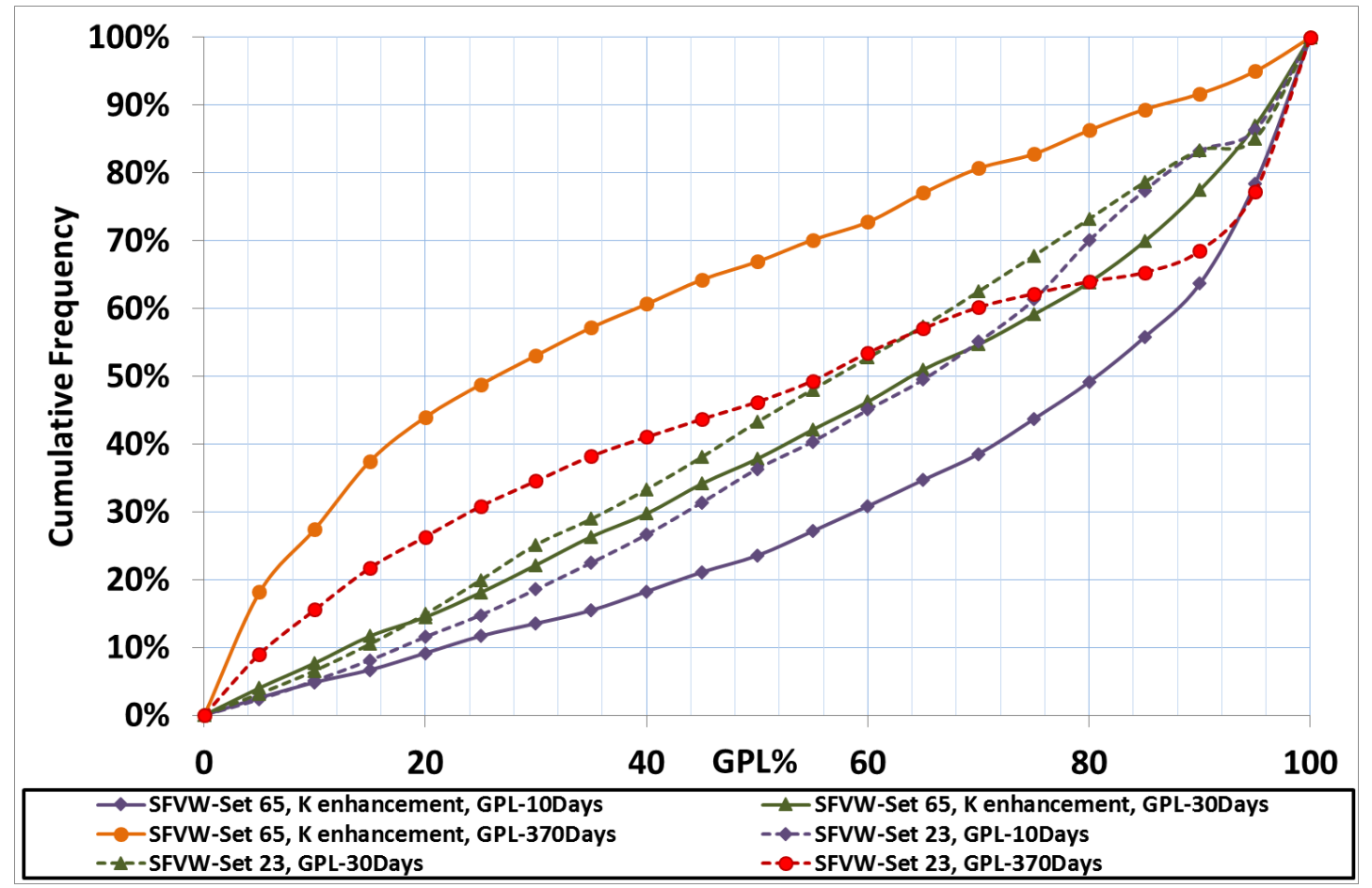

Figure 34 Histogram chart comparing cumulative frequency of SFVW-Set 65 and 23 with the only difference being inclusion of K enhancement in SFVW-Set 65 at three production periods 
SFVW-Set 66, Kmr=100, Permeability Enhancement-GPL- LRSM

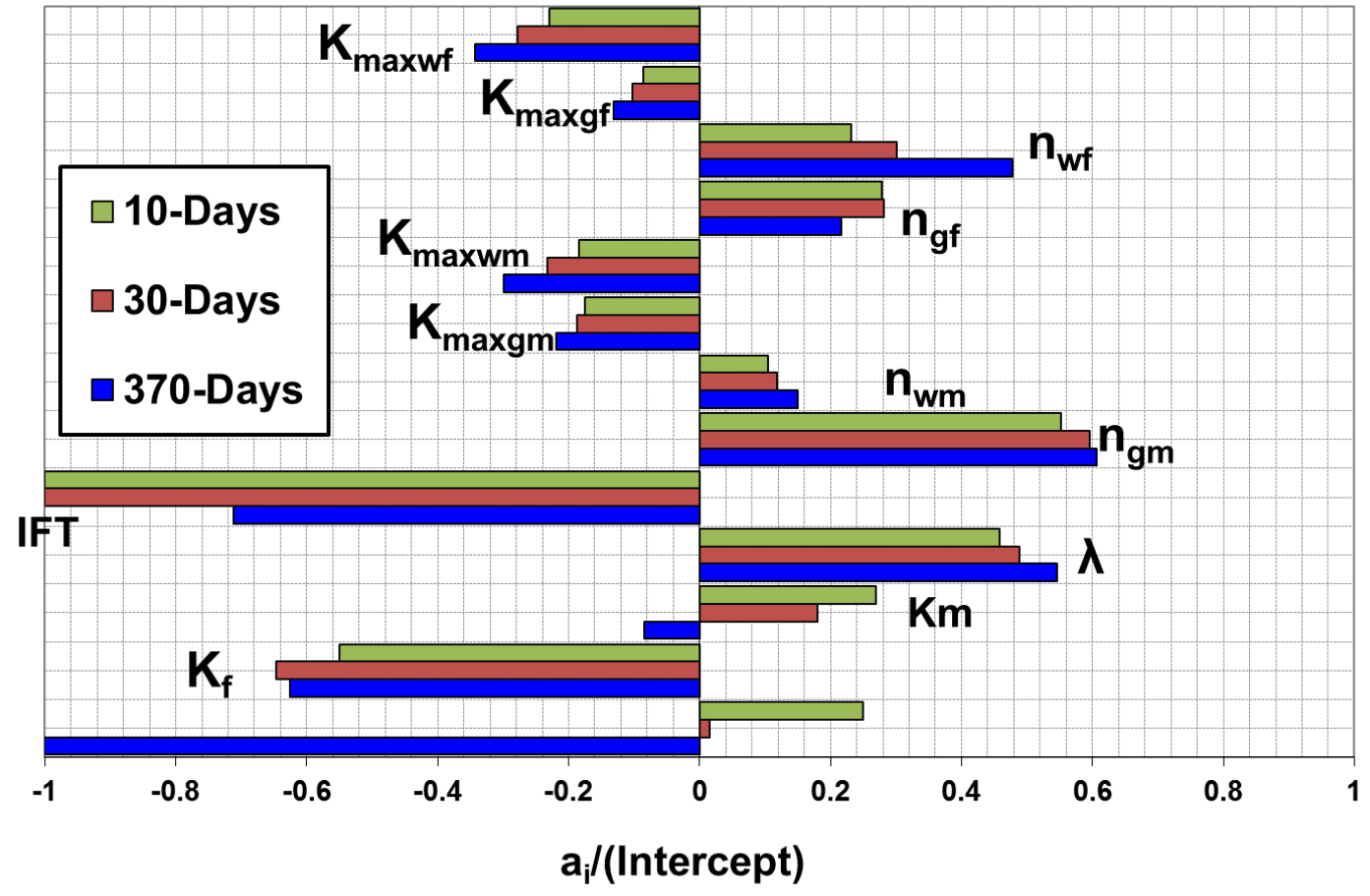

Figure 35 Tornado chart comparing LRSM coefficients of all pertinent parameters at three production stages, in SFVW-Set $66(\mathrm{Kmr}=100)$ with $\mathrm{K}$ enhancement, Long Fracture.

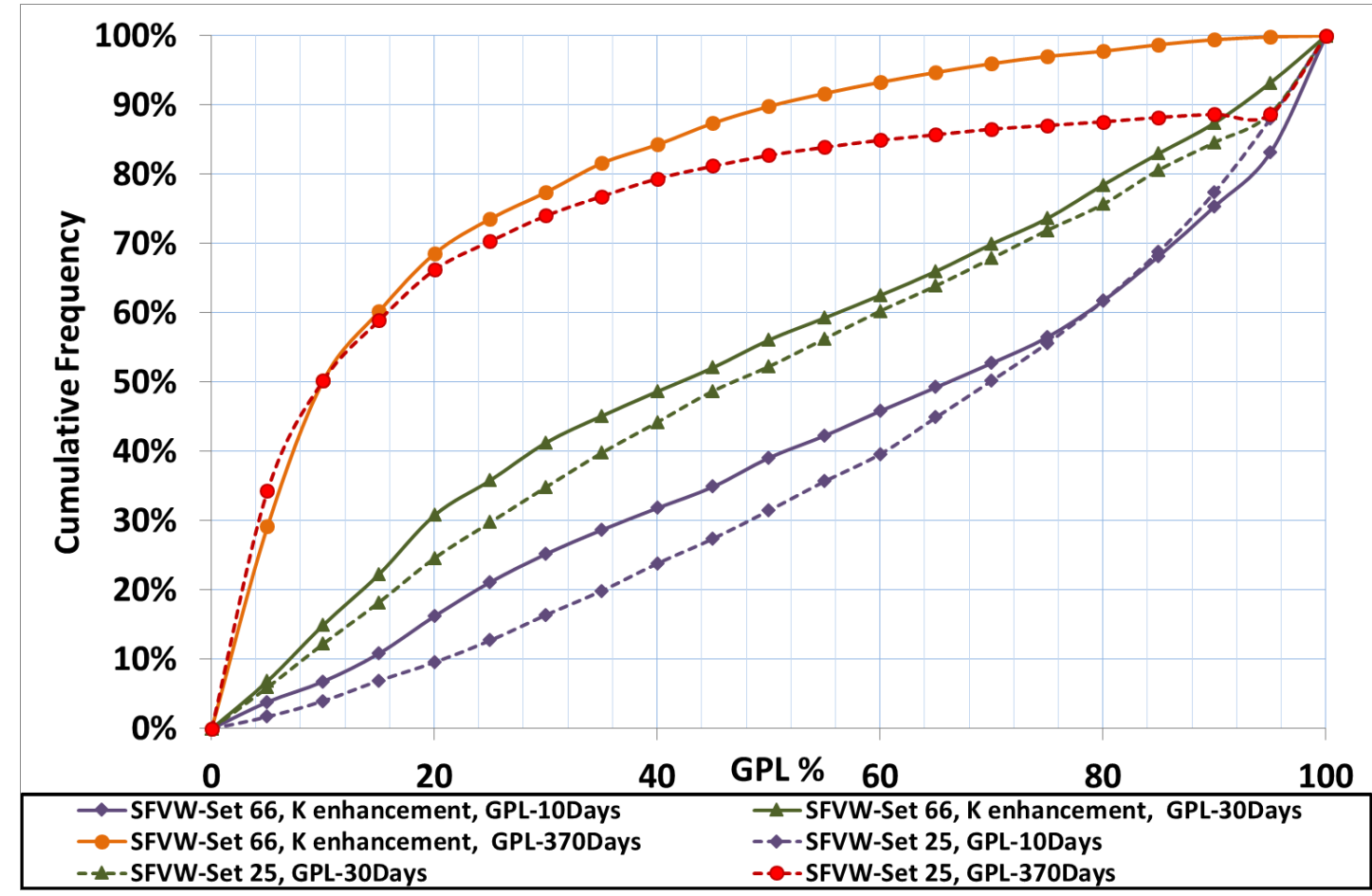

Figure 36 Histogram chart comparing cumulative frequency of SFVW-Set 66 and 25 with the only difference being inclusion of K enhancement in SFVW-Set 66 at three production periods 
SFVW-Set 18, DP=100 psi, Short Fracture, GPL - LRSM

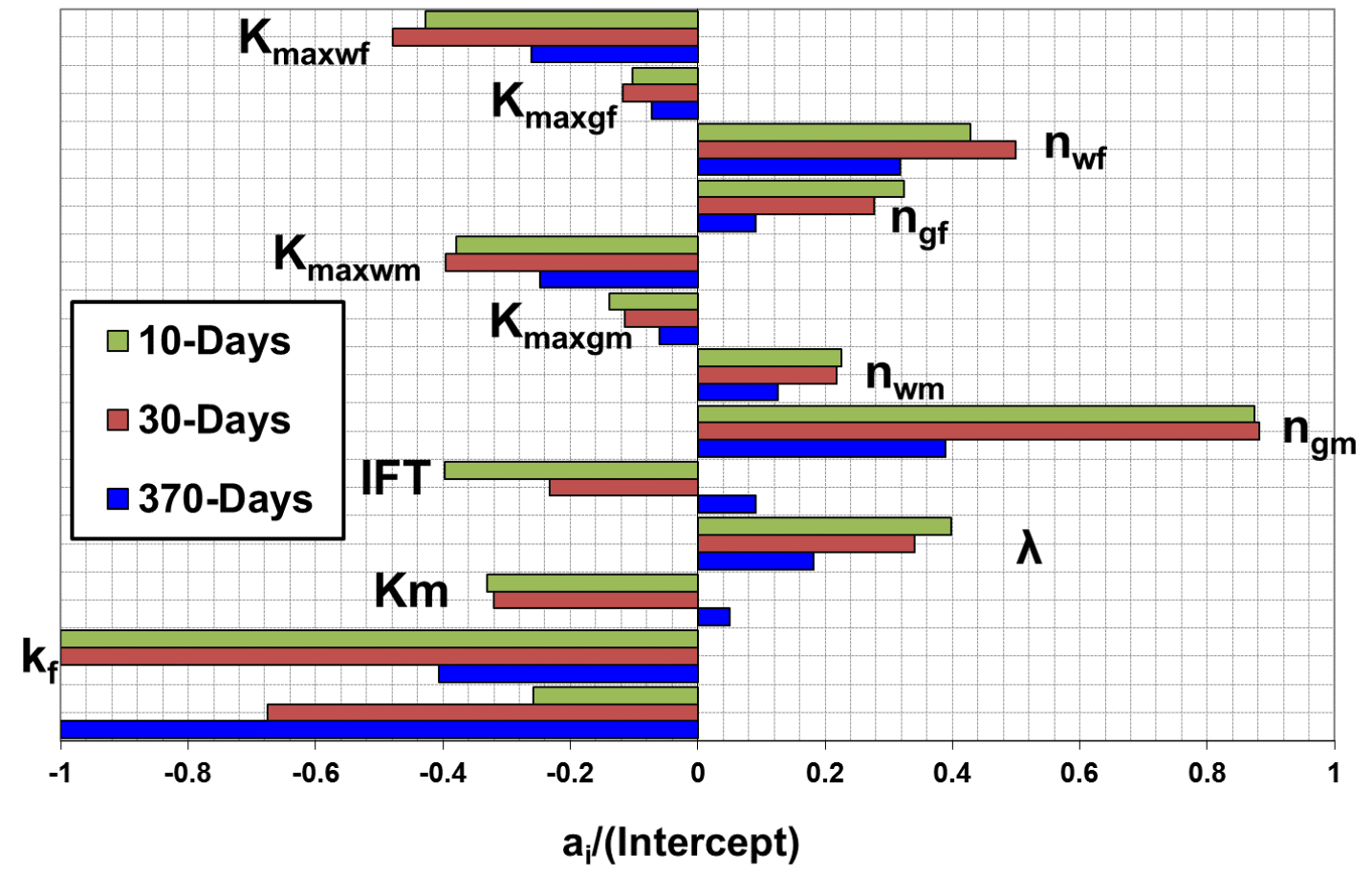

Figure 37 Tornado chart comparing LRSM coefficients of all pertinent parameters at three production stages, in SFVW-Set 18 (DP=100 psi), Short Fracture

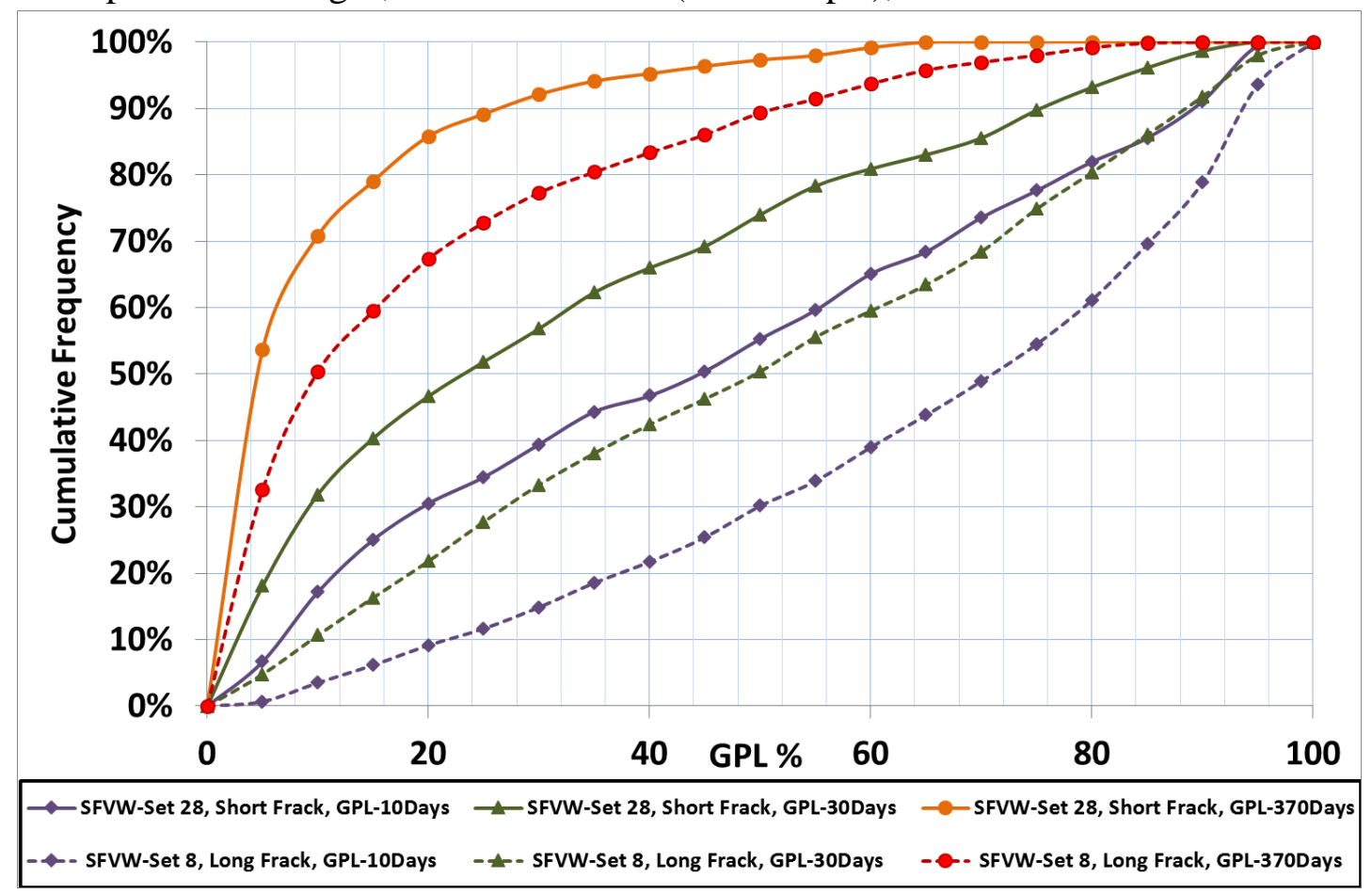

Figure 38 Histogram chart comparing cumulative frequency of SFVW-Set 28 and 8 with the only difference being a shorter fracture in SFVW-Set 28 at three production periods 